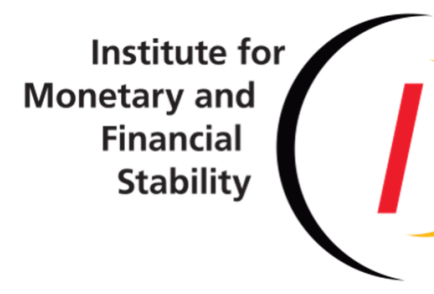

GREGOR BOEHL, GAVIN GOY, FELIX STROBEL

A Structural Investigation of Quantitative Easing

Institute for Monetary and Financial Stability

GOETHE UNIVERSITY FRANKFURT

WORKING PAPER SERIES No. 142 (2020) 
This Working Paper is issued under the auspices of the Institute for Monetary and Financial Stability (IMFS). Any opinions expressed here are those of the author(s) and not those of the IMFS. Research disseminated by the IMFS may include views on policy, but the IMFS itself takes no institutional policy positions.

The IMFS aims at raising public awareness of the importance of monetary and financial stability. Its main objective is the implementation of the "Project Monetary and Financial Stability" that is supported by the Foundation of Monetary and Financial Stability. The foundation was established on January 1, 2002 by federal law. Its endowment funds come from the sale of 1 DM gold coins in 2001 that were issued at the occasion of the euro cash introduction in memory of the D-Mark.

The IMFS Working Papers often represent preliminary or incomplete work, circulated to encourage discussion and comment. Citation and use of such a paper should take account of its provisional character.

\section{Institute for Monetary and Financial Stability}

Goethe University Frankfurt

House of Finance

Theodor-W.-Adorno-Platz 3

D-60629 Frankfurt am Main

www.imfs-frankfurt.de | info@imfs-frankfurt.de 


\title{
A Structural Investigation of Quantitative Easing
}

\author{
Latest version at http://gregorboehl.com/live/qe_bgs.pdf \\ Gregor Boehl ${ }^{a, *}$, Gavin Goy ${ }^{\mathrm{b}}$, Felix Strobel $^{\mathrm{c}}$ \\ ${ }^{a}$ University of Bonn \\ ${ }^{b}$ De Nederlandsche Bank \\ ${ }^{c}$ Deutsche Bundesbank \\ June 16, 2020
}

\begin{abstract}
Did the Federal Reserves' Quantitative Easing (QE) in the aftermath of the financial crisis have macroeconomic effects? To answer this question, we estimate a large-scale DSGE model over the sample from 1998 to 2020, including data of the Fed's balance sheet. We allow for QE to affect the economy via multiple channels that arise from several financial frictions. Our nonlinear Bayesian likelihood approach fully accounts for the zero lower bound on nominal interest rates. We find that between 2009 to 2015, QE increased output by about 1.2 percent. This reflects a net increase in investment of nearly 9 percent, that was accompanied by a 0.7 percent drop in aggregate consumption. Both, government bond and capital asset purchases were effective in improving financing conditions. Especially capital asset purchases significantly facilitated new investment and increased the production capacity. Against the backdrop of a fall in consumption, supply side effects dominated which led to a mild disinflationary effect of about 0.25 percent annually.
\end{abstract}

Keywords: Quantitative Easing, Liquidity Facilities, Zero Lower Bound, Nonlinear Bayesian Estimation

JEL: E63, C63, E58, E32, C62

\section{Introduction}

The recent outbreak of the COVID-19 virus in Europe and United States has caused severe turmoil on financial markets, last seen during the Global Financial Crisis (GFC) in

${ }^{\star}$ The views presented are those of the authors and do not reflect the official position of the Bundesbank, De Nederlandsche Bank or the Eurosystem. We are grateful to Alexander Meyer-Gohde, Kenneth Judd, Christian Matthes, Alexander Richter, Dominik Thaler, Sweder van Wijnbergen, and participants at the 2019 CEPR MMCN Conference, the PASC 19, the 2019 Conference of the Society of Economic Measurement, the Computational Economics and Finance Conference in Ottawa, 2019, the VfS Jahrestagung 2019, the 20th IWH-CIREQ-GW Macroeconometric Workshop and seminars at the University of Lund and De Nederlandsche Bank for discussions and helpful comments on the contents of this paper. Part of the research leading to the results in this paper has received financial support from the Alfred P. Sloan Foundation under the grant agreement G-2016-7176 for the Macroeconomic Model Comparison Initiative (MMCI) at the Institute for Monetary and Financial Stability.

* Corresponding author

Email addresses: gboehl@uni-bonn.de,g.w.goy@dnb.nl, felix.strobel@bundesbank.de 
2007/08. The Federal Reserve (henceforth Fed) responded - then and today - by quickly lowering its policy rate to levels near zero, providing liquidity to financial markets and purchasing assets in large scale. The latter, so the commonly held view, can be seen as a substitute for conventional monetary policy, if the short-term interest rate is constrained by the zero lower bound (ZLB) ${ }^{1}$. Such conclusions are reassuring as developed economies increasingly find themselves in a "new normal" that is characterized by a low natural rate of interest and low inflation, both of which increase the likelihood of future ZLB episodes (Williams et al., 2016; Kiley, 2018). And indeed, over the past decade, several studies showed that large-scale asset purchases (LSAPs) - the primary policy instrument at the ZLB - were effective in easing financing conditions through compressing term, credit and liquidity premia. ${ }^{2}$ Against this backdrop, unconventional monetary policy measures in general, and LSAPs in particular, have become a permanent part of central banks' toolkits.

Despite their prominent role, however, little is known about the macroeconomic impact of LSAPs, in particular, their effect on output, inflation and aggregate investment. The empirical evidence that aims at answering this question remains, by and large, limited to evidence from Vector Autoregression models (including, e.g. Kapetanios et al., 2012; Baumeister, 2013; Gambacorta et al., 2014; Weale and Wieladek, 2016; Boeckx et al., 2017). While some studies, such as Andres et al. (2004); Gertler and Karadi (2011, 2013); Chen et al. (2012) and Carlstrom et al. (2017), developed structural models to study the effects of QE, none of the studies is estimated over the relevant sample period due to the challenges posed by the ZLB and the resulting nonlinear estimation. As such, a structural investigation of quantitative easing is yet absent.

In this paper, we close this gap by estimating a large-scale DSGE model over the sample from 1998 to 2020 including data of the Fed's balance sheet. Our model incorporates different channels of the aforementioned literature thereby allowing QE to affect the economy via multiple channels. First, three financial frictions ensure limits to arbitrage between short and long-term assets. On the household side, we assume portfolio adjustment costs for patient households and further assume that impatient households are segmented from the market for short-term assets by being restricted to borrow in long-term private loans as in Chen et al. (2012). On the banks' side, an agency problem creates an endogenous constraint to the bank's net worth by limiting their ability to obtain funds from households. As a result, the balance sheet of the banking sector becomes a critical determinant of the cost of credit. These assumptions give rise to an extranormal term premium on government bonds, and similarly, extranormal credit risk premia on private loans and capital claims. Central bank asset purchases compress these risk spreads, thereby easing financing conditions for firms and households in our model. Importantly, through the portfolio rebalancing channel, these risk spreads are compressed even if the specific asset under consideration is itself not purchased (d'Amico et al., 2012). Specifically, purchases of private capital assets directly affect the real economy by increasing investment. ${ }^{3}$ Moreover, through the portfolio rebalancing, also risk

\footnotetext{
${ }^{1}$ To name a few, see e.g. Hamilton and Wu (2012); Gertler and Karadi (2013); Kiley (2018); Doniger et al. (2019); Bernanke (2020); Sims and Wu (2020)

${ }^{2}$ See e.g. Gagnon et al. (2011); Krishnamurthy and Vissing-Jorgensen (2011); d'Amico et al. (2012); Bauer and Neely (2014); Swanson (2017) for the US, or e.g. Altavilla and Giannone (2017); Altavilla et al. (2019); Eser et al. (2019) for the euro area

${ }^{3}$ Following Gertler and Karadi (2013), we model the Fed's purchases of mortgage backed securities 
premia on private loans fall, thereby stimulating consumption of impatient households. Purchases of government bonds similarly reduce the credit risk premia on capital and private loans, albeit by to a lesser extent. Ultimately, by purchasing government bonds, the central bank frees up balance sheet capacity of the banks, which can then increase their supply of credit. Finally, central bank liquidity provisions directly affect a bank's supply of credit by easing it's incentive compatibility constraint.

Our nonlinear Bayesian likelihood approach fully accounts for the ZLB on nominal interest rates. In the context of large-scale DSGE models, the solution, filtering and estimation of models with occasionally binding constraints poses a host of computational challenges. In order to overcome these challenges, we use the solution method developed in Boehl (2020b) together with the proposed nonlinear Bayesian filter and smoother. The linearized model is solved with the ZLB as an endogenous occasionally binding constraint. To allow sampling from possibly multi-modal, disjoined and high-dimensional posterior distribution, we apply a tempered version of the differential evolution Monte Carlo Markov Chain method which uses a large number of chains (Ter Braak, 2006; ter Braak and Vrugt, 2008). Different to e.g. Chen et al. (2012) or Carlstrom et al. (2017), we do not have to cut the sample before the GFC when the short-term rate reached the ZLB. Instead, our nonlinear Bayesian likelihood approach allows us to structurally assess the effects of QE through the lens of a large-scale DSGE model during a period where the QE measures were taken, but the ZLB was binding. This allows us to take a far more in-debt account of the effects of these programs.

We find that between 2009 to 2015, QE increased output by about 1.2. According to our results, this reflects a net increase in investment of nearly 9 percent, that was accompanied by a 0.7 percent drop in aggregate consumption. While emergency liquidity provision measures sharply lowered the credit spread at the onset of the crisis by around 100 basis points, their macroeoconomic effects were negligible due to their short-lived nature. Purchases of private capital securities, on the other hand, were the most expansionary by significantly facilitating new investment. Both, government bond and private security purchases were effective in improving borrowing conditions for firms, but also for households, thereby increasing investment and the productive capacity. This led to a mild disinflationary effect of about 0.25 percent annually.

Expansionary financial shocks can be disinflationary if supply effects dominate demand effects. Demand effects, for instance, dominate in models of Curdia and Woodford (2010) and Gertler and Karadi (2011). Contrary, in models with a cost channel, expansionary financial shocks can be deflationary as lower financing costs are passed on to prices. This is the case in models where firms borrow in advance of production to pay wages, as in Christiano et al. (2005) and Ravenna and Walsh (2006), or capital as in Fiore and Tristani (2013). Quantitative easing, in turn, can be interpreted as such an expansionary financial shock that substantially lowers long-term interest rates. The resulting surge in investment activates the cost channel in our model even in the absence of a loan-in-advance constraint for firms as in Carlstrom et al. (2017). In the presence of costs associated with changes in the degree of capital utilization, the higher capital stock resulting from an increase in investment induces a lower capital utilization and thereby

as the central bank buying claims on the productive capital stock. Despite this discrepancy, our model captures the link between the financial and real economy as balance sheet policies of the central bank affect extranormal credit risk and term premia and thereby lending rates. 
pushes down the associated marginal costs. This mechanism is similar to Acharya et al. (2020), who find that cheap credit to impaired firms has a disinflationary effect by creating excess production capacity. Consistent with prevailing supply effects, Barth III and Ramey (2001); Chowdhury et al. (2006) and Abbate et al. (2016) find evidence in favor of a cost channel. Abbate et al. (2016), for instance, show that - using a vector autoregression model with sign restrictions - financial shocks that lower firms' funding costs and increase credit growth and stock prices indeed reduce inflation in the short run. Similarly, using Italian firm-level data on output prices and interest rates paid on debt, Gaiotti and Secchi (2006) find the cost channel to be proportional to the working capital. A different yet related channel is proposed by Gilchrist et al. (2017). Using granular micro-data, the authors show that firms' with binding liquidity constraints increased prices during the GFC, while unconstrained firms lowered them. To rationalize this empirical finding, Gilchrist et al. (2017) build a theoretical model where firms price goods above marginal costs in order to hedge against the risk of relying on costly external finance. Against this backdrop, our results suggest that aggregate supply channels dominated in determining the response of inflation to LSAPs.

Our results are robust to the specification of the household side the related direct channel of QE to consumption. We test this by estimating the representative agent version of the model. In this model vintage, investment increases more in response to a QE shock than in our benchmark model. However, the resulting increase in the production capacity drives utilization further down, which actually induces an even larger fall in inflation and aggregate consumption. In a second vintage, we replace the impatient households by hand-to-mouth consumers inspired by Kaplan et al. (2018). Different to our impatient households, hand-to-mouth consumers do not optimize but simply consume their period labor income, which more closely ties consumption to investment. In this version, QE does not affect consumption directly, but only indirectly via the labor income. For this model vintage, aggregate consumption again falls stronger than in our benchmark model, because falling wages dominate any labor income gains from increased labor supply. The channel described above that exerts downward pressure on inflation is unaltered leaving the inflation response consistent with our benchmark model.

We further test whether our results are also robust to the model choice by estimating the Carlstrom et al. (2017) model the more recent data sample and the same methodology as for our benchmark mode. We confirm the fall in consumption to be a robust consequence of QE. In contrast to our benchmark model, however, in the estimated CFP model demand effects of LSAPs appear to outweigh their supply effects. We take this result with a considerable degree of caution due to several caveats related to the suitability of the CFP model in its original form for estimation on a post-GFC sample. For instance, we find that this model lacks any demand side shock that allows a strict co-movement of consumption and investment.

The rest of the paper is organized as follows. Section 2 presents the core of our largescale dynamic general equilibrium model. The nonlinear Bayesian estimation methodology is explained in Section 3. Our posterior estimates are discussed in Section 4, together with an empirical analysis of the GFC and its aftermath. Section 5 then presents our main results in the form of counterfactual analysis of the Fed's unconventional monetary policy measures. Subsequently, in Section 6, we show that our results are robust with respect to several model features. Finally, Section 7 concludes. 


\section{Model}

To study the macroeconomic effects of quantitative easing, we build a large-scale New Keynesian model featuring patient and impatient households, banks, firms as well as a fiscal and a monetary authority. Patient households consume, supply labor and save. Their savings can take the form of short-term bank deposits, private securities backed by firm's capital and government bonds, where the latter two are long-term assets and subject to convex portfolio adjustment costs. Instead, impatient households borrow longterm private loans from banks besides consuming and supplying labor. Similarly to Chen et al. (2012), households are thus split into "savers" and "borrowers". Banks are modeled as in Gertler and Karadi (2011). They collect deposits from patient households, which they lend on to impatient households, intermediate good producers and the government in the form of long-term bonds and loans. A moral hazard problem constrains their leverage, which creates limits to arbitrage needed for QE to have an effect on the banks balance sheet.

The production sector consists of three types of firms for reasons of tractability. Intermediate good producers employ labor and capital to produce their goods. Each period, after producing their output, they sell their used capital stock to the capital goods producers. The latter repair it and invest in new capital. At the end of the period, capital is re-sold to the intermediate good producers which use it for production in the next period. Intermediate goods are purchased by retailers which repackage them and sell them with a markup as final goods. Similarly, labor is differentiated by a union with monopoly power that faces nominal rigidities.

The government consumes final goods, collects taxes, and issues long-term government bonds. Monetary policy sets the short-term interest rate according to a Taylor-type rule which is constrained by the ZLB. In line with the literature on estimated DSGE models, our model also includes standard features such as habit formation in consumption, investment adjustment costs, variable capital utilization, nominal rigidities as in Calvo (1983) in both, price and wage setting, as well as price and wage indexation.

We model large-scale asset purchases of treasury bonds and private capital assets to follow exogenous $\operatorname{AR}(2)$ processes. This way, we allow for anticipation and stock effects without necessarily having to specify a policy rule for unconventional monetary policy. Arguably, the measures of QE came as much as a surprise to the US economy as the crisis did. At the same time, once in action the future path of these measures was public information. Our outlined setup approximates this structure. Liquidity injections by the central bank to financial intermediaries are also exogenous.

Finally, time is discrete and one period in the model represent one quarter. Below, we will describe the financial sector and the household structure in more detail, while we refer the reader to Appendix B in the Online Appendix for a full description of the model.

\subsection{The household structure}

The model is populated by two types of households. We assume a continuum of impatient households with mass $\chi$ and a continuum of patient households of mass $1-\chi$. In the spirit of Gertler and Karadi (2013), we impose that a constant fraction $f$ of the patient household works as banker, whereas the remaining fraction $1-f$ consists of workers who - like impatient households - supply labor to the intermediate good producers. While 
workers receive their wage income every period, bankers reinvest their gains in asset holdings of the bank over several periods. Only when a banker (exogenously) exits the banking sector, she contributes to the patient households' income by bringing home the accumulated profits. Perfect consumption insurance within patient households ensures that workers and bankers face the same consumption stream. The expected lifetime utility of any household $i$ is given by

$$
U_{t}=E_{0} \sum_{t=0}^{\infty} \beta_{i}^{t}\left(\frac{\left(C_{i, t}-h C_{i, t-1}\right)^{1-\sigma_{c}}-1}{1-\sigma_{c}}\right) \exp \left(\frac{\sigma_{c}-1}{1+\sigma_{l}} L_{i, t}^{1+\sigma_{l}}\right)
$$

where parameters $\beta_{i}, h, \sigma_{c}$, and $\sigma_{l}$ are, respectively, the discount factor, the degree of external habit formation in consumption, the coefficient of relative risk aversion, and a weight on the disutility of labor. The discount factor has a household-specific subscript $i$, because we assume the discount factor of impatient households $\beta_{m}$ to be smaller than the discount factor of patient households, i.e. $\beta_{m}<\beta_{p}$. Finally. $C_{i, t}$ and $L_{i, t}$ denote consumption and hours worked of household $i \in\{m, p\}$, respectively. ${ }^{4}$

\subsection{Patient households}

The patient household earns the real wage, $W_{t}$, for her supplied labor, $L_{p, t}$. She can save in one-period bank deposits, $D_{t}$, that pay an interest rate, $R_{t}^{d}$, in government bonds, $B_{h, t}$, that yield an interest rate, $R_{t}^{b}$, and in capital assets $K_{h, t}$ with an associated interest rate, $R_{t}^{k}$. These interest rates are already in real terms, i.e. accounting for inflation. Capital claims, just like government bonds, are modeled as long-term assets. As for all stock variables, we use the end-of-period notation, so that $D_{t}$ denotes the household's deposits at the end of period $t$. The return on deposits, $R_{t}^{d}=v_{u, t} R_{t}$, includes a disturbance term, $v_{u, t}$ which drives a wedge between the risk-free real rate and the return on deposits. We assume $v_{u, t}$ to follow an AR(1) process in logs. Smets and Wouters (2007) label this shock a risk-premium shock which they interpret as variations in the confidence in the banking system. Patient households spend their funds on consumption $C_{p, t}$, and save in new deposits, bonds and capital. Savings in government bonds and capital are, as in e.g. Chen et al. (2012), subject to portfolio adjustment costs with adjustment parameters $\kappa_{b}$ and $\kappa_{k}$. The budget constraint of patient households, in real terms, reads

$$
\begin{array}{r}
C_{p, t}+\frac{D_{t}}{R_{t}^{d}}+Q_{t}\left[K_{h, t}+\frac{1}{2} \kappa_{k}\left(K_{h, t}-K_{h}\right)^{2}\right]+Q_{t}^{b}\left[B_{h, t}+\frac{1}{2} \kappa_{b}\left(B_{h, t}-B_{h}\right)^{2}\right] \\
=D_{t-1}+W_{t} L_{p, t}+R_{t}^{k} Q_{t-1} K_{h, t-1}+R_{t}^{b} Q_{t-1}^{b} B_{h, t-1}-T_{t}+\mathfrak{P}_{t} .
\end{array}
$$

$T_{t}$ denotes lump sum taxes raised by the government to finance government spending, and $\mathfrak{P}_{t}$ are profits of monopolistic firms and banks that accrue to the patient households. Maximizing (1) subject to the patient household's budget constraint (2) and rearranging the first order conditions yields the well-known Euler equation, a condition for the optimal

\footnotetext{
${ }^{4}$ For the ease of notation, we only use subscripts $i \in\{m, p\}$ indicating which type of household is meant if necessarily needed.
} 
supply of labor and two no-arbitrage conditions:

$$
\begin{aligned}
1 & =\beta_{p} E_{t}\left[\exp \left(\frac{\sigma_{c}-1}{1+\sigma_{l}}\left(L_{p, t+1}^{1+\sigma_{l}}-L_{p, t}^{1+\sigma_{l}}\right)\right)\left(\frac{C_{p, t+1}-h C_{p, t}}{C_{p, t}-h C_{p, t-1}}\right)^{-\sigma_{c}}\right] R_{t}^{d}, \\
W_{t}^{h} & =\left(C_{p, t}-h C_{p, t-1} L_{p, t}^{\sigma_{l}},\right. \\
E_{t} R_{t+1}^{k} & =R_{t}^{d}\left[1+\kappa_{k}\left(K_{h, t}-K_{h}\right)\right], \\
E_{t} R_{t+1}^{b} & =R_{t}^{d}\left[1+\kappa_{b}\left(B_{h, t}-B_{h}\right)\right] .
\end{aligned}
$$

Ultimately, the no-arbitrage conditions (5) and (6) specify the patient household's optimal holdings of both capital claims and government bonds.

\subsection{Impatient households}

There is a fraction of $\chi$ impatient households which consume, supply labor and borrow long-term private loans from the banks which gives rise to the following budget constraint in real terms

$$
C_{m, t}+R_{t}^{p} Q_{t-1}^{p} B_{m, t-1}^{p}=W_{t} L_{m, t}+Q_{t}^{p} B_{m, t}^{p},
$$

where $R_{t}^{P}$ and $Q_{t}^{P}$ denote, respectively, the interest rate and price of private loans $B_{m, t}^{p}$. Price and yield of private loans are related through

$$
R_{t}^{p}=\frac{\xi+\kappa_{p} Q_{t}^{p}}{Q_{t-1}^{p}}
$$

where $\xi$ is the coupon (or redemption) and $\kappa_{p}$ denotes the decay factor (Woodford, 1998, 2001). Maximizing (1) subject to the impatient households budget constraint (7) yields, after some rearranging, an Euler equation for the optimal borrowing and a condition for the labor supply of impatient households:

$$
\begin{aligned}
1 & =\beta_{m} E_{t}\left[\exp \left(\frac{\sigma_{c}-1}{1+\sigma_{l}}\left(L_{m, t+1}^{1+\sigma_{l}}-L_{m, t}^{1+\sigma_{l}}\right)\right)\left(\frac{C_{m, t+1}-h C_{m, t}}{C_{m, t}-h C_{m, t-1}}\right)^{-\sigma_{c}}\right] R_{t}^{p}, \\
W_{t}^{h} & =\left(C_{m, t}-h C_{m, t-1}\right) L_{m, t}^{\sigma_{l}} .
\end{aligned}
$$

\subsection{Banks}

The banking sector draws on Gertler and Karadi (2013) with the extensions that we outline below. Banks collect deposits $D_{t}$ from patient households and - together with their own net worth $N_{t}$ - use these funds to extend loans $B_{b, t}^{p}$ to impatient households, purchase capital securities from intermediate good producers, $K_{b, t}$, and purchase government bonds $B_{b, t}$. Given these financial operations, the balance sheet of a representative bank then follows as

$$
Q_{t} K_{b, t}+Q_{t}^{b} B_{b, t}+Q_{t}^{p} B_{b, t}^{p}=N_{t}+D_{t}+L_{t}^{q},
$$

where $L_{t}^{q}$ denotes exogenous emergency liquidity injections by the Federal Reserve. While it can be argued that this might be an ad hoc way of modeling such injections, the provision of central bank liquidity was a very important funding source when interbank market dried up during the height of financial crisis. As such, these operations were 
essential in preserving market functioning and preventing cascading fire sales which, ultimately, might have led to a credit crunch (Bernanke, 2008; Fleming, 2012). In our model, these liquidity injections directly support bank lending by increasing banks' net worth and easing their financial constraints as shown below. Despite their relatively short duration, these liquidity injections have been sizable, and their effects have not yet been assessed empirically in a structural context. For simplicity, we assume that central bank liquidity is lent at a zero nominal interest rate (i.e. their real rate equals $R_{t}^{L}=1 / \Pi_{t+1}$, where $\Pi_{t}$ denotes gross inflation). Banks retain their earnings and add it to their current net worth. This gives rise to the following law of motion for the bank's net worth

$$
\begin{array}{r}
N_{t}=R_{t}^{k} Q_{t-1} K_{b, t-1}+R_{t}^{b} Q_{t-1}^{b} B_{b, t-1}+R_{t}^{p} Q_{t-1}^{p} B_{b, t-1}^{p} \\
-R_{t-1}^{d} D_{t-1}-R_{t-1}^{L} L_{t-1}^{q} .
\end{array}
$$

Note that while the interest rate on deposits raised in period $t-1$ is determined in the same period, the return of assets is risky and only determined after the realization of shocks at the beginning of period $t$.

Bankers continue accumulating their individual net worth until they (involuntarily) exit the business, which occurs randomly with exogenous probability, $1-\theta$. Conversely, bankers continue their operations with probability $\theta$. Draws from this lottery are i.i.d. and do not depend on the banker's history. When a banker leaves the sector, she adds her terminal wealth, $V_{t}$, to the wealth of the patient household she is member of. Therefore, bankers seek to maximize the expected discounted terminal value of their wealth

$$
\begin{aligned}
V_{t} & =\max E_{t} \sum_{i=0}^{\infty}(1-\theta) \theta^{i} \beta_{p}^{i+1} \frac{\Lambda_{p, t+1+i}}{\Lambda_{p, t+i}} N_{t+1+i} \\
& =\max E_{t}\left[\beta_{p} \frac{\Lambda_{p, t+1}}{\Lambda_{p, t}}(1-\theta) N_{t+1}+\theta V_{t+1}\right]
\end{aligned}
$$

where $\Lambda_{p, t}$ denotes the patient household's Lagrangian multiplier with respect to the budget constraint.

Banks operate under perfect competition. If financial intermediation was frictionless, the risk adjusted return on the bank's asset should equal the return on deposits. As in Gertler and Karadi (2013), however, bankers can divert a fraction of their assets and transfer it to their respective households. If they do so, their depositors will withdraw their remaining funds and force the bank into bankruptcy. This moral hazard/costly enforcement problem creates an endogenous limit to the amount of deposits that households are willing to supply. While the latter ensures that bankers earn a strictly positive excess return, it also creates limits to arbitrage, as bankers can not scale-up their balance sheet to arbitrage away any price differences. In order to prevent a banker from diverting a fraction of assets, households keep their deposits at a bank only as long as the bank's continuation value is higher or equal to the amount that the bank can divert. Formally, the latter condition is given by the following incentive compatibility constraint of the bank

$$
V_{t} \geq \lambda_{k, t} Q_{t} K_{b, t}+\lambda_{b} Q_{t}^{b} B_{b, t}+\lambda_{p} Q_{t}^{p} B_{b, t}^{p}-\lambda_{L} L_{t}^{q},
$$

where $\lambda_{j}$ for $j \in\{k, p, b\}$ denotes the respective fraction of capital claims, government bonds or private loans that the bank can diverted. Following Dedola et al. (2013) and 
Gelain and Ilbas (2017), we allow $\lambda_{k, t}$ to be time-varying, formally following an $\operatorname{AR}(1)$ process in logs with mean $\lambda_{k}$. Ultimately, this shock triggers variations in the divertiblity of capital assets and can be interpreted as variations in the trust depositors have in the quality of banks' capital assets.

In steady state, the $\lambda_{j}$ 's for $j \in\{k, p, b\}$ determine - together with other estimated parameters such as the discount factor of patient households, $\beta_{p}$, and the trend growth rate, $\gamma$ - the returns on capital claims and government bonds, $R^{k}$ and $R^{b}$, as well as the private loan rate $R^{p}$. We set the prior mean of the relevant parameters such that the respective excess returns over the deposit rate are based on data for the US treasury rate, Gilchrist and Zakrajšek (2012) corporate spread and mortgages rates for private households. This results, a priori, in $\lambda_{b}<\lambda_{p}<\lambda_{k}$, which intuitively can be motivated by the fact that, in general, the collateral value of government bonds is higher than that of mortgage loans and capital claims. ${ }^{5}$ The reason is that treasury bonds enjoy higher credit ratings and are subject to less liquidity risks than mortgage loans or capital claims. Finally, the last term in the incentive constraint is due to the assumption that liquidity injections serve to relax the incentive constraint of banks.

To solve the bank problem, let an initial guess of the value function be of the form

$$
V_{t}=\nu_{k, t} Q_{t} K_{b, t}+\nu_{b, t} Q_{t}^{b} B_{b, t}+\nu_{p, t} Q_{t}^{p} B_{b, t}^{p}+\nu_{n, t} N_{t}+\nu_{L, t} L_{t}^{q},
$$

where $\nu_{k, t}, \nu_{b, t}, \nu_{p, t}, \nu_{d, t}$, and $\nu_{L, t}$ are time-varying coefficients. Maximizing (14) with respect to $K_{b, t}, B_{b, t}$ and $B_{b, t}^{p}$ subject to (13) yields the following first order conditions for capital claims, governments bonds, private loans, and $\mu_{t}$, the Lagrangian multiplier on the incentive compatibility constraint

$$
\begin{aligned}
\nu_{k, t} & =\lambda_{k, t} \frac{\mu_{t}}{1+\mu_{t}}, \\
\nu_{b, t} & =\lambda_{b} \frac{\mu_{t}}{1+\mu_{t}}, \\
\nu_{p, t} & =\lambda_{p} \frac{\mu_{t}}{1+\mu_{t}}, \\
\nu_{n, t} N_{t}+\nu_{L, t} L_{t}^{q} & =\left(\lambda_{k, t}-\nu_{k, t}\right) Q_{t} K_{b, t}+\left(\lambda_{b}-\nu_{b, t}\right) Q_{t}^{b} B_{b, t}+\left(\lambda_{p}-\nu_{p, t}\right) Q_{t}^{p} B_{b, t}^{p} .
\end{aligned}
$$

Given that the incentive compatibility constraint binds ${ }^{6}$, we can rewrite this last equation as

$$
Q_{t} K_{b, t}=\frac{\nu_{b, t}-\lambda_{b}}{\lambda_{k, t}-\nu_{k, t}} Q_{t}^{b} B_{b, t}+\frac{\nu_{p, t}-\lambda_{p}}{\lambda_{k, t}-\nu_{k, t}} Q_{t}^{p} B_{b, t}^{p}+\frac{\nu_{L, t}+\lambda_{L}}{\lambda_{k, t}-\nu_{k t}} L_{t}^{q}+\frac{\nu_{n, t}}{\lambda_{k, t}-\nu_{k, t}} N_{t} .
$$

Intuitively, (19) states that banks' demand for capital claims decreases in $\lambda_{j}$ for $j \in$ $\{k, p, b\}$, which regulate the tightness of the incentive constraint with respect to capital claims, mortgage loans over government bonds. Central bank liquidity injections $L_{t}^{q}$, on other hand, support the demand for capital claims.

\footnotetext{
${ }^{5}$ In a similar vein, Meeks et al. (2017) use the same approach to distinguish between the collateral values of loans and asset-backed securities.

${ }^{6}$ The constraint binds in the neighborhood of the steady state. For convenience, we make the assumption that it is binding throughout all experiments.
} 
Substituting the demand for capital claims into (14), and combining the result with (15) one can write the terminal value of the banker as a function of its net worth

$$
V_{t}=\left(1+\mu_{t}\right) \nu_{n t} N_{t}+\left[\left(1+\mu_{t}\right) \nu_{L, t}+\mu_{t} \lambda_{L}\right] L_{t}^{q}
$$

A higher continuation value, $V_{t}$, is associated with a higher shadow value of holding an additional marginal unit of assets, or put differently, with a higher shadow value of marginally relaxing the incentive compatibility constraint. Then, define the bank's stochastic discount factor as

$$
\Omega_{t} \equiv \frac{\Lambda_{p, t}}{\Lambda_{p, t-1}}\left[(1-\theta)+\theta\left(1+\mu_{t}\right) \nu_{n, t}\right],
$$

and substitute (20) into the Bellman equation (12). Using the law of motion for net worth (11), one can then write the value function as

$$
\begin{aligned}
& V_{t}=\beta_{p} E_{t} {\left[\Omega _ { t + 1 } \left(\left(R_{t+1}^{k}-R_{t}^{d}\right) Q_{t} K_{b, t}+\left(R_{t+1}^{b}-R_{t}^{d}\right) Q_{t}^{b} B_{b, t}\right.\right.} \\
&+\left.\left.\left(R_{t+1}^{p}-R_{t}^{d}\right) Q_{t}^{p} B_{b, t}^{p}+\left(R_{t}^{d}-R_{L, t}\right) L_{t}^{q}+R_{t}^{d} N_{t}\right)\right] \\
&+\beta_{p} E_{t}\left[\frac{\Lambda_{p, t+1}}{\Lambda_{p, t}} \theta\left[\left(1+\mu_{t+1}\right) \nu_{L, t+1}+\mu_{t+1} \Lambda_{L}\right] L_{t+1}^{q}\right]
\end{aligned}
$$

Finally, verifying the initial guess for the value function yields

$$
\begin{aligned}
\nu_{k, t} & =\beta_{p} E_{t} \Omega_{t+1}\left(R_{t+1}^{k}-R_{t}^{d}\right) \\
\nu_{b, t} & =\beta_{p} E_{t} \Omega_{t+1}\left(R_{t+1}^{b}-R_{t}^{d}\right), \\
\nu_{p, t} & =\beta_{p} E_{t} \Omega_{t+1}\left(R_{t+1}^{p}-R_{t}^{d}\right), \\
\nu_{n, t} & =\beta_{p} E_{t} \Omega_{t+1} R_{t}^{d} \\
\nu_{L, t} & =\beta_{p} E_{t}\left[\Omega_{t+1}\left(R_{t}^{d}-R_{t}^{L}\right)+\theta \rho_{c b l} \frac{\Lambda_{p, t+1}}{\Lambda_{p, t}}\left[\left(1+\mu_{t+1}\right) \nu_{L, t+1}+\mu_{t+1} \lambda_{L}\right]\right],
\end{aligned}
$$

where the last equality follows from the fact that $L_{t}^{q}$ follows an $\operatorname{AR}(1)$ in $\operatorname{logs}$ with persistence parameter $\rho_{c b l}$.

\subsection{Monetary policies and the ZLB}

In response to the Great Recession, the Federal Reserve cut its policy rate to essentially zero. We model conventional monetary policy as a standard reaction function with the central bank responding to deviations of inflation from it's target, the output gap and its growth rate

$$
\frac{R_{t}^{s}}{R^{n}}=\left(\frac{R_{t-1}^{s}}{R^{n}}\right)^{\rho}\left[\left(\frac{\Pi_{t}}{\Pi}\right)^{\phi_{\pi}}\left(\frac{Y_{t}}{Y_{t}^{*}}\right)^{\phi_{y}}\left(\Delta\left(\frac{Y_{t}}{Y_{t}^{*}}\right)\right)^{\phi_{d y}}\right]^{1-\rho} v_{r, t},
$$

with the ZLB constraint

$$
R_{t}^{n}=\max \left\{\bar{R}, R_{t}^{s}\right\}
$$


where we refer to the unconstrained nominal rate $R_{t}^{s}$ as the notational (or shadow) rate. $Y_{t}^{*}$ denotes the potential output and $\Delta\left(\frac{Y_{t}}{Y_{t}^{*}}\right)$ denotes the growth in the output gap. The parameter $\rho_{R}$ expresses an interest rate smoothing motive by the central bank over the notational rate and $\phi_{\pi}, \phi_{y}$ and $\phi_{d y}$ are feedback coefficients. The max-operator in (28) reflects the zero lower bound (ZLB) on the nominal interest rate $R_{t}^{n}$, which we take into account in our estimation procedure. For this purpose, $\bar{R}$ denotes the exact level at which the ZLB binds. ${ }^{7}$ When the economy is away from the ZLB, the stochastic process $v_{r, t}$ - which follows an $\mathrm{AR}(1)$ in logs - represents a regular interest rate shock. However, when the nominal interest rate is zero, $v_{r, t}$ may not directly affect the level of the nominal interest rate. Instead, $v_{r, t}$ affects the expected path of the notational rate, first through it's own persistence and, second, through the persistence in the notional rate, and therefore alter the expected duration of the lower bound spell. At the ZLB, it can hence be viewed as a forward guidance shock.

At the onset of the Financial crisis, the Federal Reserve injected large amounts of liquidity into the financial sector which is known as credit easing. We capture these emergency liquidity injections with as an exogenous variable that eases banks' incentive compatibility constraint (13) and thereby stimulates lending. In our estimation, we feed the time series data on these liquidity injections into the model and assume that the associated process follow $\mathrm{AR}(1)$ process. That is, formally

$$
\tilde{L}_{t}=\rho_{c b l} \tilde{L}_{t-1}+\epsilon_{C B L, t},
$$

where $\tilde{L} \equiv \frac{L_{t}^{q}}{P_{t} Y_{t}}$ denotes central bank liquidity as percentage of GDP.

When the policy rate hit the ZLB in December 2008, the Federal Reserve further started its large scale asset purchase program, under which it purchased different debt instruments in order to suppress credit and term premia. In our analysis, we divide these purchases into private (capital) security purchases and government bond purchases, both which we assume to follow an $\mathrm{AR}(2)$ process in logs.

$$
\begin{aligned}
\tilde{K}_{c b, t} & =\rho_{k, 1} \tilde{K}_{c b, t-1}+\rho_{k, 2} \tilde{K}_{c b, t-2}+\epsilon_{Q E K, t}, \\
\tilde{B}_{c b, t} & =\rho_{b, 1} \tilde{B}_{c b, t-1}+\rho_{b, 2} \tilde{B}_{c b, t-2}+\epsilon_{Q E B, t} .
\end{aligned}
$$

Similar to the liquidity injections, $\tilde{K}$ and $\tilde{B}$ denote, respectively, the central banks capital claim and government bond purchases as a fraction of GDP. The advantage of an AR(2) process is that it can capture the hump-shaped response of the asset purchases, thereby also ensuring anticipation or stock effects at the moment the announcement was made.

\section{Estimation and Methodology}

The fact that our sample includes a long episode where the ZLB binds poses a host of technical challenges. These are related to the solution, filtering and estimation of the model in the presence of an occasionally binding constraint (OBC). While solution methods for models with OBCs exists - as do nonlinear filters - the satisfactory combination

\footnotetext{
${ }^{7}$ Given that, empirically, the Federal Funds rate remained strictly above zero, we choose $\bar{R}$ to be slightly above one in our estimation. Moreover, due to the fact that the Fed never implemented negative rates, we use the term "zero lower bound" and "effective lower bound" interchangeably.
} 
of both in the context of a large-scale DSGE model is computationally very expensive and was so far deemed impossible. In this section, we first briefly sketch the set of novel methods proposed by Boehl (2020b) that allow us to estimate such high dimensional models in the presence of a binding ZLB. Subsequently, this section describes our choices with regard to the data.

\subsection{Solution method}

Throughout this paper we apply the solution method for OBCs presented in Boehl (2020b). We refer to the original paper for details. The model is linearized around its steady state balanced growth path and thereby implicitly detrended. Respecting the ZLB, this leads to a piecewise linear model that can be represented as

$$
\mathbf{N}\left|\begin{array}{c}
\mathbf{x}_{t} \\
\mathbf{w}_{t}
\end{array}\right|+\mathbf{c} \max \left\{\mathbf{b}\left|\begin{array}{c}
\mathbf{x}_{t} \\
\mathbf{w}_{t}
\end{array}\right|, \bar{r}\right\}=E_{t}\left|\begin{array}{c}
\mathbf{x}_{t+1} \\
\mathbf{v}_{t}
\end{array}\right|
$$

where $\mathbf{v}_{t}$ contains all the (latent) state variables, $\mathbf{w}_{t}=\mathbf{v}_{t-1}+\boldsymbol{\Xi} \varepsilon_{t}$ the state from last period augmented by the current shocks, and $\mathbf{x}_{t}$ contains all forward looking variables. $\mathbf{N}$ is the system matrix and $\bar{r}$ is the minimum value of the constrained variable $r_{t}$ (here, the nominal interest rate). The vector $\mathbf{b}$ defines $r_{t}=\max \left\{\bar{r},\left\langle\mathbf{b},\left(\mathbf{x}_{t}, \mathbf{w}_{t}\right)^{\top}\right\rangle\right\}$. The vector c contains the effects of $r_{t}$ onto all other variables. Further, denote by the two integer values $k$ and $l$ respectively the expected duration of the ZLB spell and the expected number of periods before the ZLB binds.

It can be shown that the rational expectations solution to (32) for the state $s$ periods ahead, $\mathbf{v}_{t+s}$, can be expressed in terms of $\mathbf{w}_{t}$ and the expectations on $k$ and $l$ as

$$
\begin{aligned}
L_{s}\left(l, k, \mathbf{w}_{t}\right)= & \mathbf{N}^{\max \{s-l, 0\}}(\mathbf{N}+\mathbf{c b})^{\min \{l, s\}} S\left(l, k, \mathbf{w}_{t}\right) \\
& +(\mathbf{I}-\mathbf{N})^{-1}\left(\mathbf{I}-\mathbf{N}^{\max \{s-l, 0\}}\right) \mathbf{c} \bar{r} \\
= & {\left[\begin{array}{c}
\mathbf{x}_{t+1+s} \\
\mathbf{v}_{t+s}
\end{array}\right] }
\end{aligned}
$$

where

$$
S\left(l, k, \mathbf{w}_{t}\right)=\left\{\left[\begin{array}{l}
\mathbf{x}_{t} \\
\mathbf{w}_{t}
\end{array}\right]: \mathbf{Q N}^{k}(\mathbf{N}+\mathbf{c b})^{l}\left[\begin{array}{l}
\mathbf{x}_{t} \\
\mathbf{w}_{t}
\end{array}\right]=-\mathbf{Q}(\mathbf{I}-\mathbf{N})^{-1}\left(\mathbf{I}-\mathbf{N}^{k}\right) \mathbf{c} \bar{r}\right\} .
$$

Here, $\mathbf{Q}=\left[\begin{array}{ll}\mathbf{I} & -\boldsymbol{\Omega}\end{array}\right]$ for $\mathbf{x}_{t}=\boldsymbol{\Omega} \mathbf{w}_{t}$ represents the linear rational expectations solution of the unconstrained system as e.g. given by Blanchard and Kahn (1980) or Klein (2000).

Finding the equilibrium values of $(l, k)$ must be done numerically. One advantage of the above representation is that the simulation of anticipated equilibrium paths can be avoided when iterating over $(l, k)$. The resulting transition function is a nonlinear state-space representation. ${ }^{8}$

\footnotetext{
${ }^{8}$ We use the implementations of Boehl $(2020 \mathrm{a}, \mathrm{c})$, which for the model presented here will solve for the nonlinear state-space representation of about 80.000 particles draws per processor and second.
} 


\subsection{Filtering and Estimation Method}

Likelihood inference requires a nonlinear Bayesian filter (An and Schorfheide, 2007). Given the high dimensionality of our model, the particle filter is not feasible. ${ }^{9}$ To fill this gap, Boehl (2020b) introduces the transposed-ensemble Kalman filter (TEnKF) which is a hybrid of the particle filter and Kalman filter. For the transition $t-1 \rightarrow t$ an ensemble of particles is sampled from the state distribution at $t-1$. Instead of resampling (particle filter), the TEnKF applies statistical linearization to update the state estimate represented by the ensemble to match each new observation vector. This allows to efficiently approximate the distribution of states for large-scale nonlinear systems with only a few hundred particles instead of several million or billion, as for the particle filter, which is computationally advantageous. ${ }^{10}$ Boehl (2020b) also proposes a nonlinear path-adjustment smoother (NPAS) for high-dimensional nonlinear models, which we use obtain the smoothed/historic shock innovations.

We sample from the posterior distribution using a tempered version of the differential evolution Monte Carlo Markov chain method (Ter Braak, 2006; ter Braak and Vrugt, 2008, DE-MCMC). The DE-MCMC sampler is a subclass of ensemble MCMC methods. Instead of using a single Markov chain (as e.g. the Metropolis algorithm), such ensemble samplers use a large number of chains (as well called ensemble). Proposals for each iteration are generated based on the state of the previous ensemble instead of an explicit proposal distribution.. The DE-MCMC sampler is hence self-tuning and the ensemble structure make massive parallelization straightforward. This is in particular important as both the simulation and the filtering step are computationally expensive. The combination of DE-MCMC with tempering (similar to Herbst and Schorfheide, 2014) has the advantage that it is very robust to local maxima and odd-shaped or bimodal distributions. ${ }^{11}$

\subsection{Data and calibration}

In order to quantify the effects of the large scale asset purchases and liquidity injections taken in the aftermath of the Financial Crisis of 2008-09, we estimate our model on data from 1998:I to 2019:IV. Importantly, and different to earlier papers that also attempted to assess the effects of large-scale asset purchases, such as Chen et al. (2012) and Carlstrom et al. (2017), we also include the ZLB period and data on the Fed's balance sheet in our nonlinear estimation procedure. This, we believe, is crucial to properly assess the effects of QE. Using a longer time sample as in Carlstrom et al. (2017), on the other hand, bears the risk of misspecification given the large amount of parameters we

\footnotetext{
${ }^{9}$ The inversion filter used in Guerrieri and Iacoviello (2017) and discussed in Cuba-Borda et al. (2019) is also not an option as it is not a Bayesian filter and ignores uncertainty on the initial states and the observations. This may not be crucial for small-scale models without endogenous state variables as in Atkinson et al. (2019), but is important given the high dimensionality of our model and our relatively short data sample.

${ }^{10}$ For all estimations and for the numerical analysis we use an ensemble of 350 particles. For our model, the evaluation of the likelihood for one parameter vector would then take 1-2 seconds on a single CPU.

${ }^{11} \mathrm{We}$ initialize the ensemble for the parameter distribution with 200 parameter vectors sampled from the prior distribution. We then use 8 temperature scales with 200 iterations each. Finally, we let the sample 2500 iterations, of which we keep the last 500 ensembles. The posterior parameter distribution is hence represented by $500 \times 200=10000$ parameter vectors.
} 
estimate and, concomitantly, a risk of biasing the effects of QE. In particular, we chose the sample to adequately capture the current low interest rate environment and potential structural changes in the economy, like a flatter Phillips curve. ${ }^{12}$

We use a total of eleven observables in the estimation. GDP, consumption, investment and wages are all in real terms and calculated as per capita growth rates. Likewise, we use average weekly hours worked multiplied by the employment level and divided by civilian noninstitutional population to measure the per capita labor supply. Due to artificial dynamics in the civilian noninstitutional population series that arise from irregular updating (Edge et al., 2013), we use a 4-quarter trailing moving average instead. Inflation is measured as the log differences of the GDP deflator. We include the Federal Funds Rate (FFR) and the Gilchrist and Zakrajšek (2012, henceforth GZ) spread as quarterly rates. The latter is an average credit spread on corporate bonds, very similar to Moody's BAA spread, yet considers the entire spectrum of credit ratings from "single D" to "triple A". While the dynamics of both spreads is very similar over our sample (the correlation of quarterly data reaches 0.9 ), the GZ spread peaks higher during the Financial crisis but remains less elevated thereafter than the BAA spread, both which is preferred by the model.

For the unconventional monetary policies, we use three observables that we feed into the model as exogenous policy shocks. First, we take the total face value of U.S. Treasury securities held by the Federal Reserve divided by nominal GDP as measure for the Fed's government bond purchases. Second, we add the current face value of mortgage-backed obligations held by Federal Reserve to the net portfolio holdings of the Commercial Paper Funding Facility, both as a fraction of nominal GDP, and use it as a measure for purchases of private capital securities. Third, to measure the Fed's emergency liquidity injections in 2008/09, we add - in line with Fleming (2012) - the central bank liquidity swaps, the current face value of federal agency obligations held by Federal Reserve, the term auction credit held by the Federal Reserve and other loans held by the Federal Reserve, all as a fraction of nominal GDP. The latter mainly includes the Asset-backed Commercial Paper Money Market Mutual Fund Liquidity Facility and the Primary Dealer Credit Facility. Figure 1 shows those three time series.

To facilitate the nonlinear filtering, we assume small measurement errors for all variables with a variance that is 0.01 times the variance of the respective series. Since the Federal Funds rate is perfectly observable (though on higher frequency) we divide the measurement error variance here again by 100 . Except for labor supply, the data is not demeaned as we assume the non-stationary model follows a balanced growth path that we estimate in line with Smets and Wouters (2007). The measurement equations and a detailed description of the data, as well as its treatment and sources is delegated to Appendix A.

Finally, we fix several parameters prior to estimating the others. In line with Smets and Wouters (2007), we set the depreciation rate to $\delta=0.025$, the steady state govern-

\footnotetext{
${ }^{12}$ There is an extensive literature that documents a fall in the natural rate of interest and trend inflation since the 1980s (see e.g. Laubach and Williams, 2003; Brand et al., 2018, 2020). Similarly, the semi-structural estimates of Laubach and Williams (2003) and Brand et al. (2020) indicate weak relationships between inflation and economic slack, in line with structural estimates of Del Negro et al. (2015) and Kulish et al. (2017). Finally, a similar flattening has been documented for the wage Phillips curve by e.g. Daly and Hobijn (2014).
} 


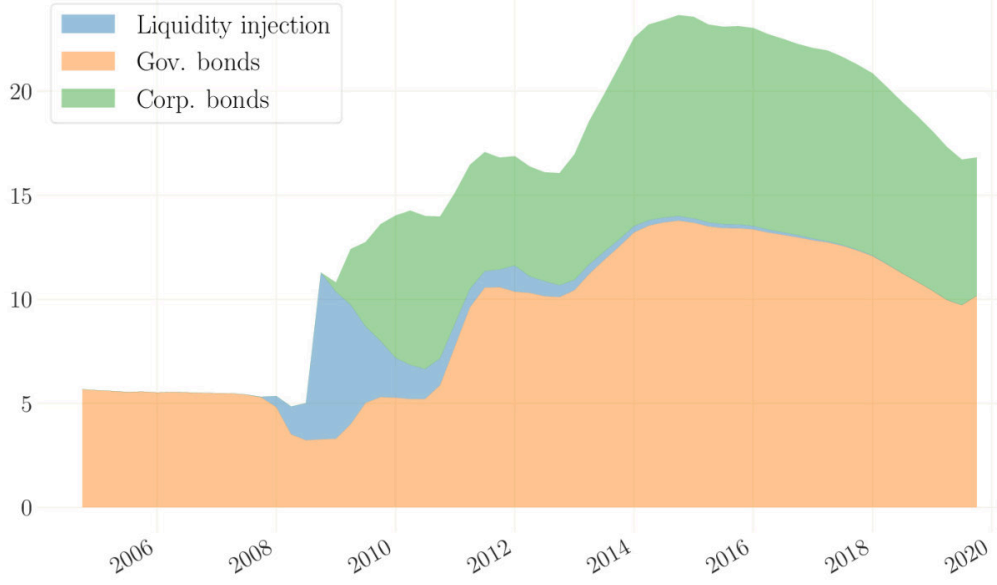

Figure 1: Unconventional monetary policy measures: The Fed's balance sheet expansion. Note: All variables are in \% of GDP. See Appendix A for more details on their construction.

ment share in GDP to $G / Y=0.18$, and the curvature parameters of the Kimball aggregators for prices and wages to $\epsilon_{p}=\epsilon_{w}=10$. The steady state markup in the labor market is set to $\lambda_{w}=1.1$. We set the decay factor for both government bonds and private loans to 0.975 , which implies an average maturity of 40 quarters. The quarterly coupon/repayment is set to 0.04 . Also, we calibrate the empirical lower bound of the nominal interest rate for the U.S. to $0.05 \%$ quarterly. Setting it exactly to zero would imply that the ZLB never binds in our estimations, as the observed FFR remained strictly above zero. Our choice therefor maintains that the ZLB is considered binding throughout the period from 2009:Q1 to 2015:Q4. More precisely, it holds that $\bar{r}=-100\left(\frac{\bar{\pi}}{(\beta \gamma)^{-\sigma_{c}}}-1\right)+0.05$. Lastly, the Fed's treasury holdings as percentage of GDP have neither been zero nor constant in the years preceding the Financial crisis (see Figure 1). In order to not account these holdings as QE measures, we fix the mean of the central bank's treasury holdings in the measurement equation to $\frac{\bar{B}_{c b}}{\bar{Y}}=5.5 \%$, and assume this was also the case prior to $2003: \mathrm{I}$ (the first data point observed).

\section{Empirical Analysis of the GFC and its Aftermath}

In this section we present our estimation results and use the estimated benchmark model to give a general account of the US dynamics from 1998 to 2019. The in-depth analysis of the quantitative easing measures is deferred to Section 5.

\subsection{Priors and parameter estimates}

Our priors and posterior estimates are shown in Tables 1 and 2. All prior distributions are characterized by their mean and standard deviation. The priors for the parameters that pertain to the real economy are chosen in line with Smets and Wouters (2007, 


\begin{tabular}{l|lll|llllll} 
& \multicolumn{3}{|c}{ Prior } & \multicolumn{5}{c}{ Posterior } \\
& dist. & mean & std & mean & std & mode & $5 \%$ & $95 \%$ \\
\hline \hline$\sigma_{c}$ & normal & 1.500 & 0.375 & 0.908 & 0.033 & 0.876 & 0.854 & 0.959 \\
$\sigma_{l}$ & normal & 2.000 & 0.750 & 1.160 & 0.351 & 1.046 & 0.581 & 1.721 \\
$\beta_{t p r}$ & gamma & 0.250 & 0.100 & 0.201 & 0.058 & 0.186 & 0.105 & 0.292 \\
$h$ & beta & 0.700 & 0.100 & 0.799 & 0.033 & 0.804 & 0.748 & 0.853 \\
$S^{\prime \prime}$ & normal & 4.000 & 1.500 & 5.119 & 0.754 & 4.181 & 3.949 & 6.370 \\
$\iota_{p}$ & beta & 0.500 & 0.150 & 0.232 & 0.067 & 0.155 & 0.128 & 0.343 \\
$\iota_{w}$ & beta & 0.500 & 0.150 & 0.426 & 0.118 & 0.648 & 0.222 & 0.617 \\
$\alpha$ & normal & 0.300 & 0.050 & 0.210 & 0.012 & 0.200 & 0.189 & 0.229 \\
$\zeta_{p}$ & beta & 0.500 & 0.100 & 0.870 & 0.025 & 0.861 & 0.828 & 0.911 \\
$\zeta_{w}$ & beta & 0.500 & 0.100 & 0.747 & 0.046 & 0.728 & 0.668 & 0.817 \\
$\Phi_{p}$ & normal & 1.250 & 0.125 & 1.331 & 0.071 & 1.364 & 1.218 & 1.445 \\
$\psi$ & beta & 0.500 & 0.150 & 0.810 & 0.067 & 0.841 & 0.696 & 0.919 \\
$\phi_{\pi}$ & normal & 1.500 & 0.250 & 1.323 & 0.207 & 1.542 & 0.962 & 1.610 \\
$\phi_{y}$ & normal & 0.125 & 0.050 & 0.171 & 0.022 & 0.168 & 0.136 & 0.207 \\
$\phi_{d y}$ & normal & 0.125 & 0.050 & 0.181 & 0.041 & 0.239 & 0.111 & 0.250 \\
$\rho$ & beta & 0.750 & 0.100 & 0.829 & 0.031 & 0.850 & 0.777 & 0.879 \\
$\bar{\gamma}$ & normal & 0.440 & 0.050 & 0.399 & 0.029 & 0.414 & 0.346 & 0.441 \\
$\bar{\pi}$ & gamma & 0.625 & 0.100 & 0.624 & 0.058 & 0.688 & 0.534 & 0.718 \\
$\bar{l}$ & normal & 0.000 & 2.000 & 1.246 & 0.488 & 0.701 & 0.416 & 2.013 \\
\hline$\kappa_{\tau}$ & gamma & 0.300 & 0.100 & 0.287 & 0.081 & 0.188 & 0.166 & 0.425 \\
$P A C$ & gamma & 2.000 & 4.000 & 0.495 & 1.189 & 0.132 & 0.107 & 0.450 \\
$L E V$ & normal & 3.000 & 1.000 & 4.312 & 0.405 & 4.433 & 3.635 & 4.986 \\
$\theta$ & beta & 0.950 & 0.050 & 0.815 & 0.034 & 0.747 & 0.761 & 0.870 \\
$\lambda_{\text {cbl }}$ & gamma & 3.000 & 3.000 & 0.229 & 0.207 & 0.086 & 0.001 & 0.519 \\
$\chi$ & beta & 0.300 & 0.100 & 0.190 & 0.059 & 0.133 & 0.099 & 0.284 \\
$\overline{\text { termspread }}$ & gamma & 0.500 & 0.100 & 0.594 & 0.106 & 0.427 & 0.418 & 0.773 \\
$\overline{p p r e m i u m}$ & gamma & 0.100 & 0.030 & 0.083 & 0.020 & 0.110 & 0.049 & 0.114 \\
spread & normal & 0.500 & 0.100 & 0.428 & 0.051 & 0.563 & 0.340 & 0.513
\end{tabular}

Table 1: Estimation results for the baseline model: model parameters

henceforth SW). ${ }^{13}$ The upper part of Table 1 - the parameters from $\sigma_{c}$ to $\bar{l}$ - displays the estimates of the parameters inherited from the SW backbone of our model. We compare the posterior estimates for these parameters, among others, to the estimates of Boehl and Strobel (2020, henceforth BS), who apply the same methodology on the same sample in a pure SW-type framework (and extended versions). This comparison seems to be more obvious than the comparison with the results of Kulish et al. (2017), who use a different methodology on a longer data sample. The bottom part of Table 1 contains the new parameters for the financial sector, which are central for the transmission of the large-scale asset purchases. We discuss these parameters mainly in Section 6.1.

Our estimates of the parameters inherited from SW are much aligned with those from BS. The finding that intertemporal elasticity of substitution, $\sigma_{c}$, is close to unity (and well below the prior mean) is widely shared in the literature (see e.g. Smets and Wouters,

\footnotetext{
${ }^{13}$ In contrast to Gust et al. (2017), the computational efficiency of our approach allows us to use the same priors as in SW instead of using tighter prior standard deviations.
} 


\begin{tabular}{l|lll|l|lllll} 
& \multicolumn{9}{|c}{ Prior } \\
& dist. & mean & std & mean & std & mode & $5 \%$ & $95 \%$ \\
\hline \hline$\rho_{r}$ & beta & 0.500 & 0.200 & 0.566 & 0.086 & 0.525 & 0.421 & 0.700 \\
$\rho_{g}$ & beta & 0.500 & 0.200 & 0.887 & 0.081 & 0.944 & 0.738 & 0.965 \\
$\rho_{i}$ & beta & 0.500 & 0.200 & 0.734 & 0.048 & 0.651 & 0.656 & 0.810 \\
$\rho_{z}$ & beta & 0.500 & 0.200 & 0.951 & 0.025 & 0.954 & 0.915 & 0.993 \\
$\rho_{p}$ & beta & 0.500 & 0.200 & 0.617 & 0.098 & 0.624 & 0.462 & 0.777 \\
$\rho_{w}$ & beta & 0.500 & 0.200 & 0.735 & 0.070 & 0.707 & 0.625 & 0.852 \\
$\rho_{u}$ & beta & 0.500 & 0.200 & 0.896 & 0.013 & 0.906 & 0.873 & 0.917 \\
$\rho_{l k}$ & beta & 0.500 & 0.200 & 0.934 & 0.027 & 0.936 & 0.893 & 0.977 \\
$\rho_{c b l}$ & beta & 0.500 & 0.200 & 0.762 & 0.036 & 0.762 & 0.704 & 0.826 \\
root $_{b, 1}$ & beta & 0.500 & 0.200 & 0.903 & 0.049 & 0.786 & 0.835 & 0.982 \\
$\operatorname{root}_{b, 2}$ & beta & 0.500 & 0.200 & 0.880 & 0.054 & 0.973 & 0.794 & 0.966 \\
$\operatorname{root}_{k, 1}$ & beta & 0.500 & 0.200 & 0.901 & 0.041 & 0.917 & 0.833 & 0.967 \\
$\operatorname{root}_{k, 2}$ & beta & 0.500 & 0.200 & 0.926 & 0.037 & 0.902 & 0.870 & 0.982 \\
$\mu_{p}$ & beta & 0.500 & 0.200 & 0.450 & 0.139 & 0.293 & 0.195 & 0.649 \\
$\mu_{w}$ & beta & 0.500 & 0.200 & 0.517 & 0.102 & 0.485 & 0.345 & 0.679 \\
$\rho_{g z}$ & normal & 0.500 & 0.250 & 0.570 & 0.188 & 0.463 & 0.325 & 0.943 \\
$\sigma_{g}$ & inv. gamma & 0.100 & 0.250 & 0.260 & 0.029 & 0.235 & 0.214 & 0.307 \\
$\sigma_{z}$ & inv. gamma & 0.100 & 0.250 & 0.345 & 0.035 & 0.313 & 0.282 & 0.395 \\
$\sigma_{r}$ & inv. gamma & 0.100 & 0.250 & 0.147 & 0.031 & 0.164 & 0.096 & 0.194 \\
$\sigma_{i}$ & inv. gamma & 0.100 & 0.250 & 0.610 & 0.086 & 0.766 & 0.485 & 0.760 \\
$\sigma_{p}$ & inv. gamma & 0.100 & 0.250 & 0.235 & 0.070 & 0.190 & 0.125 & 0.341 \\
$\sigma_{w}$ & inv. gamma & 0.100 & 0.250 & 0.691 & 0.074 & 0.687 & 0.570 & 0.807 \\
$\sigma_{u}$ & inv. gamma & 0.100 & 0.250 & 0.482 & 0.086 & 0.454 & 0.339 & 0.617 \\
$\sigma_{l k}$ & inv. gamma & 0.100 & 0.250 & 0.272 & 0.040 & 0.244 & 0.208 & 0.339 \\
$\sigma_{c b l}$ & inv. gamma & 0.100 & 0.250 & 0.956 & 0.084 & 0.966 & 0.816 & 1.090 \\
$\sigma_{q e b}$ & inv. gamma & 0.100 & 0.250 & 0.197 & 0.014 & 0.186 & 0.175 & 0.220 \\
$\sigma_{q e k}$ & inv. gamma & 0.100 & 0.250 & 0.176 & 0.015 & 0.183 & 0.152 & 0.198 \\
\hline & & & & & & & &
\end{tabular}

Table 2: Estimation results for the baseline model: shock processes

2007; Gelain and Ilbas, 2017; Kulish et al., 2017; Boehl and Strobel, 2020). The posterior mean of $\beta_{t p r}$, the time preference rate, is close to the estimates by SW, BS, and others. Similarly, BS also find a very high degree of habit formation in their re-estimation of the SW model on the crisis sample (0.833 in BS vs. 0.799 here) as well as substantial investment adjustment costs $\left(S^{\prime \prime}=5.287\right.$ in BS vs 5.119 here). Both the price and wage Phillips Curves are estimated to be quite flat, with an estimated price Calvo parameter of $\zeta_{p}=0.87$ in line with BS and Kulish et al. (2017). Similarly, values for wage and price indexation $\iota_{p}$ and $\iota_{w}$, as well as the the fixed cost parameter, $\Phi_{p}$ are in a standard range, albeit notably higher than e.g. SW due to the more recent sample. The estimated feedback coefficients of the policy rule as well as the interest rate smoothing parameter, $\rho$, match the estimates in BS.

We follow Kulish et al. (2017) and BS in the choice of our prior for the common trend $\bar{\gamma}$ and opt for a tighter prior of this parameter than in SW. Arguably, the economy deviated strongly and persistently from its steady state during the Great Recession. In order to dampen the data's pull of the parameter down to the sample mean, we therefore prefer the tight prior as well. This circumvents unrealistically low estimates of the trend 
growth rate which would imply implausibly high levels of consumption and output after 2008. Our estimates of $\bar{l}$ and mean inflation, $\bar{\pi}$ are in line with BS. ${ }^{14}$ The effects of the priors on the macroeconomic dynamics are illustrated in the impulse response functions in Figures 6 and C.15.

For the non-SW part of our model, we estimate the steady state leverage of financial intermediaries, $L E V$, their survival rate $\theta$, the sensitivity of the incentive constraint to liquidity injections $\lambda_{C B L}$, and the feedback coefficient for government debt in the tax rule, $\kappa_{\tau}$. Additionally, we estimate the $\mathrm{AR}(2)$ shock processes for the QE measures, which are identified independently of the model choice. For the prior of $L E V$ we choose a normal distribution centered around 3, and with a standard deviation of 1 . Intuitively, a high leverage $L E V$ implies a high initial vulnerability of the financial system to shocks that affect its asset prices or funding costs. Conversely, it also implies that the small steady state net worth that is associated with a high leverage will be replenished (reduced) faster by increased (compressed) excess returns on banks' assets such that the financial system reverses more quickly to its original state. Depending on the nature of the shock this can come either with an amplification or an attenuation of the effects on the real economy. As we are not aware of prior estimates of this parameter in the context of a structural model, we opt for choosing a rather wide prior. ${ }^{15}$ For $\theta$, we choose a beta distribution for the prior with a mean of 0.95 , corresponding to an expected time horizon of the bankers of 5 years. This value is only slightly below the value of 0.975 in Gertler and Karadi (2011), but the standard deviation of 0.05 allows for significant departures from the prior mean. Generally, a higher $\theta$ is associated with a higher stochastic discount factor of financial intermediaries and therefore shapes the persistence of the effects of QE shocks. Our estimations however suggest that the data favors large values for $L E V$ and a relatively small $\theta$. As we will discuss below, both values point towards rather smaller effects of the QE measures. For $\lambda_{C B L}$ we set a wide prior around a mean of 3. The shape and width of the prior reflect our agnostic approach to the effect of central bank liquidities injections. For $\lambda_{C B L}=0$, liquidity injections have no effect at all. In fact, the estimate for $\lambda_{C B L}$ of 0.229 is quite low, allowing only for limited effects of the Fed's liquidity provision program.

\subsection{A decomposition of the dynamics}

Figures 2 and 3 show the historical decompositions of a selection of smoothed states into the contributions of the different shocks. The effect of each shock is normalized as suggested by Boehl and Strobel (2020). This means that each shock reflects the exact contribution, independently of any ordering effects that might occur in nonlinear models. The overall picture of the historical decomposition points towards variations in the risk premium shock, $\epsilon_{t}^{u}$, as the most important driver of the observables. This financial shock affects banks' funding conditions and has a demand shock type effect on the real economy

\footnotetext{
${ }^{14} \bar{\pi}$ not only is the constant in the measurement equation for inflation, but also the Fed's inflation target and the long-run trend in inflation. We, however, refrain from setting the prior value to $2 \%$ p.a. because we assume that the original SW prior better reflects the long-run trend while still being flexible enough to allow for lower estimates if necessary. Moreover, note that the Fed targets headline inflation while, in the estimation, we use GDP deflator.

${ }^{15}$ Villa (2016) estimates a version of the model by Gertler and Karadi (2011) on US data, but calibrates $L E V$ and $\theta$ to fixed values.
} 

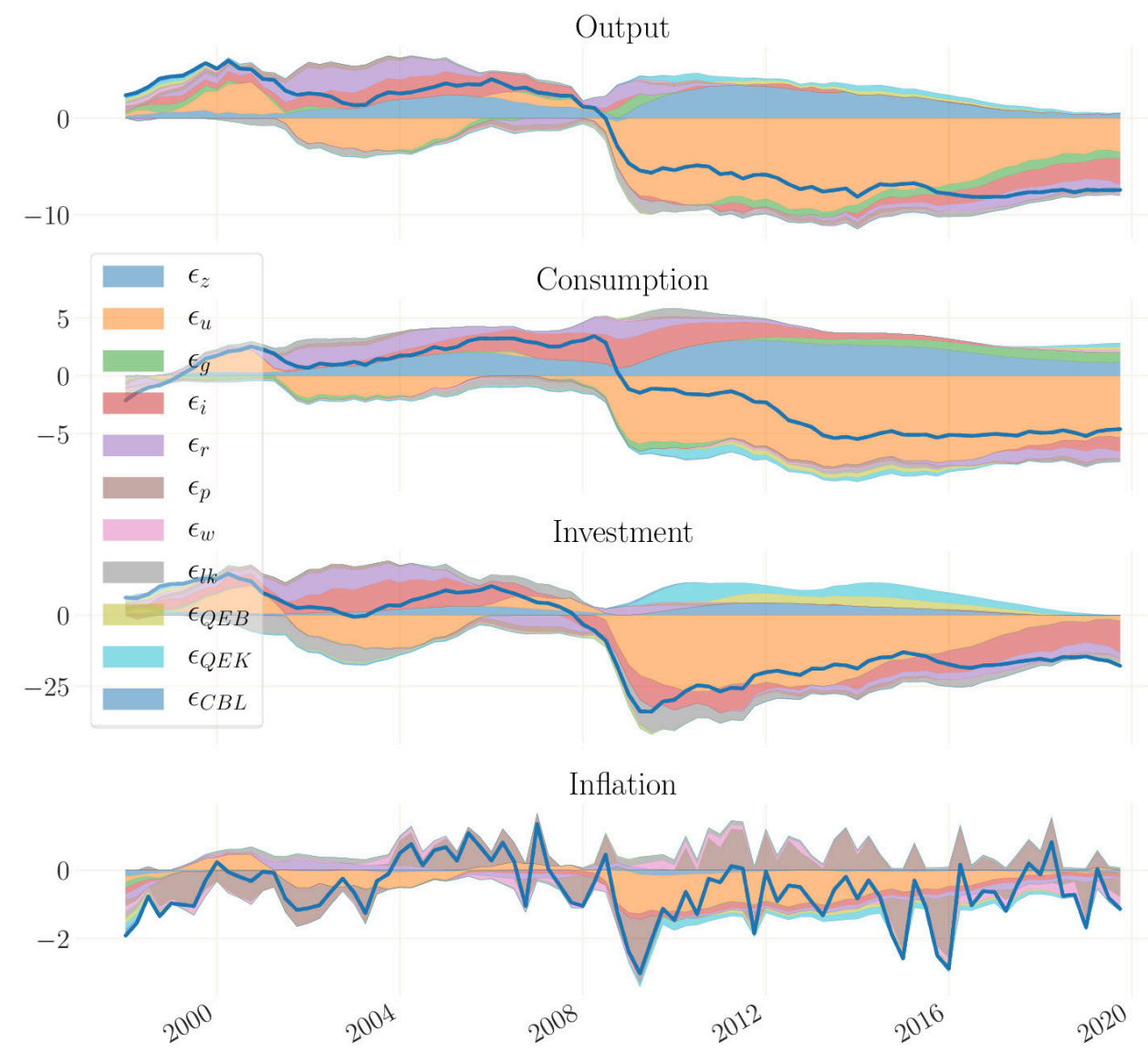

Figure 2: Estimated baseline model. Decomposition of the smoothed states into the contribution of the different shocks.

Note: Means over 1000 simulations drawn from the posterior. The contribution of each shock is normalized and calculated as in Boehl and Strobel (2020). Annual measures where applicable.

in our model. Besides its role in the GFC, it was also identified as a main driver in the pre-crisis period by Smets and Wouters (2007). As such, the high risk premium can not only explain the 2008-2009 drop in consumption, but can also account for a large share of the fall in investment. Ultimately, the lasting effect of an elevated risk premium resonates in a high estimate of $\rho_{u}$ of 0.896 . The plunge in investment is further supported by a fall in the efficiency of investment, $\epsilon_{t}^{i}$. To our surprise, the other financial shock $\epsilon_{t}^{l k}$ to the divertibility of capital assets, $\lambda_{k, t}$, that we adopted from Dedola et al. (2013), substantially raises the credit spread during the financial crisis but only plays a minor role in driving macroeconomic dynamics. ${ }^{16}$

\footnotetext{
${ }^{16}$ We also experimented with various other financial shocks, such as the capital quality shock in Gertler and Karadi (2011).We find that the risk-premium shock together with the investment-specific technology
} 


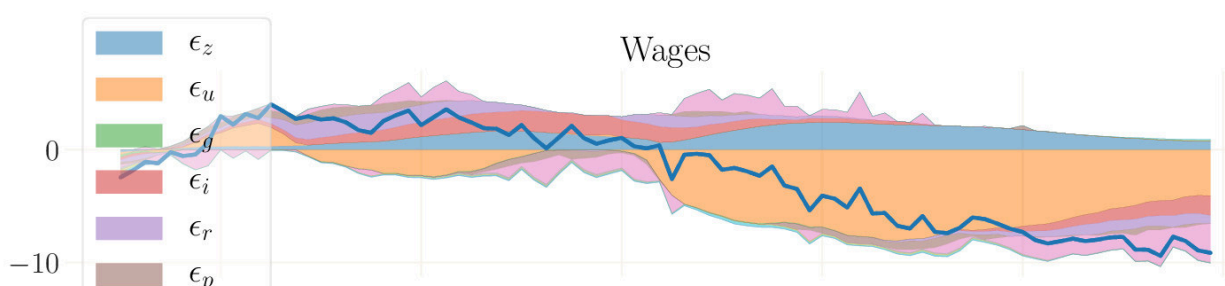

(Shadow) Interest rate

0

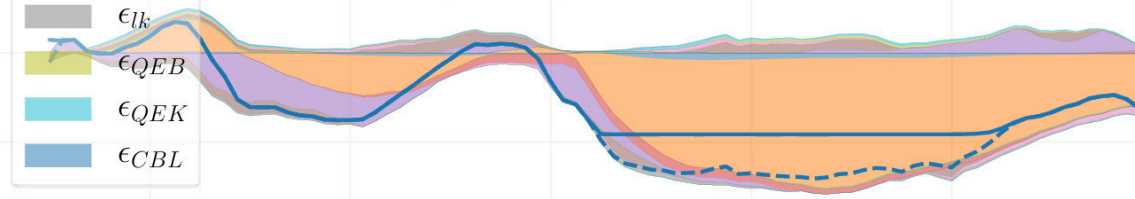

Credit spread

5

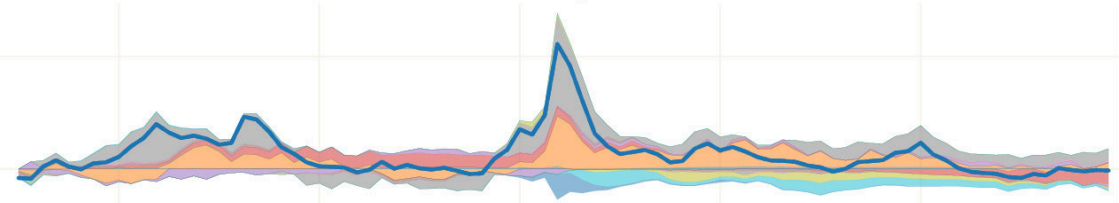

Capital utilization

2
0
-2

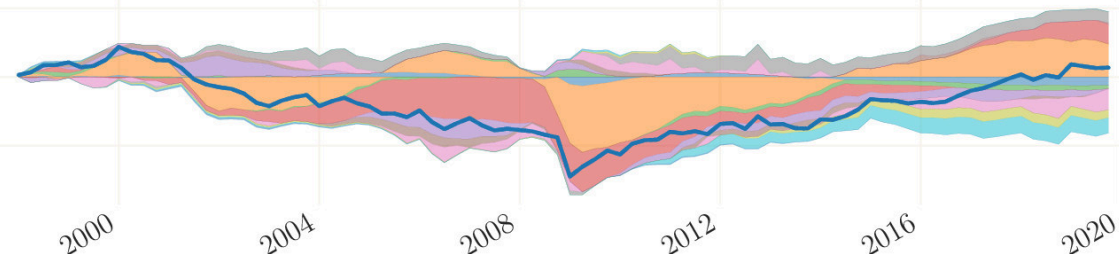

Figure 3: Estimated baseline model. Decomposition of the smoothed states into the contribution of the different shocks.

Note: Means over 1000 simulations drawn from the posterior. The contribution of each shock is normalized and calculated as in Boehl and Strobel (2020). Annual measures where applicable.

The finding of a flat Phillips Curve is mirrored in the dynamics of inflation. While the risk premium shock persistently depresses price level dynamics, the crumb of inflation in 2009 is explained by exogenous movements in the firms' price markup. In fact, this process governs almost all high-frequency movements in inflation. Consequently, exogenous impulses to the price markup process are rather short-lived with an estimate of $\rho_{p}=0.617$. As expected, the technology level $z_{t}$ is a driver of the low-frequency dynamics, which is reflected in a very high estimate of $\rho_{z}$. A similar result holds for the process of government spending, which only plays a secondary role. ${ }^{17}$

shock, the latter which has also been interpreted as a financial shock (see, e.g. Justiniano et al., 2011; Gust et al., 2017; Kulish et al., 2017), to deliver the most robust results and are preferred in terms of the marginal data density.

${ }^{17}$ In principle, our model additionally allows for forward guidance shocks at the ZLB. However, we 
The parameters for the exogenous processes of the QE measures are identified independently of the model parameters and are entirely driven by the time series of the central bank's balance sheet that are fed into the estimation. In the next section, we provide an in-depth account of the effects of $\mathrm{QE}$ and discuss their impact key macroeconomic variables in more detail.

Finally, note that our estimate of the notional rate differs conceptually from those inferred from affine term structure models, such as Krippner (2013) or Cynthia and Dora (2016). Our estimate reflects the implications of a Taylor-type policy rule and is not based on information of the cross-section of yields. The estimate thus provides a counterfactual, indicating by how much lower the short-term rate would have been given the levels of inflation and the output gap. ${ }^{18}$ As we assume that at the ZLB, the Fed considers the shadow rate for interest rate smoothing rather than the nominal rate, the shadow rate directly enters the model. It thus is an important measure as it drives expectation dynamics. At this point, we also want to highlight that our model matches expected durations at the ZLB from survey data surprisingly well. ${ }^{19}$ Importantly - and different from Kulish et al. (2017) - we do neither target these expectation nor feed them in to our estimation procedure. They are instead determined endogenously by our solution method.

\section{The Quantitative Effects of QE}

In response to the GFC, the Federal Reserve undertook several measures in unprecedented scale to address disruptions on financial markets and later to further ease the monetary stance once the ZLB was reached. Among the first such programs are the Term Auction Facility Program (TAF), the Term Asset-Backed Securities Loan Facility (TALF), as well as the primary dealer and other broker-dealer credit programs, which were aimed at addressing elevated pressures in short-term funding markets at the height of the financial crisis in 2007/08. We summarize these measures under the umbrella of "emergency liquidity injections".

In order to provide further monetary accommodation, the Federal Reserve turned to programs of large-scale asset purchases. The first of these programs, later dubbed "QE1", lasted from December 2008 to March 2010 and included net purchases of $\$ 1.25$ trillion in mortgage-backed securities (MBS), $\$ 175$ billion in agency securities and roughly $\$ 300$ billion in treasury. After a brief pause, a second round of purchases (called "QE2") in November 2010 involved net-purchases of $\$ 600$ billion plus reinvestment of the proceeds from the earlier MBS purchases in longer term government Treasury securities. After yet another brief pause, the Fed started what is now known as Operation Twist, a portfolio shift of the size of $\$ 600$ billion from short and medium-term Treasuries with a maturity up to three years, to long-term Treasuries with maturities of six years and above. Our

find that, in the absence of additional data input such as, e.g., term premia, nonlinear filters do not perform reliably well in identify forward guidance shocks at the ZLB. For a related discussion, see Boeh and Strobel (2020).

${ }^{18}$ Note that this ignores the general equilibrium effect of such lower rates: if rates would have been lower, inflation and output would have been higher, and, in turn, the Federal Funds Rate would have been higher than our shadow rate.

${ }^{19}$ Figure D.17 in the Appendix illustrates the course of the number of expected periods at the ZLB. 
analysis does not explicitly incorporate the effects of Operation Twist, as our data series of government bonds pools Treasuries of all maturities and hence does not account for effectively sterilized actions. Lastly, QE3 started in September 2012 and lasted until December 2014. It further increased the Fed's balance sheet through net-purchases of $\$ 95$ billion each months - $\$ 45$ billion in long-term treasury bonds and $\$ 40$ billion in MBS.

In this section, we investigate the macroeconomic effects of these liquidity provisions and large-scale asset purchases through the lens of our estimated model. As touched upon in Section 2.4, we assume that liquidity provisions directly affect a bank's supply of credit by easing it's incentive compatibility constraint. MBS and commercial paper purchases under QE1 and government bond purchases under QE2, on the other hand, can be interpreted as central bank intermediation (Gertler and Karadi, 2013). The financial frictions in our model give rise to an extranormal term premium on government bonds, and similarly, extranormal credit risk premia on private loans and capital claims. Central bank asset purchases compress these risk spreads, thereby easing financing conditions for firms and households. Importantly, through the portfolio rebalancing channel, these risk spreads are compressed even if the specific asset under consideration is itself not purchased.

We illustrate by the means of counterfactual experiments how output, inflation and the other key macroeconomic variables would have evolved in the absence of the liquidity injections and LSAP programs. While all these measures have prevented a further contraction in investment and hence output, we find LSAPs to have suppressed aggregate consumption by around 0.7 percentage point. Moreover, by increasing the production capacity, LSAPs created additional downward pressure on prices. Although the latter result may appear counterintuitive at first, we show that (positive) financial shocks can have disinflationary effects if aggregate supply effects dominate the aggregate demand.

\subsection{The Effects of the QE Measures}

What would have happened to the economy if the Fed did not expand its balance sheet in this unprecedented way? We answer this question by looking at counterfactual experiments in which we isolate the effects of each of the balance sheet policies taken. These counterfactuals are summarized in Figures 4 and 5. The red-dashed line on the left indicates the mean of the respective smoothed observable or state. The right side of each Figure then shows the net contribution of the policy measures by adding one measure at the time.

Starting with the liquidity provisions in dashed-blue, denoted CBL in Figures 4 and 5 , we observe a sharp fall in the credit spread of around 100 basis points in the beginning of 2009. Despite this large effect on financial conditions, output only increased marginally driven by an increase in consumption of borrowing (i.e. impatient) households and an increase in investment. In the model, liquidity injections trigger a relaxation of the bank's financial constraint which is associated with a broad increase in banks' supply of credit. Their overall macroeconomic effect, however, remained limited: the peak output increase was $0.20 \%$. With the injections reaching around $8 \%$ of GDP, their peak output multiplier is only roughly 0.025 . Our findings contrast those of Del Negro et al. (2017), who report large effects of liquidity injections on the real economy. One potential reason for this discrepancy is the high persistence of the liquidity shock in their model. Yet Figure 1 suggests and our estimation confirms that the liquidity injections were relatively short- 


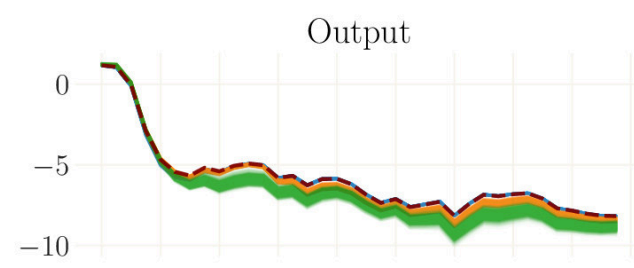

Consumption

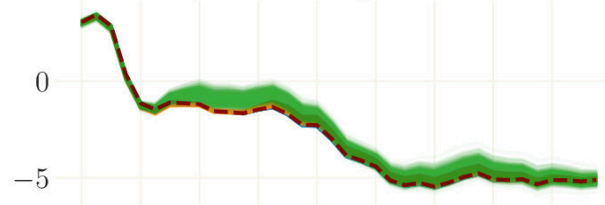

Investment

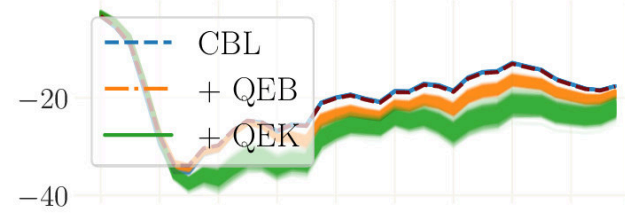

Term premium

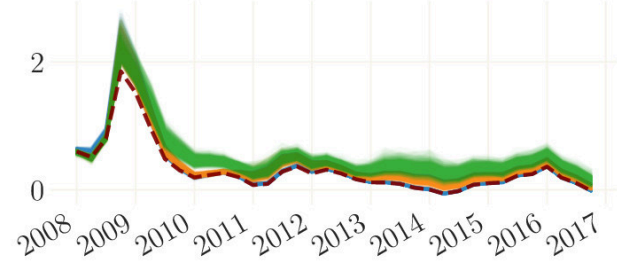

Output

1

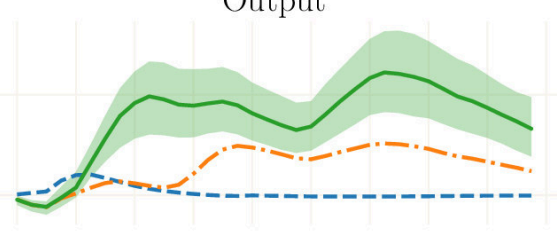

Consumption

0

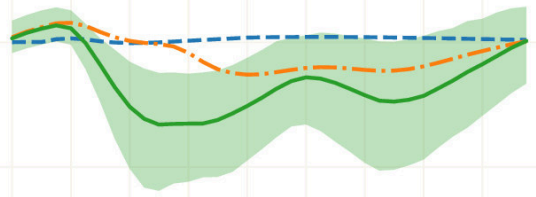

Investment

10

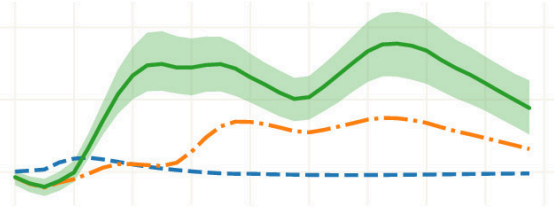

Term premium

0

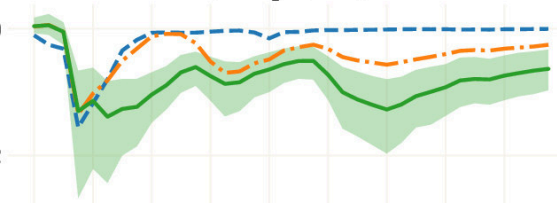

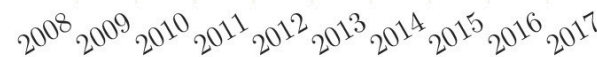

Figure 4: Left: counterfactual simulations without the QE measures. Right: net contribution of each QE measure. Effects in both graphs are cumulative.

Note: Means over 1000 simulations drawn from the posterior. Annualized measures where applicable.

lived, with our posterior mean estimate for persistence parameter $\rho_{c b l}=0.762$ being substantially smaller than the calibrated value of 0.953 in Del Negro et al. (2017). ${ }^{20}$

We argue, therefore, that the effects of liquidity injections have to be assessed against the backdrop of a smaller magnitude and duration relative to the LSAP programs (as can be seen in Figure 1). In line with the intuition from Equation (19), liquidity injections support bank lending to firms which, in turn, translates into higher investment. ${ }^{21}$ The simultaneous fall in the credit spread spills over to the interest rate on private mortgages, which leads to an increase in lending to impatient households, thereby boosting their consumption. However, due to an initial mild fall in inflation the real rate increases, causing

\footnotetext{
${ }^{20}$ To be precise, Del Negro et al. (2017) model the liquidity shock to be very persistent and with the central bank liquidity policy to respond to the deviations of this persistent shock from its steady state.

${ }^{21}$ Figure C.14 in the Appendix provides further details on how central bank liquidity injections transmit by showing the posterior impulse response functions.
} 


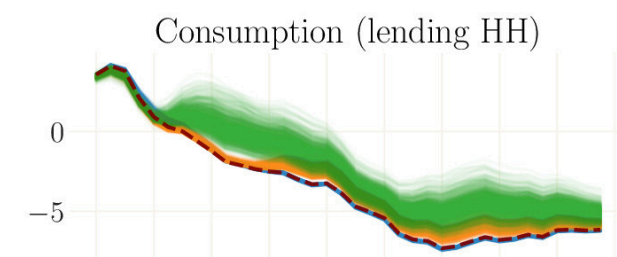

Consumption (borrowing $\mathrm{HH}$ )

0

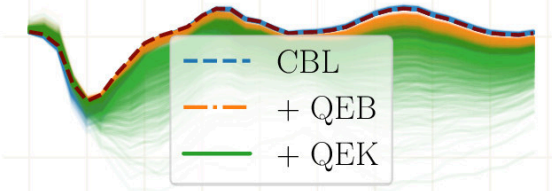

Inflation

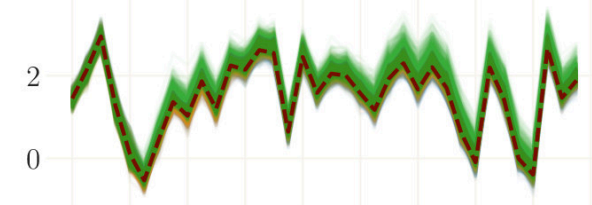

10

Credit spread

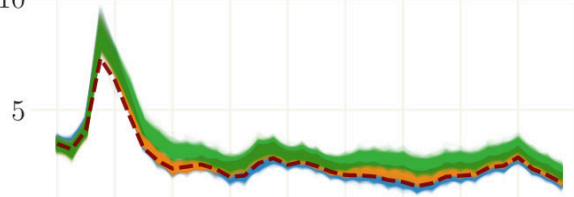

$200^{8} 200^{9} 20^{10} 20^{11_{2}} 20^{12} 20^{13} 0_{2} 1_{2}^{x_{2}} 20^{15} 20^{16} 20^{17}$

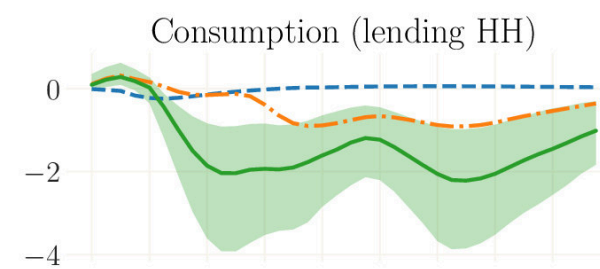

Consumption (borrowing $\mathrm{HH}$ )

10

0

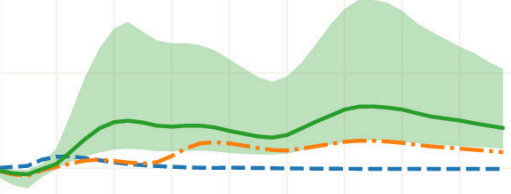

Inflation

0.0

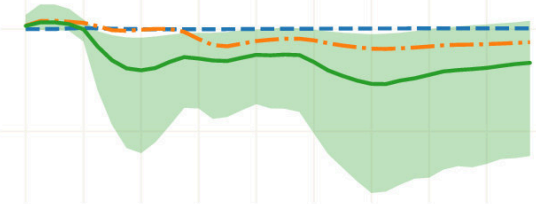

Credit spread

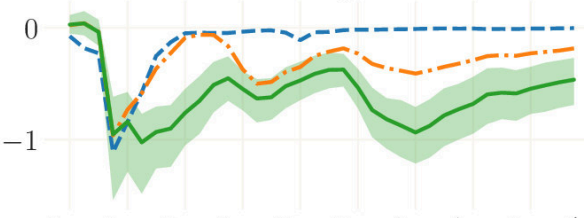

$200^{8} 200^{9} 20^{10} 20^{11_{2}} 20^{12} 20^{13} 20^{1 x_{2}} 20^{15} 200^{16} 20^{17}$

Figure 5: Left: counterfactual simulations without the QE measures. Right: net contribution of each QE measure. Effects in both graphs are cumulative. Measures of spreads and inflation are annualized. Note: Means over 1000 simulations drawn from the posterior. Annualized measures where applicable.

a fall in consumption of patient households, which pushes down aggregate consumption in the short run. Total output increases nonetheless, boosting labor demand and wages. The latter, in turn supports a pick-up of inflation in the longer term.

In the last quarter of 2008, the Fed started purchasing private securities in order to further ease financing conditions. These holdings reached 9,7\% of GDP in 2015 before the Fed slowly started to reduce its position. The securities purchases consisted largely of mortgage-backed securities (MBS), but also included the smaller and more shortly-lived commercial paper funding facility (CPFF) program. Other than the liquidity provisions, LSAPs were very persistent with both roots of each $\mathrm{AR}(2)$ process around 0.9 . The solid-green line in Figures 4 and 5 indicates that the effects the private capital security purchases are substantial: investment and output were $7 \%$ and $0.8 \%$ higher, respectively, and the effect persisted over roughly six years before gradually dissipating. In our model, capital securities purchasing basically reflect central bank intermediation (see Gertler 
and Karadi, 2013), which compressed corporate credit spreads very persistently. The resulting broad appreciation of long-term debt prices via the no-arbitrage conditions bolsters banks' balance sheets and increases their net worth; an effect Brunnermeier and Sannikov (2016) called a "stealth recapitalization" of banks. The increase in banks' net worth, in turn, stimulates lending to impatient households and the government, i.e. the portfolio rebalancing channel (see e.g. Gagnon et al., 2011; d'Amico et al., 2012).

Notwithstanding the positive effects of LSAPs on economic activity, we observe an inconvenient effect of private security purchases on inflation. Our counterfactual suggests that inflation would have been $0.2 \%$ higher in the absence of private security purchases, with the $95 \%$ credible set even includes a fall of inflation by $0.7 \%$. Although such disinflationary effects may seem counterintuitive at first, the following section will explain the channels of why this result is, in fact, not that surprising, and discusses its robustness together with other empirical literature that support this finding.

At the end of 2010, the Federal Reserve embarked in large-scale purchases of treasury bonds in its second round of QE, which - after a short pause - got extended in September 2012 by the QE3 program. Overall the government bond holdings of the Fed reached close to $14 \%$ of GDP. In line with earlier studies, we find purchases of assets that entail some credit risk to be more effective in compressing the excess return on capital assets than purchases of government bonds. ${ }^{22}$ The latter translates into a stronger response of investment, consumption of borrowing households and ultimately output. Our counterfactual analysis suggests these treasury purchases to have lifted GDP by $0.5 \%$ in 2012 (orange dash-dotted line in Figures 4 and 5). Again, this effect was driven by an increase in investment of more than $4 \%$ and consumption of borrowing households of around $3 \%$. The effect on aggregate consumption is, however, more benign, as consumption of savers (i.e. patient households) slightly falls. The reason for the latter is again a mild disinflationary effect of the government bond purchases, which leads to an increase in the real deposit rate. Additionally, the rise in the return on capital increases impatient households' marginal benefits of investing over and above their marginal costs of foregone consumption. Contrary, borrowing households see their risk spread decline (via the portfolio rebalancing channel) by more than the fall in inflation, which stimulates their consumption.

\subsection{The disinflationary effect of Quantitative Easing}

As displayed in Figure 5, we find that the LSAPs had an unpleasant effect on inflation and consumption. This implies that, at a time when inflation was still depressed by the persistent effect of the GFC, the QE measures exerted additional downward pressure on the price level. The disinflationary effects are particularly true for the purchases under QE1, which - over the course of the program - induced inflation to drop an additional $0.25 \%$ with the maximum effect in the $95 \%$ credible set even exceeding $0.7 \%$ p.a. While the main goal of QE in the US was to create favorable financing conditions and to

\footnotetext{
${ }^{22}$ Krishnamurthy and Vissing-Jorgensen (2011), for instance, find that default risk/default risk premium for corporate bonds fell in response to QE1, thus lowering corporate bond yields. Relatedly Caballero and Farhi (2018) show that central bank purchases of risky assets (in contrast to save government bonds) in a swap for safe assets (central bank reserves) can boost the economy and lower risk premia.
} 
Output

4

2

0

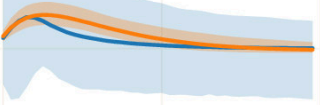

Inflation

15

10

5

0

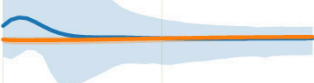

Credit spread

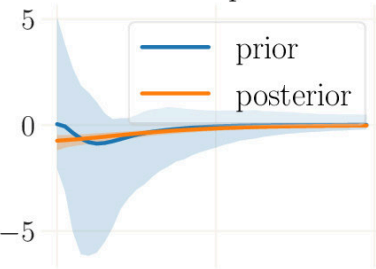

0

20

t)

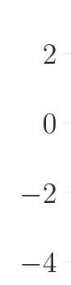

Cons. lending $\mathrm{HH}$

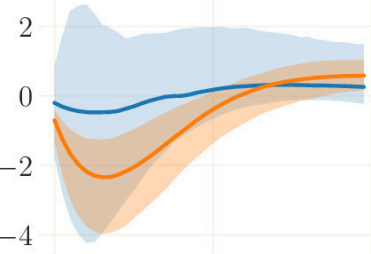

Investment

10

0

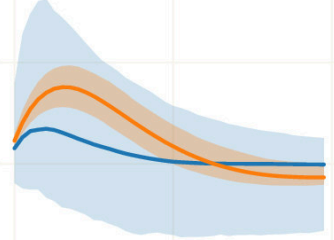

Net worth of banks 20
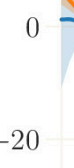

Figure 6: Prior and posterior impulse response functions of a shock to private security purchases. .

Note: Posterior IRFs in orange, with 95\% credible set. Posterior sample obtained from 1000 draws from the posterior distribution. Prior IRFs in blue. Solid lines represent the mean. For each draw, the strength of the shock is chosen such that the peak of the corresponding stochastic process matches the peak of the empirical time series. See Appendix F for details. The prior sample is obtained from 2000 draws to account for the strong heterogeneity of effects. Prior draws adjusted for high autoregressive coefficients with mean/std of 0.9 and 0.05 because AR-coefficients are identified independently from the model. Annualized measures where applicable.

stimulate lending ${ }^{23}$, our finding of a disinflationary effect of QE is highly policy relevant. Specifically, in the US, LSAPs create a trade-off for policymakers between the stabilizing prices and employment. But the results may be even more important for the Euro Area, where the asset purchase programme (APP) of the ECB was explicitly undertaken to stabilize inflation and inflation expectations at a time when fears of deflation surged. ${ }^{24}$

It is important to note that this result stands in stark contrast to the effects that occur when sampling from the prior distribution. To illustrate this, Figure 6 shows the response functions to an impulse in private security purchases at both our prior and posterior

\footnotetext{
${ }^{23}$ See the Fed's statement from November 25th, 2008.

${ }^{24}$ See, for instance, the ECB's press release from January 2015, which rationalizes the public sector asset purchase programme (PSPP) "in order to address the risks of a too prolonged period of low inflation."
} 
mean. The former suggests a peak effect on inflation of $2 \%$, with the $95 \%$ credible set even allowing to peak at $14 \%$. Against this backdrop, we see our posterior result as a strong case for the data to prefer a disinflationary effect of the Fed's Quantitative Easing measures.

To understand this effect, let us recognize that in our model, LSAPs can be interpreted as expansionary financial shock that loosens liquidity and balance sheet constraints. The response of inflation depends, inter alia, on whether aggregate demand or supply effects dominate. For instance, inflation may rise if demand effects dominate, as is the case in Curdia and Woodford (2010) and Gertler and Karadi (2011). Contrary, if supply side effects dominate, expansionary financial shocks may in fact be disinflationary as lower financing costs may be passed on to prices.

According to our prior predictive analysis, the priors we choose, give an edge to demand side effects on unconventional monetary policy. An easing of borrowing conditions for households and firms stimulates aggregate spending. Higher aggregate demand, in turn, increases factor demand, thereby raising factor prices. Elevated marginal costs are, over time, passed on to consumers in form of higher prices. Higher inflation, in turn, further lowers real interest rates which amplifies the initial increase in aggregate demand. In fact and to the best of our knowledge, such effects also prevail in all common models of QE, including the original Gertler and Karadi (2013) framework which lends as a blueprint for our benchmark model and its derivatives. ${ }^{25}$

Notwithstanding, our estimation favors the dominance of the supply side channels of QE. To formally understand the mechanism in our model, recall that firms use a standard Cobb-Douglas production function of the form $Y_{t}=F\left(Z_{t}, L_{t}, \bar{K}_{t}\right)$, where $\bar{K}_{t}=U_{t} K_{t-1}$ is the effective capital in period $t$. That is, in each period, firms must take their capital stock as given but can decide over the utilization rate $U_{t}$. As in Smets and Wouters (2007), the costs for changes in the utilization rate are given by a function $\Psi\left(U_{t}\right)$ that increases proportionally when $U_{t}$ deviates from its steady-state value. Thus, the marginal product of effective capital, $\widehat{m p k}_{t}$ only depends on the capital utilization rate and can, up to a first-order approximation, be expressed as

$$
\widehat{m p k}_{t}=\frac{\psi}{1-\psi} \hat{u}_{t}
$$

where $\hat{x}_{t}$ represents a variable $X_{t}$ in percentage deviations from its steady state. The parameter $\psi$ depends positively on the elasticity of the capital utilization adjustment cost function and is defined on $(0,1)$. Moreover, since marginal costs $\widehat{m c}_{t}$ must equal the marginal factor product, we have

$$
\widehat{m c}_{t}=(1-\alpha) \hat{w}_{t}-\hat{z}_{t}+\alpha \frac{\psi}{1-\psi} \hat{u}_{t}
$$

i.e. marginal costs increase in real wages $\hat{w}_{t}$ and the rate of capital utilization $\hat{u}_{t}$ and decrease in total factor productivity, $\hat{z}_{t}$.

For simplicity, let us picture the purchases of capital assets by the central banks as an exogenous shock on the capital stock (via increased investment). For a given aggregate

\footnotetext{
${ }^{25}$ Figure C.16 in the Appendix confirms that standard mechanism of monetary policy shocks holds true for our benchmark estimation.
} 
demand, an increase in the capital stock will mechanically decrease the utilization rate and, correspondingly, the marginal product of effective capital. Holding wages constant, this directly translates into lower marginal costs and, in turn, prices and inflation via the New Keynesian Phillips curve. Additionally, the decrease in consumption by patient households supports a slight decline in wages via the wealth effect on the labor supply. This adds to the downward pressure on inflation.

The notion that a loosening of financial constraints is associated with disinflationary tendencies is quite common in the literature. This is the case in models with a cost channel where firms borrow in advance of production to pay wages, as in Christiano et al. (2005) and Ravenna and Walsh (2006), or capital as in Fiore and Tristani (2013). As is the case in this class of models, higher credit spreads (and hence financing costs) are associated with an increase in firms' marginal costs, which are passed on to consumers in the form of higher prices. As discussed above, in our model, the cost channel materializes via the capital utilization cost, which decrease following a QE-induced rise in investment. This mechanism is similar to Acharya et al. (2020), who find that cheap credit to impaired firms has a disinflationary effect by creating excess production capacity. Consistent with prevailing supply effects, Barth III and Ramey (2001); Chowdhury et al. (2006) and Abbate et al. (2016) find evidence in favor of a cost channel. Abbate et al. (2016), for instance, show that - using a vector autoregression model with sign restrictions financial shocks that lower firms' funding costs and increase credit growth and stock prices actually reduce inflation in the short run. Similarly, using Italian firm-level data on output prices and interest rates paid on debt, Gaiotti and Secchi (2006) find the cost channel to be proportional to the working capital. A different yet related channel is proposed by Gilchrist et al. (2017). Using granular micro-data, the authors show that firms' with binding liquidity constraints increased prices during the GFC, while unconstrained firms did lowered them. To rationalize this empirical finding, Gilchrist et al. (2017) build a theoretical model where firms price goods above marginal costs in order to hedge against the risk of relying on costly external finance. Against this backdrop, our results suggest that aggregate supply channels dominated in determining the response of inflation to LSAPs.

\section{Robustness}

In this section, we first analyze which parameters are the root cause for the disinflationary effects and the fall in consumption resulting from LSAPs in section 6.1. We then show that our main results are also robust to specific model assumption by estimating different model vintages in section 6.2. Lastly, we present the effects of LSAPs through the lens of an estimated version of the model by Carlstrom et al. (2017) and discuss the differences to our benchmark results.

\subsection{Model parameters - Inspecting the mechanism}

As shown in the previous section, according to (38), the effect of an increase in the utilization rate on marginal costs depends, ceteris paribus, positively on $\psi$ and $\alpha$. The estimate of $\alpha$ additionally governs the relative weight of the marginal product of capital and wages in the marginal costs. The blue line and shades in Figure 7 show the posterior IRFs to capital asset purchases together with their $95 \%$ credible sets. To highlight the 

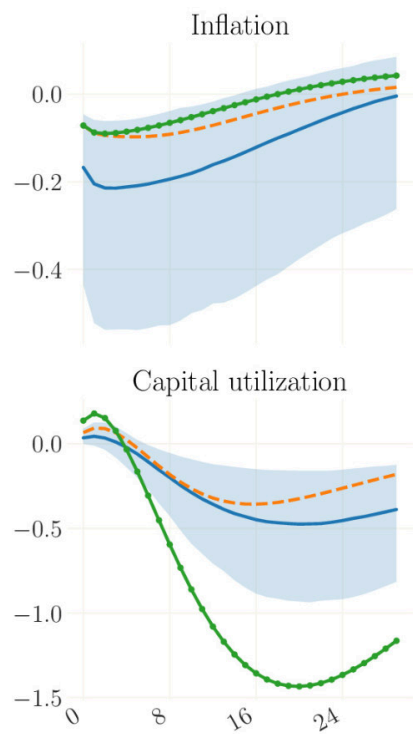
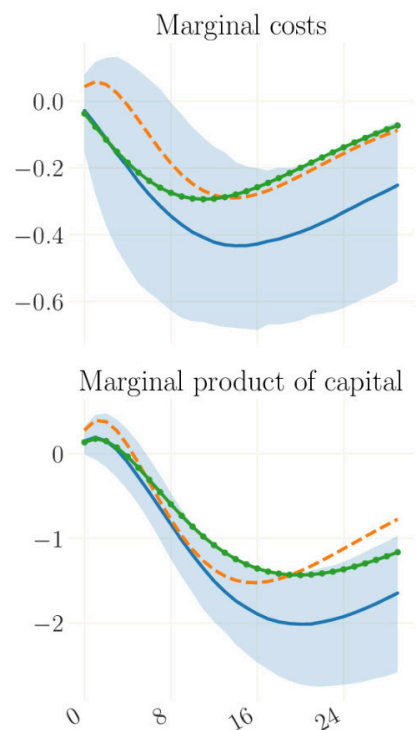
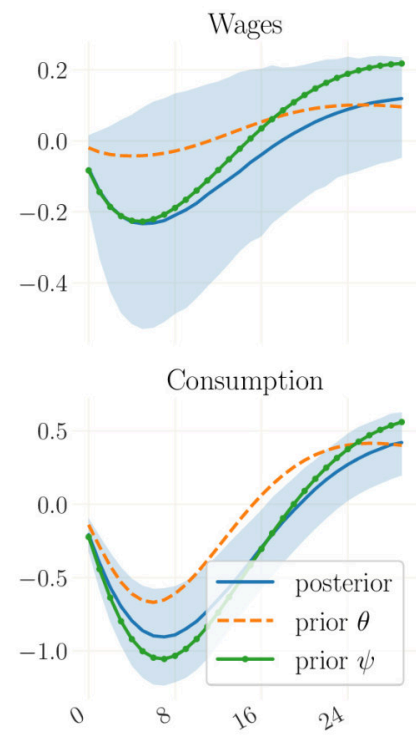

Figure 7: Impulse response functions with respect to a shock of capital securities purchases in blue, sampled from the posterior distribution with $95 \%$ credible set. In orange impulse responses at the posterior mean with $\theta=0.95$. In green impulse responses at the posterior mean with $\psi=0.5$.

Note: Posterior sample obtained from 1000 draws from the posterior distribution, solid line represent the mean. For each draw, the strength of the shock is chosen such that the peak of the corresponding stochastic process matches the peak of the empirical time series. See Appendix F for details. Annualized measures where applicable.

effect of the parameter estimates on inflation dynamics, the green lines show the IRFs for the case in which $\psi$ is set to their prior mean.

The increased capital stock induced by higher investments leads to a fall in capital utilization, $\hat{u}_{t}$, and, correspondingly, the marginal product of capital. In addition with the decline in wages this implies a proportional decline in marginal costs and, ultimately, inflation. As can be seen in Figure 7, our estimate of $\psi$ supports a disinflationary effect of the asset purchasing program in our benchmark model. The posterior mean value of $\psi$ is 0.810 with a standard deviation of 0.067 (see Table 1 ) lies between the estimate of a plain Smets and Wouters (2007) model on the same sample using the same methodology (see Table E.3 in Appendix E) and the one reported in Kulish et al. (2017). Contrary, for the capital share, our posterior mean estimate of $\alpha=0.210$ dampens the disinflationary effect compared to a simulation in which $\alpha$ is replaced by its prior mean of 0.3 . However, this effect is rather mild. The posterior mean value is notably higher than those from either a plain SW model, those reported by Kulish et al. (2017) and those reported for a selection of models in Boehl and Strobel (2020), which all range between 0.16-0.174.

For the financial sector, we estimate the survival probability of banks, $\theta$, and the steady state leverage ratio, $L E V$. Figure 7 illustrates the effects of $\theta$ on the transmission of central bank capital purchases. The posterior mean estimate of $\theta=0.815$ lies well below the parameter's prior mean of 0.95 . The lower survival probability is associated with a smaller share of incumbent bankers in this sectors, whose excess returns are affected 


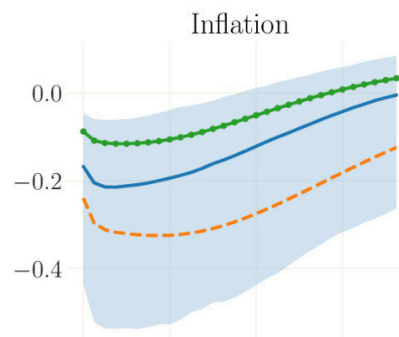

Capital utilization

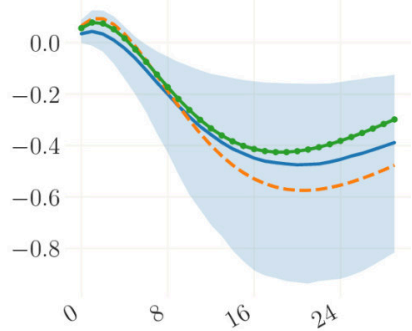

Marginal costs

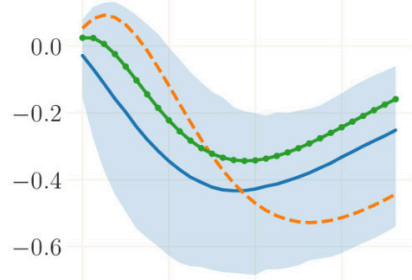

Marginal product of capital

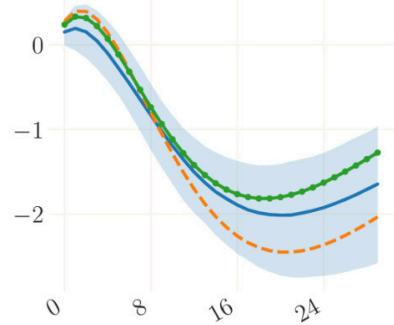

Wages

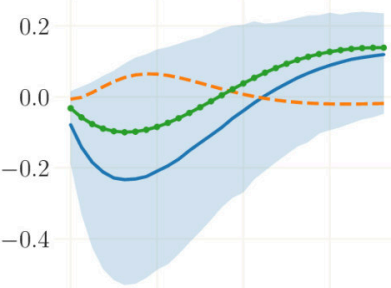

Consumption

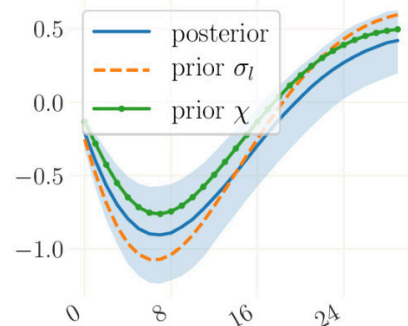

Figure 8: Impulse response functions with respect to a shock of capital securities purchases in blue, sampled from the posterior distribution with $95 \%$ credible set. In orange impulse responses at the posterior mean with $\sigma_{l}=2$. In green impulse responses at the posterior mean with $\chi=0.3$.

Note: Posterior sample obtained from 1000 draws from the posterior distribution, solid line represent the mean. For each draw, the strength of the shock is chosen such that the peak of the corresponding stochastic process matches the peak of the empirical time series. See Appendix F for details. Annualized measures where applicable.

by current and past shocks. Therefore, in the model a lower $\theta$ somewhat insulates the sector as a whole from the effects of reduced profitability of bank assets. Overall, the impulse to investment is strengthened by a lower survival probability of bankers, and therefore aggregate output as well. The stronger expansion of the capital stock again lowers marginal costs inflation. Hence, the low estimate of $\theta$ supports the disinflationary effects of unconventional monetary policy. The estimate of $L E V$ above its prior mean is associated with a relatively attenuated expansion of investment and output in response to LSAPs. Inflation is, however, barely affected. The attenuation of these shocks associated with a high steady state leverage ratio can be explained by the fact that the compressed excess returns on bank assets quickly undo the gains in net worth triggered by the central banks asset purchases (see Equation (11)). This reduction in the profitability on assets drives this process faster, when the asset position is relatively large compared to the net worth of banks. As the gains in the financial sector are more short-lived, the investment response is attenuated. ${ }^{26}$

On the household side, the preference parameters $\sigma_{c}$ and $\sigma_{l}$ affect the transmission of unconventional monetary policy shocks. Figure 8 compares the IRFs sampled from

\footnotetext{
${ }^{26}$ Note, that a higher $L E V$ is also associated with an amplification of risk premium shocks, which affect financial intermediates primarily via their funding costs. This is important, as risk premium shocks drive the bulk of the business cycle. Higher leverage ratios can therefore be associated with a deeper recession following the GFC.
} 
the posterior with IRFs in which the inverse of the Frisch elasticity, $\sigma_{l}$, is set to its prior mean. Our estimate of $\sigma_{l}$ is below its prior mean. The low slope of the labor supply schedule comes with a stronger but more short-lived fall of wages in response to central bank capital asset purchases. This translates to a qualitatively similar pattern in marginal costs and, since inflation is strongly forward looking, is associated with a attenuated decrease in inflation compared to the case, in which $\sigma_{l}$ is replaced by its prior mean. As discussed in section 3, a posterior mean estimate of $\sigma_{c}=0.908$ is in close proximity to values commonly found in the literature. A high coefficient of relative risk aversion at its prior mean implies a low sensitivity to changes in the real rate and establishes a positive co-movement of household spending and labor hours via the non-separabilities in preferences (see Equations (3) and (8)). In contrast, the posterior value slightly below unity reduces the latter channel and even slightly reverses its effect, such that, in sum, aggregate spending declines. In turn, the fall in consumption causes an expansion of the labor supply schedule and reduces real wages. Consequently, the low estimate of $\sigma_{c}$ substantially weakens the demand effect of quantitative easing and supports its disinflationary implications. Importantly, this parameter is well identified, which adds to our argument that the data favors disinflationary effects of LSAPs. Also on the household side of the model, the fraction of impatient households, $\chi$ affects the response of consumption, real wages and inflation to unconventional monetary policy measures. We show the counterfactual simulation with $\chi$ at its prior mean as well in Figure 8. The households profit from lower funding costs and increase their spending in response to quantitative easing. Our estimate of this parameter is at 0.190 and therefore considerably below its prior mean. For a higher value of $\chi$, the reduction in consumption and inflation is dampened. Notably, given the other parameter estimates, it would require a fraction of borrowing households as high as 0.5 to generate roughly neutral effects of LSAPs on inflation and consumption - a value which is far away from what the data favors.

\subsection{Model features}

In Gertler and Karadi (2013), the representative household is a "saver", with those savings in form of bank deposits and investments into both, corporate and government bonds. In response to a $\mathrm{QE}$ shock (private security or government bond purchases), household consumption only increases to the extent that the real deposit rates falls. The model, however, does not allow QE to directly affect consumption. For this reason, our baseline model features a second type of households, namely the impatient, that can borrow using long-term private mortgages to finance his consumption. This channel is comparable to the one presented in Chen et al. (2012) and allows for a direct impact of loser financing conditions on private consumption. In particular, after a $\mathrm{QE}$ shock, impatient households will see their borrowing costs falling, which stimulates their consumption and thereby, possibly, aggregate consumption. As discussed in the previous section, we estimate the fraction of impatient households to equal $\chi=0.195$.

In order to show that our results do not hinge on this additional channel of QE, we propose two alternative specifications of our benchmark in this section. First, we estimate the representative agent version of our model, which we call the RANK version, by setting the share of impatient households $\chi=0$. This model vintage does not allow for indebted households and, as a result, QE does not affect household consumption directly, but only to the extent that it affects the real deposit rate. Second, we estimate 

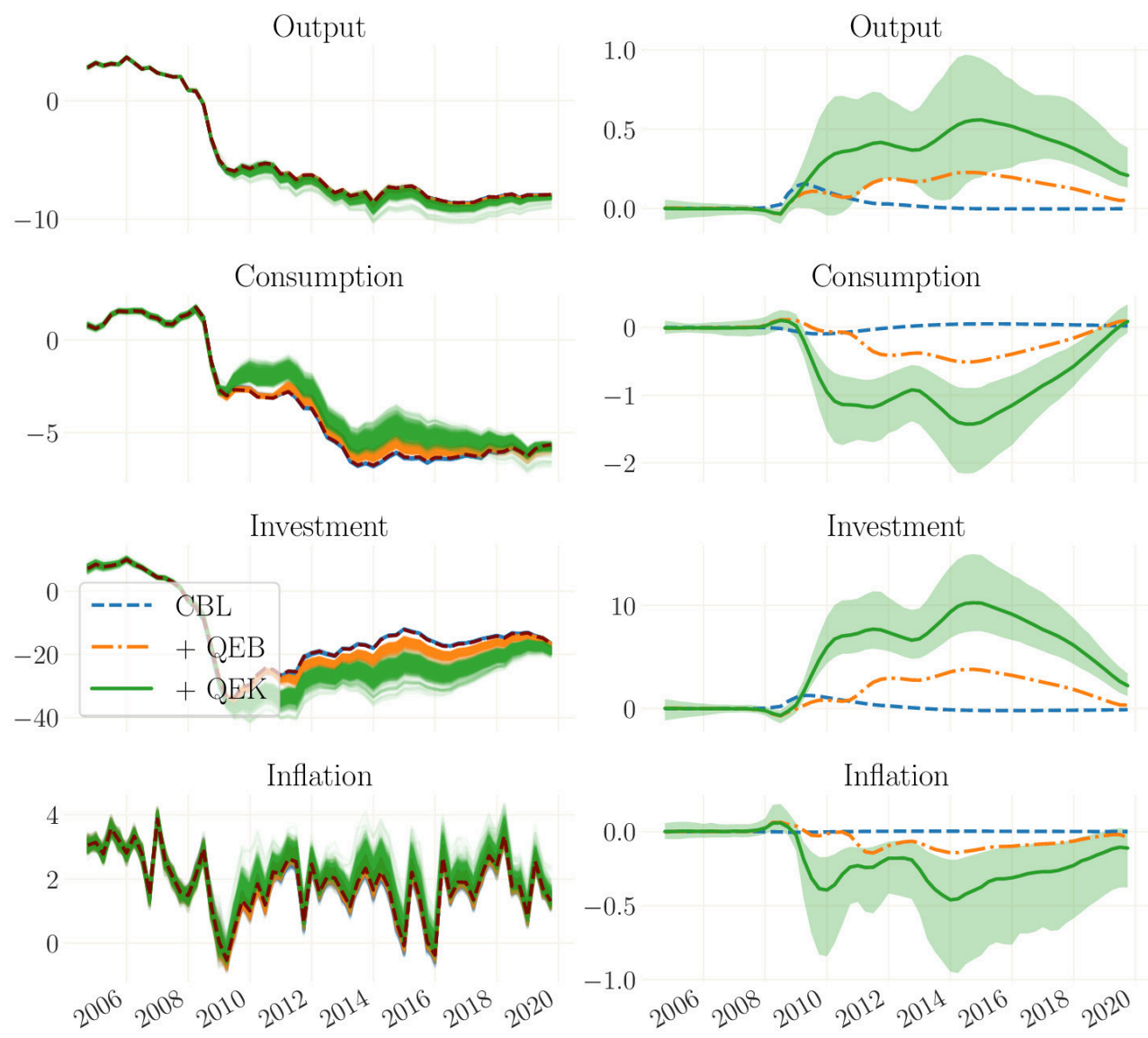

Figure 9: RANK specification of benchmark model. Left: counterfactual simulations without the QE measures. Right: net contribution of each QE measure. Effects in both graphs are cumulative.

Note: Means over 1000 simulations drawn from the posterior. Annual measures where applicable.

a model in which we replace the fraction of impatient households with "hand-to-mouth" (H2M) consumers inspired by Kaplan et al. (2018) in the spirit of Campbell and Mankiw $(1989,1991)$. Neither in this model vintage, denoted H2M, does QE affect consumption directly. Instead, any effects on consumption have to come from the response of labor income (i.e. real wages and/or labor supply) and again the real deposit rate.

Figure 9 repeats the counterfactual analysis of section 5.1 for the RANK model. The overall effects of the UMP measures seem to be consistent even in the absence of the above described channel. Despite a similar increase in investment increases of around $10 \%$, the overall effect on output is more muted, peaking at around $0.5 \%$. The reason for this substantially smaller output effect lies in the twice as large decline in the price level, now reaching on average $-0.5 \%$, and the accompanied stronger fall in consumption that weighs on aggregate demand. While most parameter estimates remain, by and large, 


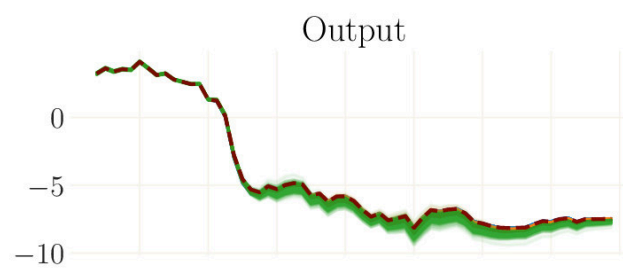

Ricardian consumption

0

$-5$

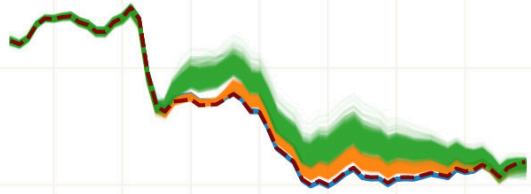

H2M Consumption

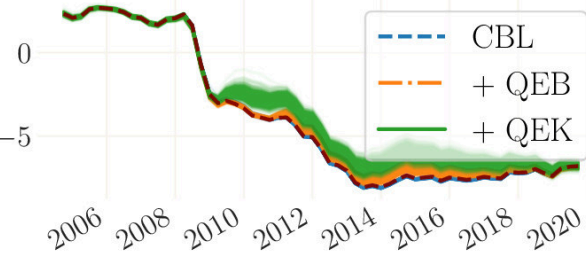

1.0

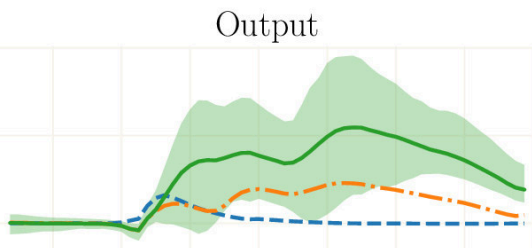

Ricardian consumption

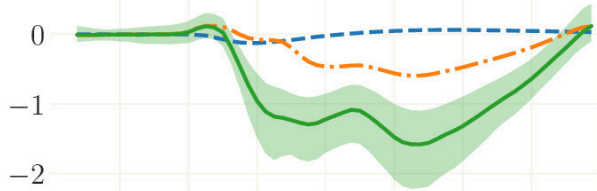

H2M Consumption

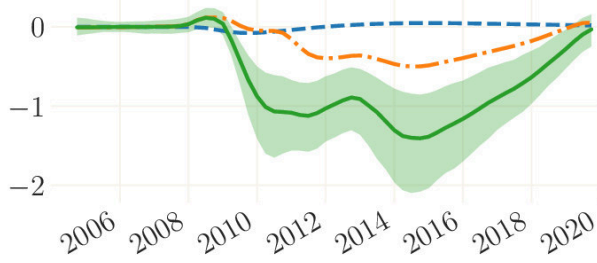

Figure 10: H2M specification of benchmark model. Left: counterfactual simulations without the QE measures. Right: net contribution of each QE measure. Effects in both graphs are cumulative.

Note: Means over 1000 simulations drawn from the posterior. Annual measures where applicable.

unchanged, a handful of parameter estimates reflects these dynamics. ${ }^{27}$ Specifically, in $\sigma_{l}$ falls from 1.231 in the benchmark model to 0.654 in order to rationalize the stronger fall in consumption with an simultaneous increase in labor supply. The reduced overall effectiveness of QE in stimulating the economy is also mirrored in (i) higher investment adjustment costs which mutes the investment response, (ii) a lower value for the portfolio adjustment costs which implies less limits to arbitrage and (iii) a higher leverage which facilitates a speedy normalization of the financial sector and therefore implies a weaker expansionary impulse for the real economy.

Similarly, Figures 10 and 11 illustrate the counterfactual of how key macroeconomic series would have evolved in the absence of the UMPs through the lens of the H2M vintage of our model. As is the case in our benchmark model, all three UMPs stimulated investment, with the largest effect - an increase of about 7\% - coming from the MBS purchases. However, despite this larger response of investment, the overall response of output remains muted relative to our benchmark model. The reason again is a larger fall in aggregate consumption because both, Ricardian and H2M households reduce their consumption. In line with the patient households in our benchmark model, Ricardian households see an increase in the real deposit rate. The latter is even amplified by the

\footnotetext{
${ }^{27}$ See Table H.4 in Appendix $\mathrm{H}$ for more details.
} 


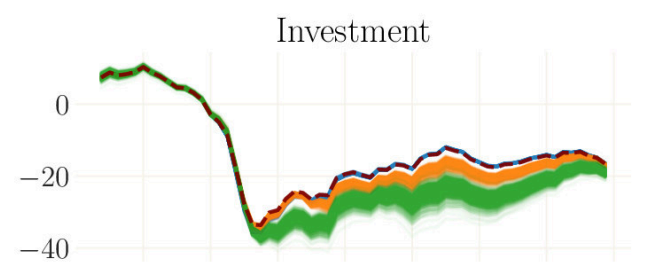

Inflation

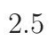

0.0

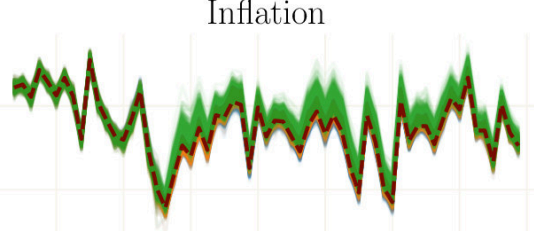

Credit Spread

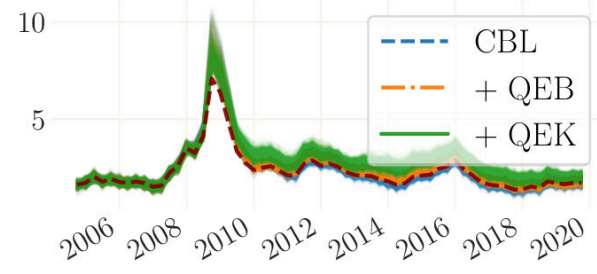

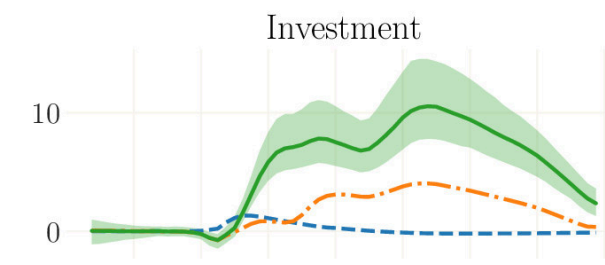

Inflation

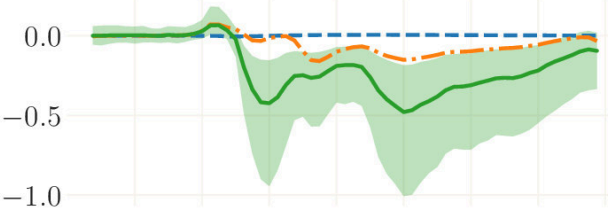

Credit Spread

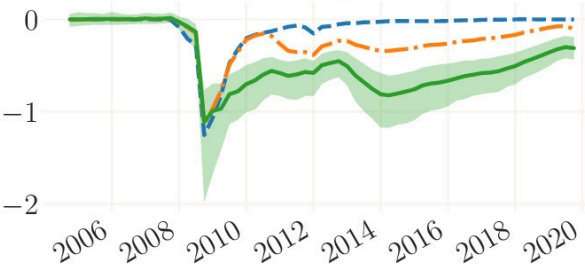

Figure 11: H2M specification of benchmark model. Left: counterfactual simulations without the QE measures. Right: net contribution of each QE measure. Effects in both graphs are cumulative. Measures of spreads and inflation are annualized.

Note: Means over 1000 simulations drawn from the posterior. Annual measures where applicable.

larger fall in inflation by $-0.5 \%$ on average, with the $95 \%$ credible set including a fall in the price level of up to $1 \%$. On the other hand, consumption of H2M households actually falls because falling wages reduce their labor income.

Again, these dynamics are reflected in a small set of parameter estimates that differ notably from the benchmark estimation. In order to square the rising labor input induced by QE with an even stronger fall in consumption than in the RANK model, the estimation prefers yet a lower value of $\sigma_{l}=0.332$ (instead of 1.231 in the benchmark model and 0.654 in the RANK vintage). Also - as is the case in the RANK model - higher investment adjustment costs, $S^{\prime \prime}$ and lower portfolio adjustment costs $P A C$ reduce the effectiveness of QE. Finally, we estimate a substantial share of H2M households $\chi=0.348$, which aligns previous estimates of the literature. ${ }^{28}$ Yet note that despite this estimate being larger than our estimated share of impatient households in the benchmark model, both types of households are fundamentally different which makes a direct comparison impossible.

To conclude, both model vintages above show that our results do not hinge on the inclusion of impatient households in the model. In fact, if anything, we find the inclusion of market segmentation on the household side imply larger effects on economic activity

${ }^{28}$ See, e.g., Kaplan et al. (2014). 

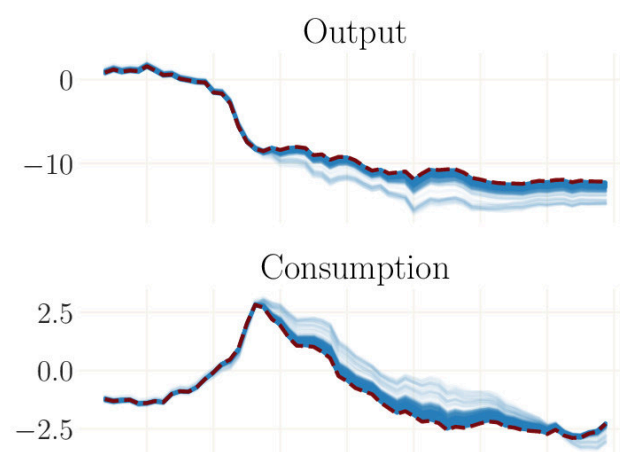

Wages

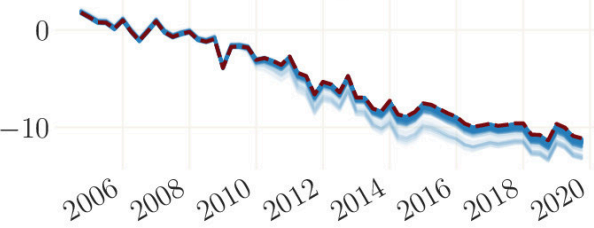

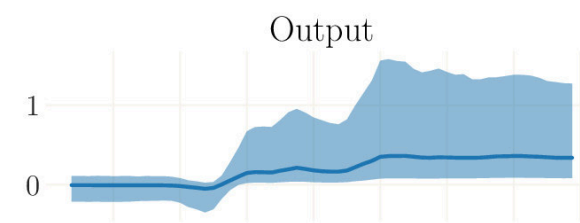

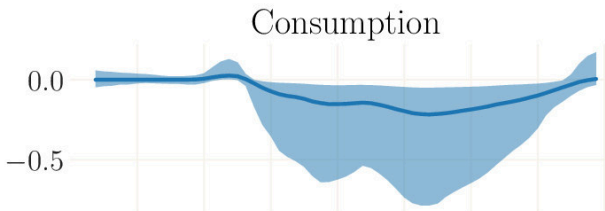

Wages

1

0

$$
200^{6} 200^{8} 20^{10} 20^{12} 20^{1 *} 20^{10} 20182020
$$

Figure 12: CFP model. Left: counterfactual simulations without the QE measures. Right: net contribution of each QE measure. Effects in both graphs are cumulative.

Note: Means over 1000 simulations drawn from the posterior. Annual measures where applicable.

and less deflationary effects, together with a smaller decline in aggregated consumption. We therefore regard the disinflationary effect presented in the benchmark model as a conservative estimate, which indicates a lower bound.

\subsection{Model choice}

Besides the framework proposed by Gertler and Karadi (2013) - which serves as a backbone of our financial sector - two other widely used models to study the effects of quantitative easing include Chen et al. (2012) and Carlstrom et al. (2017). Chen et al. (2012) basically add market segmentation and transaction cost to an otherwise standard Smets and Wouters (2007)-type model in line with Andres et al. (2004), such that QE directly affects consumption of restricted households. Our model captures this channel as impatient households have to borrow using long-term private loans, but are effectively restricted from short-term assets. As discussed above, this feature allows QE to affect consumption directly rather than via its effect on the real deposit rate. Carlstrom et al. (2017, henceforth CFP), on the other hand, assume that households are segmented from long-term debt markets and can only save in bank deposits. A hold-up problem - similar in spirit to our bank's moral hazard problem - together with portfolio adjustment costs further limits the financial intermediary from arbitraging yield gaps between short and long-term debt. Lastly, as firms' have to issue long-term debt in oder to finance their capital demand, central bank asset purchases have real effects.

While this model shares several features with ours, there are two important differences. First, the price (and hence yield) of corporate and government bonds is assumed 

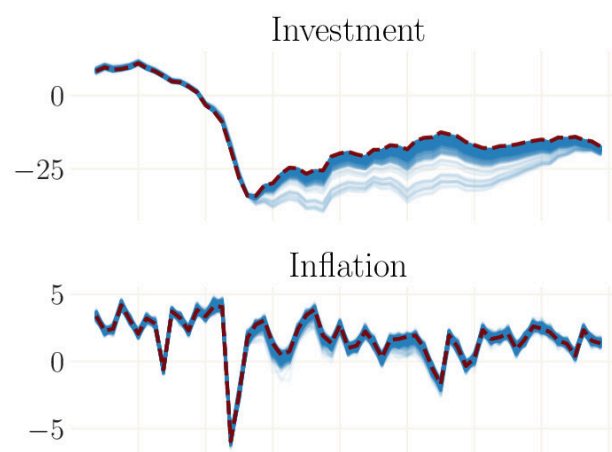

Term Premium

2.5

0.0

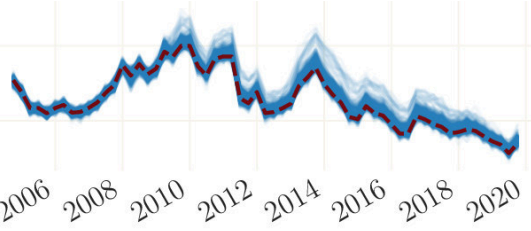

Investment

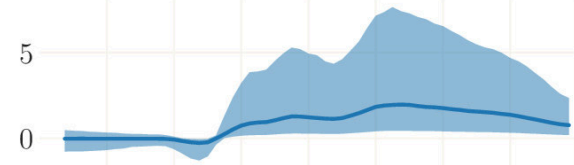

Inflation

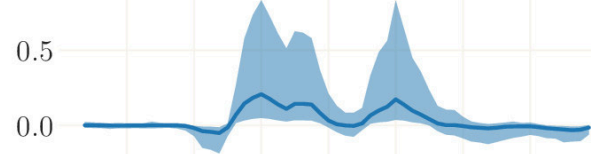

Term Premium

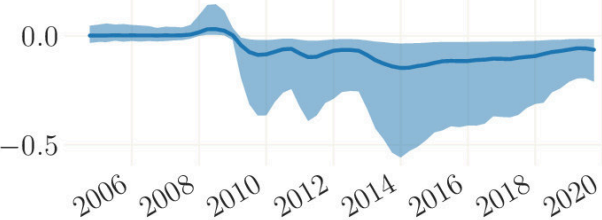

Figure 13: CFP model. Left: counterfactual simulations without the QE measures. Right: net contribution of each QE measure. Effects in both graphs are cumulative.

Note: Means over 1000 simulations drawn from the posterior. Annual measures where applicable.

to be same, which restricts us from separating the effects of MBS and government bond purchases. Second, the model does not include a shock that moves consumption and investments into the same direction, which renders the estimation of the GFC difficult, as we will discuss below. ${ }^{29}$

In order to gauge whether our results are also robust to the model choice, we replicate Carlstrom et al. (2017) by estimating their model using their priors, but our nonlinear Bayesian likelihood approach and the same sample period including the ZLB. ${ }^{30}$

We find the sample choice to affect the posterior parameter estimates in a nonnegligible way, confirming our intuition of the importance of structural changes in the economy. For instance, we find a substantially steeper wage Phillips curve, despite a notable flatter price Phillips curve. But more broadly, various of our parameter estimates are even outside the $95 \%$ credible set reported in CFP. Besides this, the most important difference lies in the estimate of $\psi_{n}$, the adjustment costs parameter on net worth, which is the most important driver of $\mathrm{QE}$. We find $\psi_{n}=0.14$ instead of 0.7850 reported in CFP, which substantially lowers the effectiveness of QE. The reason is that lower net worth adjustment cost imply less limits to arbitrage.

Let us study the counterfactuals of how the key macroeconomic variables would have evolved in the absence of unconventional monetary policy measures in the CFP model. As evident from Figures 12 and 13, MBS and government purchases jointly compress the

\footnotetext{
${ }^{29}$ In addition, it is not straightforward to add liquidity injections to the model in a comparable fashion due to the reduced form moral hazard problem.

${ }^{30}$ See Appendix $\mathrm{K}$ for more details on the data and the parameter estimates.
} 
term premium, albeit only a little, with the peak effect of around -10 basis points. The reason for the latter is our low estimate for the net worth adjustment cost $\psi_{n}=0.14$ which govern the limits to arbitrage. The small reduction in the term premium, in turn, translates into similarly muted responses of investment and output. Consumption, on the other hand, falls as it does in our model. Even though the real deposit rate falls, the increase in the return on capital raises the marginal benefits to invest over and above the marginal benefit to consume. So far, the dynamics are consistent with our reported results, although the magnitude is significantly reduced. Contrary to our analysis above, however, inflation seems to fall only initially, but turns positive later on. The latter can be explained by increasing marginal costs. Specifically, without capital utilization, higher investment increases the marginal product of capital. In order to keep the ratio of marginal products constant, also labor demand has to increase mechanically, leading to an increase in wages. Both rising wages and the return on capital which - at first order - equals the marginal product of capital in this model, push up marginal cost and ultimately inflation.

Thus, in contrast to our benchmark model, the demand effects of LSAPs outweigh their supply effects in the estimated CFP model. However, we take this result with a considerable degree of caution. In particular, we argue that the CFP model in its original form is not well suited to study the GFC because it lacks a shock that can explain the joint decline of consumption and investment in the Great Recession. In fact, the historical decomposition suggests that through the lens of the CFP model, the GFC was driven by a negative monetary policy shock. At the same time, CFP do not include consumption as an observable. Following their approach, we see that the smoothed state of consumption suggests that household spending actually peaked in the direct aftermath of the GFC. ${ }^{31}$ Both observations let us conclude that the CFP model would require some substantial adjustments to facilitate a meaningful empirical analysis of macroeconomic dynamics in the US on a sample that includes the GFC and its aftermath.

\section{Conclusion}

After several years of recovery from the Global Financial Crisis, the Federal Reserve embarked again in large-scale asset purchases once the policy rate reached the ZLB in spring 2020. Although the commonly held view points towards expansionary effects of Quantitative Easing, its macroeconomic impact remains unclear.

Using a nonlinear Bayesian likelihood approach that fully accounts for the ZLB on nominal interest rates, we are the first to provide a structural investigation of the macroeconomic effects of QE. Our large-scale New Keynesian model includes several channels for QE to have macroeconomic effects and is estimated over the sample from 1998 until 2019 including data of the Federal Reserves balance sheet.

According to our results, the QE programs in the aftermath of GFC had sizable expansionary effects raising output by around $1.2 \%$. This effect was by and large driven by a large increase investment of around 9 percent. Aggregate consumption, on the other

\footnotetext{
${ }^{31}$ See Figures K.27 and K.28 in Appendix K. Adding consumption as an observable together with an additional demand shock such as a government spending shock does not resolve this problem since then, consumption is solely explained by this additional shock.
} 
hand, contracted by $0.7 \%$. This finding is robust across models and different vintages with a representative agent or heterogeneous agents.

The surge in investment raises the production capacity which led to a mild disinflationary effect of 0.25 percent. Different to conventional monetary policy, supply side effects of LSAPs seem to dominate the aggregate demand effects, consistent with a cost channel of monetary policy. Our finding of a disinflationary effect of QE is highly policy relevant. In the US, LSAPs create a trade-off for policymakers between the stabilizing prices and employment. For the Euro Area, the result may be even more pressing as its asset purchase programme (APP) was explicitly undertaken with the goal to stabilize inflation and inflation expectations at a time when fears of deflation surged.

In times when central banks in developed countries review the robustness of their monetary policy strategies against the backdrop of a higher likelihood of future ZLB episodes, our novel results provide a useful guidance of the macroeconomic effects of large-scale asset purchases. What role wealth or income inequality plays in this context is an important question we leave for future research.

\section{References}

Abbate, A., Eickmeier, S., Prieto, E., 2016. Financial shocks and inflation dynamics

Acharya, V.V., Crosignani, M., Eisert, T., Eufinger, C., 2020. Zombie credit and (dis-) inflation: evidence from Europe. Technical Report. National Bureau of Economic Research.

Adrian, T., Crump, R.K., Moench, E., 2013. Pricing the term structure with linear regressions. Journal of Financial Economics 110, 110-138.

Altavilla, C., Brugnolini, L., Gürkaynak, R.S., Motto, R., Ragusa, G., 2019. Measuring euro area monetary policy. Journal of Monetary Economics 108, 162-179.

Altavilla, C., Giannone, D., 2017. The effectiveness of non-standard monetary policy measures: Evidence from survey data. Journal of Applied Econometrics 32, 952-964. doi:10.1002/jae.2559.

An, S., Schorfheide, F., 2007. Bayesian analysis of dsge models. Econometric reviews 26, 113-172.

Andres, J., López-Salido, J.D., Nelson, E., 2004. Tobin's imperfect asset substitution in optimizing general equilibrium. Journal of Money, Credit and Banking , 665-690.

Atkinson, T., Richter, A.W., Throckmorton, N.A., 2019. The zero lower bound and estimation accuracy. Journal of Monetary Economics.

Barth III, M.J., Ramey, V.A., 2001. The cost channel of monetary transmission. NBER macroeconomics annual 16, 199-240.

Bauer, M.D., Neely, C.J., 2014. International channels of the fed's unconventional monetary policy. Journal of International Money and Finance 44, 24-46.

Baumeister, C., 2013. i benati, l.(2013). unconventional monetary policy and the great recession: estimating the macroeconomic effects of a spread compression at the zero lower bound. International Journal of Central Banking 9, 165-212.

Bernanke, B., 2008. Liquidity provision by the federal reserve. speech given at the federal reserve bank of atlanta financial markets conference, sea island, georgia. 13 may.

Bernanke, B.S., 2020. The new tools of monetary policy. American Economic Review 110, 943-83.

Blanchard, O.J., Kahn, C.M., 1980. The solution of linear difference models under rational expectations. Econometrica: Journal of the Econometric Society , 1305-1311.

Boeckx, J., Dossche, M., Peersmanc, G., 2017. Effectiveness and transmission of the ecb's balance sheet policies. International Journal of Central Banking 13, 297-333.

Boehl, G., 2020a. econsieve - a collection of linear and nonlinear (kalman) filters for economic models. URL: https://github.com/gboehl/econsieve.

Boehl, G., 2020b. Efficient Solution, Filtering and Estimation of Models with OBCs. Technical Report. URL: https://gregorboehl.com.

Boehl, G., 2020c. pydsge - a package to simulate, filter, and estimate dsge models with occasionally binding constraints. URL: https://github.com/gboehl/pydsge.

Boehl, G., Strobel, F., 2020. US Business Cycle Dynamics at the Zero Lower Bound. Technical Report. unpublished manuscript. URL: https://gregorboehl.com. 
Bohn, H., 1998. The behaviour of us public debt and deficits. The Quarterly Journal of Economics 117 , 949-963.

ter Braak, C.J., Vrugt, J.A., 2008. Differential evolution markov chain with snooker updater and fewer chains. Statistics and Computing 18, 435-446.

Brand, C., Bielecki, M., Penalver, A., 2018. The natural rate of interest: estimates, drivers, and challenges to monetary policy. ECB Occasional Paper .

Brand, C., Goy, G., Lemke, W., 2020. Natural rate chimera and bond pricing reality. De Nederlandsche Bank Working Paper .

Brunnermeier, M.K., Sannikov, Y., 2016. The i theory of money. National Bureau of Economic Research

Caballero, R.J., Farhi, E., 2018. The Safety Trap. Review of Economic Studies 85, 223-274.

Calvo, G.A., 1983. Staggered prices in a utility-maximizing framework. Journal of Monetary Economics $12,383-398$.

Campbell, J.Y., Mankiw, N.G., 1989. Consumption, income, and interest rates: Reinterpreting the time series evidence. NBER macroeconomics annual 4, 185-216.

Campbell, J.Y., Mankiw, N.G., 1991. The response of consumption to income: a cross-country investigation. European economic review 35, 723-756.

Carlstrom, C.T., Fuerst, T.S., Paustian, M., 2017. Targeting long rates in a model with segmented markets. American Economic Journal: Macroeconomics 9, 205-42. URL: http://www.aeaweb.org/ articles?id=10.1257/mac. 20150179 , doi:10.1257/mac. 20150179.

Chen, H., Cúrdia, V., Ferrero, A., 2012. The macroeconomic effects of large-scale asset purchase programmes*. The Economic Journal 122, F289-F315. doi:10.1111/j.1468-0297.2012.02549.x.

Chowdhury, I., Hoffmann, M., Schabert, A., 2006. Inflation dynamics and the cost channel of monetary transmission. European Economic Review 50, 995-1016.

Christiano, L., Eichenbaum, M., Evans, C., 2005. Nominal rigidities and the dynamic effects of a shock to monetary policy. Journal of Political Economy 113, 1-45. URL: https://EconPapers.repec.org/ RePEc:ucp: jpolec:v:113:y:2005:i:1:p:1-45.

Cuba-Borda, P., Guerrieri, L., Iacoviello, M., Zhong, M., 2019. Likelihood evaluation of models with occasionally binding constraints. Journal of Applied Econometrics 34, 1073-1085.

Curdia, V., Woodford, M., 2010. Credit spreads and monetary policy. Journal of Money, credit and Banking 42, 3-35.

Cynthia, W.J., Dora, X.F., 2016. Measuring the macroeconomic impact of monetary policy at the zero lower bound. Journal of Money, Credit and Banking 48, 253-291. URL: https://onlinelibrary.wiley.com/doi/abs/10.1111/jmcb.12300, doi:10.1111/jmcb.12300, arXiv:https://onlinelibrary.wiley.com/doi/pdf/10.1111/jmcb.12300.

Daly, M.C., Hobijn, B., 2014. Downward nominal wage rigidities bend the phillips curve. Journal of Money, Credit and Banking 46, 51-93.

Dedola, L., Karadi, P., Lombardo, G., 2013. Global implications of national unconventional policies. Journal of Monetary Economics 60, 66-85. URL: https://ideas.repec.org/a/eee/moneco/ v60y2013i1p66-85.html, doi:10.1016/j.jmoneco.2012.12.

Del Negro, M., Eggertsson, G., Ferrero, A., Kiyotaki, N., 2017. The Great Escape? A Quantitative Evaluation of the Fed's Liquidity Facilities. American Economic Review 107, 824-857.

Del Negro, M., Giannoni, M.P., Schorfheide, F., 2015. Inflation in the great recession and new keynesian models. American Economic Journal: Macroeconomics 7, 168-96.

Doniger, C., Hebden, J., Pettit, L., Skaperdas, A., 2019. Substitutability of monetary policy instruments. FED Notes , 17

d'Amico, S., English, W., López-Salido, D., Nelson, E., 2012. The federal reserve's large-scale asset purchase programmes: rationale and effects. The Economic Journal 122, F415-F446.

Eberly, J., Stock, J.H., Wright, J.H., 2019. The federal reserve's current framework for monetary policy: A review and assessment. NBER Working Paper .

Edge, R.M., Gürkaynak, R.S., Kisacikoglu, B., 2013. Judging the DSGE model by its forecast. Technical Report. mimeo.

Eser, F., Lemke, W., Nyholm, K., Radde, S., Vladu, A., 2019. Tracing the impact of the ecb's asset purchase programme on the yield curve .

Fiore, F.D., Tristani, O., 2013. Optimal monetary policy in a model of the credit channel. The Economic Journal 123, 906-931.

Fleming, M.J., 2012. Federal reserve liquidity provision during the financial crisis of 2007-2009. Annu. Rev. Financ. Econ. 4, 161-177.

Gagnon, J., Raskin, M., Remache, J., Sack, B., et al., 2011. The financial market effects of the federal 
reserve's large-scale asset purchases. international Journal of central Banking 7, 3-43.

Gaiotti, E., Secchi, A., 2006. Is there a cost channel of monetary policy transmission? an investigation into the pricing behavior of 2,000 firms. Journal of Money, Credit and Banking , 2013-2037.

Gambacorta, L., Hofmann, B., Peersman, G., 2014. The effectiveness of unconventional monetary policy at the zero lower bound: A cross-country analysis. Journal of Money, Credit and Banking 46, 615-642.

Gelain, P., Ilbas, P., 2017. Monetary and macroprudential policies in an estimated model with financial intermediation. Journal of Economic Dynamics and Control 78, 164-189.

Gertler, M., Karadi, P., 2011. A model of unconventional monetary policy. Journal of monetary Economics 58, 17-34.

Gertler, M., Karadi, P., 2013. QE 1 vs. 2 vs. 3. . . : A Framework for Analyzing Large-Scale Asset Purchases as a Monetary Policy Tool. International Journal of Central Banking 9, 5-53.

Gertler, M., Kiyotaki, N., 2010. Financial intermediation and credit policy in business cycle analysis, in: Friedman, B.M., Woodford, M. (Eds.), Handbook of Monetary Economics. Elsevier. volume 3. chapter 11, pp. 547-599.

Gilchrist, S., Schoenle, R., Sim, J., Zakrajšek, E., 2017. Inflation dynamics during the financial crisis American Economic Review 107, 785-823. URL: http://www . aeaweb.org/articles?id=10.1257/aer . 20150248, doi:10.1257/aer.20150248.

Gilchrist, S., Zakrajšek, E., 2012. Credit spreads and business cycle fluctuations. American Economic Review 102, 1692-1720. URL: http://www.aeaweb.org/articles?id=10.1257/aer.102.4.1692, doi:10. 1257 /aer.102.4.1692.

Guerrieri, L., Iacoviello, M., 2017. Collateral constraints and macroeconomic asymmetries. Journal of Monetary Economics 90, 28-49. URL: https://ideas.repec.org/a/eee/moneco/v90y2017icp28-49. html, doi:10.1016/j.jmoneco.2017.06.

Gust, C., Herbst, E., López-Salido, D., Smith, M.E., 2017. The empirical implications of the interest-rate lower bound. American Economic Review 107, 1971-2006.

Hamilton, J.D., Wu, J.C., 2012. The effectiveness of alternative monetary policy tools in a zero lower bound environment. Journal of Money, Credit and Banking 44, 3-46.

Herbst, E., Schorfheide, F., 2014. Sequential monte carlo sampling for dsge models. Journal of Applied Econometrics 29, 1073-1098.

Justiniano, A., Primiceri, G., Tambalotti, A., 2011. Investment Shocks and the Relative Price of Investment. Review of Economic Dynamics 14, 101-121. URL: https://ideas.repec.org/a/red/issued/ 09-248.html, doi:10.1016/j.red.2010.07.003

Kapetanios, G., Mumtaz, H., Stevens, I., Theodoridis, K., 2012. Assessing the economy-wide effects of quantitative easing. The Economic Journal 122, F316-F347.

Kaplan, G., Moll, B., Violante, G.L., 2018. Monetary policy according to hank. American Economic Review 108, 697-743.

Kaplan, G., Violante, G.L., Weidner, J., 2014. The Wealthy Hand-to-Mouth. Working Paper 20073. National Bureau of Economic Research.

Kiley, M.T., 2018. Quantitative easing and the 'new normal'in monetary policy. The Manchester School 86, 21-49.

Kimball, M.S., 1995. The Quantitative Analytics of the Basic Neomonetarist Model. NBER Working Papers 5046. National Bureau of Economic Research, Inc.

Klein, P., 2000. Using the generalized schur form to solve a multivariate linear rational expectations model. Journal of Economic Dynamics and Control 24, 1405-1423.

Krippner, L., 2013. Measuring the stance of monetary policy in zero lower bound environments. Economics Letters 118, 135-138.

Krishnamurthy, A., Vissing-Jorgensen, A., 2011. The effects of quantitative easing on interest rates: channels and implications for policy.

Kulish, M., Morley, J., Robinson, T., 2017. Estimating dsge models with zero interest rate policy. Journal of Monetary Economics 88, 35 - 49. URL: http://www.sciencedirect.com/science/article/pii/ S0304393217300442, doi:https://doi.org/10.1016/j.jmoneco.2017.05.003.

Laubach, T., Williams, J.C., 2003. Measuring the natural rate of interest. Review of Economics and Statistics 85, 1063-1070.

Meeks, R., Nelson, B., Alessandri, P., 2017. Shadow banks and macroeconomic instability. Journal of Money, Credit and Banking 49, 1483-1516.

Ravenna, F., Walsh, C.E., 2006. Optimal monetary policy with the cost channel. Journal of Monetary Economics 53, 199-216.

Sims, E., Wu, J.C., 2020. Evaluating central banks' tool kit: Past, present, and future. Journal of Monetary Economics . 
Smets, F., Wouters, R., 2007. Shocks and frictions in us business cycles: A bayesian dsge approach. American Economic Review 97, 586-606.

Swanson, E.T., 2017. Measuring the Effects of Federal Reserve Forward Guidance and Asset Purchases on Financial Markets. Working Paper 23311. National Bureau of Economic Research. doi:10.3386/ w23311.

Ter Braak, C.J., 2006. A markov chain monte carlo version of the genetic algorithm differential evolution: easy bayesian computing for real parameter spaces. Statistics and Computing 16, 239-249.

Villa, S., 2016. Financial frictions in the euro area and the united states: A bayesian assessment. Macroeconomic Dynamics 20, 1313-1340. doi:10.1017/S1365100514000881.

Weale, M., Wieladek, T., 2016. What are the macroeconomic effects of asset purchases? Journal of monetary Economics 79, 81-93.

Williams, J.C., et al., 2016. Monetary policy in a low r-star world. FRBSF Economic Letter 23, 1-23.

Woodford, M., 1998. Public debt and the price level. mimeo .

Woodford, M., 2001. Fiscal requirements of price stability. Journal of Money, Credit and Banking 33, $669-728$.

\section{Appendix A Data}

Our eleven observables are mapped into the model equations using the following measurement equations:

Real GDP growth $=\bar{\gamma}+\left(y_{t}-y_{t-1}\right)$,

Real consumption growth $=\bar{\gamma}+\left(c_{t}-c_{t-1}\right)$,

Real investment growth $=\bar{\gamma}+\left(i_{t}-i_{t-1}\right)$,

Real wage growth $=\bar{\gamma}+\left(w_{t}-w_{t-1}\right)$,

Labor hours $=\bar{l}+l_{t}$,

Inflation $=\bar{\pi}+\pi_{t}$,

Federal funds rate $=\left(\frac{\bar{\pi}}{\beta \gamma^{-\sigma_{c}}}-1\right) * 100+r_{t}$,

GZ-spread $=\overline{\text { spread }}+E_{t}\left[\widetilde{r}_{t+1}^{k}-r_{t}\right]$,

Gov. bonds purchases $=\frac{\bar{B}_{c b}}{\bar{Y}}+b_{c b, t}$,

Corp. bonds purchases $=k_{c b, t}$,

Liquidity injections $=l_{t}^{q}$.

These observables are constructed as follows:

- GDP: $\ln ($ GDP/GDPDEF/CNP16OV_ma $) * 100$

- CONS: $\ln ($ (PCEC-PCEDG) / GDPDEF / CNP16OV_ma)*100

- INV: $\ln ($ (GPDI+PCEDG) / GDPDEF / CNP16OV_ma)*100

- LAB: $\ln \left(13^{*}\right.$ AWHNONAG * CE16OV / CNP16OV_ma $) * 100$

- INFL: $\ln (\text { GDPDEF })^{*} 100$

- WAGE: $\ln (\text { COMPNFB / GDPDEF })^{*} 100$

- FFR: FEDFUNDS/4 
- GZ Spread: GZSpread/4

- CB GBonds: TREAST/GDP

- CB CBonds: (WSHOMCB+WCPFF)/GDP

- CB Liquidity: (WACBS + FEDDT + TERAUCT + OTHLT)/GDP

We take log changes for GDP, CONS, INV and WAGE in our measurement equations. Except the GZ spread, which can be downloaded from the Federal Reserves homepage ${ }^{32}$, all data is downloaded from the FRED database of the St. Louis Fed, with the above mnemonics representing:

- GDP: GDP - Gross Domestic Product, Billions of Dollars, Quarterly, Seasonally Adjusted Annual Rate, FRED

- GDPDEF: Gross Domestic Product: Implicit Price Deflator , Index 2012=100, Quarterly, Seasonally Adjusted, FRED

- CNP16OV: Civilian noninstitutional population, Thousands of Persons, Quarterly, Seasonally Adjusted, FRED

- CNP16OV_ma: a four-quarter trailing average of CNP16OV

- PCEC: Personal Consumption Expenditures, Billions of Dollars, Quarterly, Seasonally Adjusted Annual Rate, FRED

- PCEDG: Personal Consumption Expenditures: Durable Goods, Billions of Dollars, Quarterly, Seasonally Adjusted Annual Rate, FRED

- GPDI: Gross Private Domestic Investment, Billions of Dollars, Quarterly, Seasonally Adjusted Annual Rate, FRED

- AWHNONAG: Average Weekly Hours of Production and Nonsupervisory Employees: Total private, Hours, Quarterly, Seasonally Adjusted, FRED

- CE16OV: Employment Level, Thousands of Persons, Quarterly, Seasonally Adjusted, FRED

- COMPNFB, Nonfarm Business Sector: Compensation Per Hour, Index 2012=100, Quarterly, Seasonally Adjusted, FRED

- FEDFUNDS: Effective Federal Funds Rate, Percent, FRED

- GZ Spread: A corporate bond credit spread with a high information content for economic activity constructed by Gilchrist and Zakrajšek (2012) using secondary market prices of senior unsecured bonds issued by a large representative sample of US non-financial firms. Quarterly, Percent, Federal Reserve Board.

- TREAST: U.S. Treasury securities held by the Federal Reserve: All Maturities, Millions of Dollars, Quarterly, Not Seasonally Adjusted, FRED

${ }^{32}$ https://www.federalreserve.gov/econresdata/notes/feds-notes/2016/files/ebp_csv.csv 
- WSHOMCB: Current face value of mortgage-backed obligations held by Federal Reserve Banks: All Maturities, Millions of Dollars, Quarterly, Not Seasonally Adjusted, FRED

- WCPFF: Net Portfolio Holdings of Commercial Paper Funding Facility LLC, Billions of Dollars, Quarterly, Not Seasonally Adjusted, FRED

- WACBS: Central Bank Liquidity Swaps, Millions of Dollars, Quarterly, Not Seasonally Adjusted, FRED

- FEDDT: Federal agency debt securities held by the Federal Reserve: All Maturities, Millions of Dollars, Quarterly, Not Seasonally Adjusted, FRED

- TERAUCT: Term auction credit held by the Federal Reserve: All Maturities, Millions of Dollars, Quarterly, Not Seasonally Adjusted, FRED

- OTHLT: Other loans held by the Federal Reserve: All Maturities, Millions of Dollars, Quarterly, Not Seasonally Adjusted, FRED

\section{Appendix B Full model}

For our analysis, we extend a standard medium scale model as in Smets and Wouters (2007) and financial intermediates as in Gertler and Karadi (2013), patient and impatient households as well as unconventional monetary policy tools. Time is discrete, and one period in the model represents one quarter. The model features households, banks, intermediate good producers, capital good producers, retailers, labor unions, a fiscal and a monetary authority. The model includes habit formation in consumption, investment adjustment costs, variable utilization of productive capital and nominal rigidities that give rise to a price and wage Phillips curves as in Smets and Wouters (2007)to enhance the empirical plausibility of the model dynamics.

\section{Appendix B.1 The household structure}

The model is populated by two types of households. There is a continuum of impatient households with mass $\chi$ and a continuum of patient households of mass $1-\chi$. In the spirit of Gertler and Karadi (2013), we assume that a constant fraction $f$ of each patient household's members works as banker, whereas the remaining fraction $(1-f)$ consists of workers who - like impatient households - supply labor to the intermediate good producers. While workers receive their wage income every period, bankers reinvest their gains in asset holdings of the bank over several periods. Only when a banker (exogenously) exits the banking sector, she contributes to the patient households' income by bringing home the accumulated profits. Perfect consumption insurance within patient households ensures that workers and bankers face the same consumption stream. The expected lifetime utility of any household $i$ is given by

$$
U_{t}=E_{0} \sum_{t=0}^{\infty} \beta_{i}^{t}\left(\frac{\left(C_{i, t}-h C_{i, t-1}\right)^{1-\sigma_{c}}-1}{1-\sigma_{c}}\right) \exp \left(\frac{\sigma_{c}-1}{1+\sigma_{l}} L_{i, t}^{1+\sigma_{l}}\right)
$$

where parameters $\beta_{i}, h, \sigma_{c}$, and $\sigma_{l}$ are, respectively, the discount factor, the degree of external habit formation in consumption, the coefficient of relative risk aversion, and a 
weight on the disutility of labor. The discount factor has a household-specific subscript $i$, because we assume the discount factor of impatient households $\beta_{m}$ to be smaller than the discount factor of patient households, i.e. $\beta_{m}<\beta_{p}$. Finally. $C_{i, t}$ and $L_{i, t}$ denote consumption and hours worked of household $i \in\{m, p\}$, respectively. ${ }^{33}$

\section{Appendix B.2 Patient households}

The patient household earns the real wage, $W_{t}$, for her supplied labor, $L_{p, t}$. She can save in one-period bank deposits, $D_{t}$, that pay an interest rate, $R_{t}^{d}$, in government bonds, $B_{h, t}$, that yield an interest rate, $R_{t}^{b}$, and in capital assets $K_{h, t}$ with an associated interest rate, $R_{t}^{k}$. These interest rates are already in real terms. Capital claims, just like government bonds, are modeled as long-term assets. As for all stock variables, we use the end-of-period notation, so that $D_{t}$ denotes the household's deposits at the end of period $t$. The return on deposits, $R_{t}^{d}=v_{u, t} R_{t}$, includes a disturbance term, $v_{u, t}$ which drives a wedge between the risk-free real rate and the return on deposits. We assume $v_{u, t}$ to follow an AR(1) process in logs. Patient households spend their funds on consumption $C_{p, t}$, and save in new deposits, bonds and capital. Savings in government bonds and capital are subject to portfolio adjustment costs with adjustment parameters $\kappa_{b}$ and $\kappa_{k}$. The budget constraint of patient households, in real terms, reads

$$
\begin{array}{r}
C_{p, t}+\frac{D_{t}}{R_{t}^{d}}+Q_{t}\left[K_{h, t}+\frac{1}{2} \kappa_{k}\left(K_{h, t}-K_{h}\right)^{2}\right]+Q_{t}^{b}\left[B_{h, t}+\frac{1}{2} \kappa_{b}\left(B_{h, t}-B_{h}\right)^{2}\right] \\
=D_{t-1}+W_{t} L_{p, t}+R_{t}^{k} Q_{t-1} K_{h, t-1}+R_{t}^{b} Q_{t-1}^{b} B_{h, t-1}-T_{t}+\mathfrak{P}_{t} .
\end{array}
$$

$T_{t}$ denotes lump sum taxes raised by the government to finance government spending, and $\mathfrak{P}_{t}$ are profits of monopolistic firms and banks that accrue to the patient households. Maximizing (B.1) subject to the patient household's budget constraint (B.2) and rearranging the first order conditions yields the Euler equation, a condition for the optimal supply of labor and two no-arbitrage conditions:

$$
\begin{aligned}
1 & =\beta_{p} E_{t}\left[\exp \left(\frac{\sigma_{c}-1}{1+\sigma_{l}}\left(L_{p, t+1}^{1+\sigma_{l}}-L_{p, t}^{1+\sigma_{l}}\right)\right)\left(\frac{C_{p, t+1}-h C_{p, t}}{C_{p, t}-h C_{p, t-1}}\right)^{-\sigma_{c}}\right] R_{t}^{d}, \\
W_{t}^{h} & =\left(C_{p, t}-h C_{p, t-1}\right) L_{p, t}^{\sigma_{l}}, \\
E_{t} R_{t+1}^{k} & =R_{t}^{d}\left[1+\kappa_{k}\left(K_{h, t}-K_{h}\right)\right], \\
E_{t} R_{t+1}^{b} & =R_{t}^{d}\left[1+\kappa_{b}\left(B_{h, t}-B_{h}\right)\right] .
\end{aligned}
$$

Ultimately, the no-arbitrage conditions (B.5) and (B.6) specify the patient household's optimal holdings of both capital claims and government bonds.

$$
\begin{gathered}
K_{h, t}=K_{h}+E_{t} \beta_{p} \frac{\lambda_{p, t+1}}{\lambda_{p, t}}\left(\frac{R_{t+1}^{k}-R_{t}^{d}}{\kappa_{k}}\right), \\
B_{h, t}=B_{h}+E_{t} \beta_{p} \frac{\lambda_{p, t+1}}{\lambda_{p, t}}\left(\frac{R_{t+1}^{b}-R_{t}^{d}}{\kappa_{b}}\right) .
\end{gathered}
$$

\footnotetext{
${ }^{33}$ For the ease of notation, we only use subscripts $i \in\{m, p\}$ indicating which type of household is meant if necessarily needed.
} 


\section{Appendix B.3 Impatient households}

There is a fraction of $\chi$ impatient households which consume, supply labor and borrow long-term private loans from the banks which gives rise to the following budget constraint in real terms

$$
C_{m, t}+R_{t}^{p} Q_{t-1}^{p} B_{m, t-1}^{p}=W_{t} L_{m, t}+Q_{t}^{p} B_{m, t}^{p},
$$

where $R_{t}^{P}$ and $Q_{t}^{P}$ denote, respectively, the interest rate and price of private loans $B_{m, t}^{p}$. Price and yield of private loans are related through

$$
R_{t}^{p}=\frac{\xi+\kappa_{p} Q_{t}^{p}}{Q_{t-1}^{p}}
$$

where $\xi$ is the coupon (or redemption) and $\kappa_{p}$ denotes the decay factor (Woodford, 1998, 2001). Maximizing (B.1) subject to the impatient households budget constraint (B.9) yields, after some rearranging, an Euler equation for the optimal borrowing and a condition for the labor supply of impatient households:

$$
\begin{aligned}
1 & =\beta_{m} E_{t}\left[\exp \left(\frac{\sigma_{c}-1}{1+\sigma_{l}}\left(L_{m, t+1}^{1+\sigma_{l}}-L_{m, t}^{1+\sigma_{l}}\right)\right)\left(\frac{C_{m, t+1}-h C_{m, t}}{C_{m, t}-h C_{m, t-1}}\right)^{-\sigma_{c}}\right] R_{t}^{p}, \\
W_{t}^{h} & =\left(C_{m, t}-h C_{m, t-1}\right) L_{m, t}^{\sigma_{l}} .
\end{aligned}
$$

\section{Appendix B.4 Firm sectors}

The model contains three types of firms. Intermediate goods are produced by perfectly competitive firms, which use capital and labor as inputs for production. Monopolistically competitive retailers buy a continuum of intermediate goods, and assemble them into a final good. Nominal frictions make the retailers optimization problem dynamic. Additionally, a capital producing sector buys up capital from the intermediate good producer, repairs it, and builds new capital, which it sells to the intermediate good sector again. Investment in new capital is subject to investment adjustment costs.

\section{Intermediate good producers}

Intermediate good producers are in monopolistic competition, employ labor and capital services from households, and set their prices as markups over the marginal cost. Firm $i$ produces according to the Cobb-Douglas Function

$$
Y_{m, t}(i)=e^{z_{t}} \bar{K}_{t}(i)^{\alpha}\left(\gamma^{t} L_{t}(i)\right)^{1-\alpha}-\gamma^{t} \bar{\Phi}
$$

Here, $Y_{m, t}(i)$ are intermediate goods, $z_{t}$ is a TFP-shock, $\bar{K}_{t}(i)$ is the effective capital used in production defined as $\bar{K}_{t}(i)=U_{t}(i) K_{t-1}(i)$, and parameter $\alpha$ is the output elasticity with respect to effective capital. $\gamma^{t}$ represents the labor-augmenting growth rate in the economy, and $\bar{\Phi}$ is the fixed cost of production.

At the end of each period the intermediate good producer sells the capital stock that it used for production to the capital producer which repairs the capital, and purchases the capital stock that it is going to use in the next period from the capital producer. To finance the purchase of the new capital at the price $Q_{t}$ per unit, it issues a claim for each unit of capital it acquires to banks, which trade at the same price. The interest rate the firm has to pay on the loans is $R_{t}^{k}$. Under the assumption that the competitive 
firms make zero profits, the interest rate on their debt will just equal the realized ex-post return on capital. Furthermore, we assume that the firm incurs costs of capital utilization that are proportional to the amount of capital used, $\Psi\left(U_{t}\right) P_{m, t} K_{t-1}$. This assumptions for the utilization costs are set to match the setting in Smets and Wouters (2007). In steady state it holds that $a(\cdot)=0$. The operating profit of firm $i$ is therefore

$$
P_{m, t}(i) Y_{t}(i)-W_{t} L_{t}(i)-a\left(U_{t}(i)\right) P_{m, t} K_{t-1}(i) .
$$

Note that $P_{m, t}$, the price of the intermediate good, represents the marginal cost from the viewpoint of final good producers, which purchase intermediate goods. Each period the firm determines its optimal capital purchase by maximizing

$E_{t}\left[\beta \Lambda_{t, t+1}\left(-R_{t+1}^{k} Q_{t} K_{t}(i)+P_{m, t+1}(i)\left[Y_{m, t+1}(i)-\Psi\left(U_{t}(i)\right) K_{t}(i)\right]-W_{t+1} L_{t+1}(i)+(1-\delta) Q_{t+1} K_{t}(i)\right)\right]$

with respect to $K_{t}(i)$. As all firms make the same decisions, we can drop the index $i$. In optimum the ex-post return then is as follows

$$
R_{t+1}^{k}=\frac{P_{m, t+1}\left[\alpha \frac{Y_{m, t+1}}{K_{t}}-\Psi\left(U_{t+1}\right)\right]+(1-\delta) Q_{t+1}}{Q_{t}} .
$$

Additionally, the choices for optimal labor input and optimal capital utilization yield the first order conditions

$$
\begin{aligned}
W_{t} & =P_{m, t}(1-\alpha) \frac{Y_{m, t}}{L_{t}} . \\
\Psi^{\prime}\left(U_{t}\right) K_{t-1} & =\alpha \frac{Y_{m, t}}{U_{t}} \Leftrightarrow \Psi^{\prime}\left(U_{t}\right)=\alpha \frac{Y_{m, t}}{\bar{K}_{t}}
\end{aligned}
$$

Capital good producers

Capital evolves according to the following law of motion

$$
K_{t}=(1-\delta) K_{t-1}+v_{i, t}\left(1-S\left(\frac{I_{t}}{I_{t-1}}\right)\right) I_{t},
$$

where $\delta$ is the depreciation rate and the function $S(\cdot)$, indicates a cost of adjusting the level of investment. In steady state it holds that $S=0, S^{\prime}=0$, and $S^{\prime \prime}>0$. and $v_{i, t}$ follows an AR(1) process in logs. The capital good producer's role in the model is to isolate the investment decision that becomes dynamic through the introduction of convex investment adjustment costs, which is a necessary feature to generate variation in the price of capital. Capital good producers buy the used capital, restore it and produce new capital goods. Since capital producers buy and sell at the same price, the profit they make is determined by the difference between the quantities sold and bought, i.e. investment. Capital producers bear the resource costs associated with changes in investment. They 
choose the optimal amount of investment to maximize

$$
E_{0} \sum_{t=0}^{\infty} \beta^{t} \Lambda_{0, t}\left\{Q_{t}\left(1-S\left(\frac{I_{t}(k)}{I_{t-1}(k)}\right)\right) v_{i, t}-1\right\} I_{t}
$$

The first order condition of the capital producer reads

$$
\begin{aligned}
1= & Q_{t} v_{i, t}\left(1-S\left(\frac{I_{t}}{I_{t-1}}\right)-S^{\prime}\left(\frac{I_{t}}{I_{t-1}}\right) \frac{I_{t}}{I_{t-1}}\right) \\
& +E_{t}\left\{\Lambda_{t, t+1} Q_{t+1} v_{i, t+1} S^{\prime}\left(\frac{I_{t+1}}{I_{t}}\right)\left(\frac{I_{t+1}}{I_{t}}\right)^{2}\right\}
\end{aligned}
$$

\section{Final good producers}

Final good producers buy the goods produced by the intermediate good producers and sell them to final good producers. They act under monopolisitic competition. Each period, retailers firms face a constant probability of being able to optimally adjust their prices, $\zeta_{p}$. Those firms, which cannot optimally adjust their prices in a given period, index their prices to a weighted average of last periods inflation and steady state inflation. These assumptions give rise to the following maximization problem for firm $i$

$$
\begin{array}{r}
\max _{P_{t}(i)} E_{t} \sum_{s=0}^{\infty}\left(\beta \zeta_{p}\right)^{s} \frac{\Lambda_{t, t+s}}{\Pi_{t, t+s}}\left[P_{t}(i) \Pi_{l=1}^{s}\left(\Pi_{t+l-1}^{1_{p}} \Pi^{1-1_{p}}\right)-M C_{t+s}\right] Y_{t+s}(i) \\
\text { s.t. } \quad \frac{Y_{t+s}(i)}{Y_{t+s}}=G^{\prime-1}\left(\frac{P_{t}(i) \Pi_{l=1}^{s}\left(\Pi_{t+l-1}^{1 p} \Pi^{1-1_{p}}\right)}{P_{t+s}} \tau_{t+s}\right) .
\end{array}
$$

$P_{t}(i)$ is the price set by firm $i, \Pi_{t, t+s}$ is the accumulated change in the aggregate price level between periods $t$ and $t+s, \Lambda_{t, t+s}$ is the stochastic discount factor of the firm, $Y_{t+s}$ is the demand by final good firms for intermediate goods. Parameter $1_{p}$ is the degree of price indexation. Function $G$ governs how the relative price of firm $i$ affects the amounts of goods it can sell. We make the same assumptions on G as Smets and Wouters (2007). ${ }^{34}$ Furthermore, $\tau_{t+s} \equiv \int_{0}^{1} G^{\prime}\left(\frac{Y_{t+s}(i)}{Y_{t+s}}\right) \frac{Y_{t+s}(i)}{Y_{t+s}} d i$. The aggregate price index is in this case given by

$$
P_{t}=\left[\left(1-\zeta_{p}\right)\left(P_{t}^{*}\right) G^{\prime}-1\left[\frac{P_{t}^{*} \tau_{t}}{P_{t}}\right]+\zeta_{p} \Pi_{t-1}^{1 p} \Pi^{\left(1-1_{p}\right)} P_{t-1} G^{\prime-1}\left[\frac{\left.\Pi_{t-1}^{1_{p}} \Pi^{\left(1-1_{p}\right)}\right) P_{t-1} \tau_{t}}{P_{t}}\right]\right.
$$

where $P_{t}^{*}$ is the optimal price in period $t$. The price markup set by final goods producers, $v_{p, t}$, is time-varying and subject to markup shocks, $v_{p, t}$, which follow an $\operatorname{AR}(1)$-process in $\log \mathrm{s}$.

\footnotetext{
${ }^{34}$ That is that $G^{\prime}>0, G^{\prime \prime}<0$, and $G(1)=1$. As shown by Kimball (1995), the assumptions on $\mathrm{G}$ imply that the demand for a good is decreasing in its relative price, and that the elasticity of demand for a good increases with its relative price, which in turn implies a higher persistence of aggregate inflation dynamics.
} 


\section{Retailers}

Retailers act under perfect competition. They buy the goods from final good producers, bundle them in final goods. and sell them to the public. Their maximization problem reads

$$
\begin{array}{r}
\max _{Y_{t}, Y_{t}(i)} P_{t} Y_{t}-P_{t}(i) Y_{t}(i) \\
\text { s.t. }\left[\int_{0}^{1} G\left(\frac{Y_{t}(i)}{Y_{t}}, \lambda_{p, t}\right) d i\right]=1 .
\end{array}
$$

\section{Unions and Labor Packers}

The supply of labor to intermediate good firms is organized by unions and labor packers. Households of both types supply labor to a labor union, which differentiates the labor services and sets wages. Unions act in monopolistic competition with each other and set their wages, $W_{t}(i)$, as a markup over the average marginal rate of substitution between consumption and leisure of households. We assume that the wage setting process, in the same way as price setting, is subject to a Calvo type friction, and that unions, which cannot adjust their wages in a given period, index their last wage to a weighted average of last periods inflation and steady state inflation. Labor packers buy the labor services from unions, bundle them, and provide them to intermediate good firms at the wage $W_{t}$. Thus, the maximization problem of labor packers is

$$
\begin{array}{r}
\max _{L_{t}, L_{t}(i)} W_{t} L_{t}-W_{t}(i) L_{t}(i) \\
\text { s.t. }\left[\int_{0}^{1} G_{w}\left(\frac{L_{t}(i)}{L_{t}}, \lambda_{w, t}\right) d i\right]=1,
\end{array}
$$

where $L_{t}$ is labor provided by labor packers to intermediate good firms, $L_{t}(i)$ denotes the labor services sold by unions to labor packers, and $G_{w}$ is the labor aggregator on which we make the same assumptions as on G. The wage markup, $\lambda_{w, t}$, is time-varying and subject to wage markup shocks, $v_{w, t}$, which follows an $\mathrm{AR}(1)$-process in logs.

Labor unions observe the average marginal rate of substitution between consumption and leisure of all households and charge a markup on top of it. Their maximization problem is

$$
\begin{array}{r}
\max _{W_{t}(i)} E_{t} \sum_{s=0}^{\infty}\left(\beta \zeta_{w}\right)^{s} \frac{\Lambda_{t, t+s}}{\Pi_{t, t+s}}\left[W_{t}(i) \Pi_{l=1}^{s}\left(\Pi_{t+l-1}^{1 w} \Pi^{1-1_{w}}\right)-W_{t+s}^{h}\right] L_{t+s}(i) \\
\text { s.t. } \frac{L_{t+s}(i)}{L_{t+s}}=G_{w}^{\prime-1}\left(\frac{W_{t}(i) \Pi_{l=1}^{s}\left(\Pi_{t+l-1}^{1 w} \Pi^{1-1_{w}}\right)}{W_{t+s}} \tau_{t+s}^{w}\right) .
\end{array}
$$

$W_{t}(i)$ is the wage set by union, $i . W_{t}^{h}$ is the households' marginal rate of substitution between consumption and leisure (i.e. the wage that would prevail in the absence of wage setting power). Parameter $1_{w}$ is the degree of wage indexation, and $\tau_{t+s}^{w} \equiv \int_{0}^{1} G_{w}^{\prime}\left(\frac{L_{t+s}(i)}{L_{t+s}}\right) \frac{L_{t+s}(i)}{L_{t+s}} d i$. The aggregate wage index is in this case given by 
$W_{t}=\left[\left(1-\zeta_{w}\right)\left(W_{t}^{*}\right) G_{w}^{\prime-1}\left[\frac{W_{t}^{*} \tau_{t}^{w}}{W_{t}}\right]+\zeta_{w} \Pi_{t-1}^{1 w} \Pi^{\left(1-1_{w}\right)}\right) W_{t-1} G_{w}^{\prime-1}\left[\frac{\left.\Pi_{t-1}^{1_{w}} \Pi^{\left(1-1_{w}\right)}\right) W_{t-1} \tau_{t}^{w}}{W_{t}}\right]$,

where $W_{t}^{*}$ is the optimal wage set by labor unions in period $t$.

\section{Appendix B.5 Banks}

The banking sector builds on Gertler and Karadi (2013) with some extensions that we outline below. Banks collect deposits $D_{t}$ from patient households and - together with their own net worth $N_{t}$ - use these funds to extend loans $B_{b, t}^{p}$ to impatient households, purchase capital securities from intermediate good producers, $K_{b, t}$, and purchase government bonds $B_{b, t}$. Given these financial operations, the balance sheet of a representative bank then follows as

$$
Q_{t} K_{b, t}+Q_{t}^{b} B_{b, t}+Q_{t}^{p} B_{b, t}^{p}=N_{t}+D_{t}+L_{t}^{q},
$$

where $L_{t}^{q}$ denotes exogenous emergency liquidity injections by the Federal Reserve. For simplicity, we assume that central bank liquidity is lent at a zero nominal interest rate (i.e. their real rate equals $R_{t}^{L}=1 / \Pi_{t+1}$, where $\Pi_{t}$ denotes gross inflation). Banks retain their earnings and add it to their current net worth. This gives rise to the following law of motion for the bank's net worth

$$
\begin{array}{r}
N_{t}=R_{t}^{k} Q_{t-1} K_{b, t-1}+R_{t}^{b} Q_{t-1}^{b} B_{b, t-1}+R_{t}^{p} Q_{t-1}^{p} B_{b, t-1}^{p} \\
-R_{t-1}^{d} D_{t-1}-R_{t-1}^{L} L_{t-1}^{q} .
\end{array}
$$

Note that while the interest rate on deposits raised in period $t-1$ is determined in the same period, the return of assets is risky and only determined after the realization of shocks at the beginning of period $t$.

Bankers continue accumulating their net worth until they (involuntarily) exit the business, which occurs randomly with exogenous probability, $1-\theta$. Conversely, bankers continue their operations with probability $\theta$. Draws from this lottery are i.i.d. and do not depend on the banker's history. When a banker leaves the sector, she adds her terminal wealth, $V_{t}$, to the wealth of the patient household she is member of. Therefore, bankers seek to maximize the expected discounted terminal value of their wealth

$$
\begin{aligned}
V_{t} & =\max E_{t} \sum_{i=0}^{\infty}(1-\theta) \theta^{i} \beta_{p}^{i+1} \frac{\Lambda_{p, t+1+i}}{\Lambda_{p, t+i}} N_{t+1+i}, \\
& =\max E_{t}\left[\beta_{p} \frac{\Lambda_{p, t+1}}{\Lambda_{p, t}}(1-\theta) N_{t+1}+\theta V_{t+1}\right],
\end{aligned}
$$

where $\Lambda_{p, t}$ denotes the patient household's Lagrangian multiplier with respect to the budget constraint.

Banks operate under perfect competition. If financial intermediation was frictionless, the risk adjusted return on the bank's asset should equal the return on deposits. As in Gertler and Karadi (2013), however, bankers can divert a fraction of their assets and 
transfer it to their respective households. If they do so, their depositors will withdraw their remaining funds and force the bank into bankruptcy. This moral hazard/costly enforcement problem creates an endogenous limit to the amount of deposits that households are willing to supply. While the latter ensures that bankers earn a strictly positive excess return, it also creates limits to arbitrage, as bankers can not scale-up their balance sheet to arbitrage away any price differences. In order to prevent a banker from diverting a fraction of assets, households keep their deposits at a bank only as long as the bank's continuation value is higher or equal to the amount that the bank can divert. Formally, the latter condition is given by the following incentive compatibility constraint of the bank

$$
V_{t} \geq \lambda_{k, t} Q_{t} K_{b, t}+\lambda_{b} Q_{t}^{b} B_{b, t}+\lambda_{p} Q_{t}^{p} B_{b, t}^{p}-\lambda_{L} L_{t}^{q},
$$

where $\lambda_{j}$ for $j \in\{k, p, b\}$ denotes the respective fraction of capital claims, government bonds or private loans that the bank can diverted. Following Dedola et al. (2013) and Gelain and Ilbas (2017), we allow $\lambda_{k, t}$ to be time-varying, formally following an AR(1) process in logs with mean $\lambda_{k}$. Ultimately, this shock triggers variations in the divertiblity of capital assets and can be interpreted as variations in the trust depositors have in the quality of banks' capital assets.

In steady state, the $\lambda_{j}$ 's for $j \in\{k, p, b\}$ determine - together with other estimated parameters such as the discount factor of patient households, $\beta_{p}$, and the trend growth rate, $\gamma$ - the returns on capital claims and government bonds, $R^{k}$ and $R^{b}$, as well as the private loan rate $R^{p}$. The respective excess returns over the deposit rate imply that $\lambda_{b}<\lambda_{p}<\lambda_{k}$, which intuitively can be motivated by the fact that, in general, the collateral value of government bonds is higher than that of mortgage loans and capital claims. ${ }^{35}$ Finally, the last term in the incentive constraint is due to the assumption that liquidity injections serve to relax the incentive constraint of banks.

To solve the bank problem, let an initial guess of the value function be of the form

$$
V_{t}=\nu_{k, t} Q_{t} K_{b, t}+\nu_{b, t} Q_{t}^{b} B_{b, t}+\nu_{p, t} Q_{t}^{p} B_{b, t}^{p}+\nu_{n, t} N_{t}+\nu_{L, t} L_{t}^{q},
$$

where $\nu_{k, t}, \nu_{b, t}, \nu_{p, t}, \nu_{d, t}$, and $\nu_{L, t}$ are time-varying coefficients. Maximizing (B.31) with respect to $K_{b, t}, B_{b, t}$ and $B_{b, t}^{p}$ subject to (B.30) yields the following first order conditions for capital claims, governments bonds, private loans, and $\mu_{t}$, the Lagrangian multiplier on the incentive compatibility constraint

$$
\begin{aligned}
\nu_{k, t} & =\lambda_{k, t} \frac{\mu_{t}}{1+\mu_{t}}, \\
\nu_{b, t} & =\lambda_{b} \frac{\mu_{t}}{1+\mu_{t}}, \\
\nu_{p, t} & =\lambda_{p} \frac{\mu_{t}}{1+\mu_{t}} \\
\nu_{n, t} N_{t}+\nu_{L, t} L_{t}^{q} & =\left(\lambda_{k, t}-\nu_{k, t}\right) Q_{t} K_{b, t}+\left(\lambda_{b}-\nu_{b, t}\right) Q_{t}^{b} B_{b, t}+\left(\lambda_{p}-\nu_{p, t}\right) Q_{t}^{p} B_{b, t}^{p} .
\end{aligned}
$$

Given that the incentive compatibility constraint binds ${ }^{36}$, we can rewrite the last equation

\footnotetext{
${ }^{35}$ In a similar vein, Meeks et al. (2017) use the same approach to distinguish between the collateral values of loans and asset-backed securities.

${ }^{36}$ The constraint binds in the neighborhood of the steady state. For convenience, we make the as-
} 
above as

$$
Q_{t} K_{b, t}=\frac{\nu_{b, t}-\lambda_{b}}{\lambda_{k, t}-\nu_{k, t}} Q_{t}^{b} B_{b, t}+\frac{\nu_{p, t}-\lambda_{p}}{\lambda_{k, t}-\nu_{k, t}} Q_{t}^{p} B_{b, t}^{p}+\frac{\nu_{L, t}+\lambda_{L}}{\lambda_{k, t}-\nu_{k t}} L_{t}^{q}+\frac{\nu_{n, t}}{\lambda_{k, t}-\nu_{k, t}} N_{t} .
$$

Intuitively, (B.36) states that banks' demand for capital claims decreases in $\lambda_{j}$ for $j \in$ $\{k, p, b\}$, which regulate the tightness of the incentive constraint with respect to capital claims, mortgage loans over government bonds. Central bank liquidity injections $L_{t}^{q}$, on other hand, support the demand for capital claims.

Substituting the demand for capital claims into (B.31), and combining the result with (15) one can write the terminal value of the banker as a function of its net worth

$$
V_{t}=\left(1+\mu_{t}\right) \nu_{n t} N_{t}+\left[\left(1+\mu_{t}\right) \nu_{L, t}+\mu_{t} \lambda_{L}\right] L_{t}^{q}
$$

A higher continuation value, $V_{t}$, is associated with a higher shadow value of holding an additional marginal unit of assets, or put differently, with a higher shadow value of marginally relaxing the incentive compatibility constraint. Then, define the bank's stochastic discount factor as

$$
\Omega_{t} \equiv \frac{\Lambda_{p, t}}{\Lambda_{p, t-1}}\left[(1-\theta)+\theta\left(1+\mu_{t}\right) \nu_{n, t}\right]
$$

and substitute (B.37) into the Bellman equation (B.29). Using the law of motion for net worth (B.28), one can then write the value function as

$$
\begin{aligned}
V_{t}=\beta_{p} E_{t} & {\left[\Omega _ { t + 1 } \left(\left(R_{t+1}^{k}-R_{t}^{d}\right) Q_{t} K_{b, t}+\left(R_{t+1}^{b}-R_{t}^{d}\right) Q_{t}^{b} B_{b, t}\right.\right.} \\
& \left.\left.+\left(R_{t+1}^{p}-R_{t}^{d}\right) Q_{t}^{p} B_{b, t}^{p}+\left(R_{t}^{d}-R_{L, t}\right) L_{t}^{q}+R_{t}^{d} N_{t}\right)\right] \\
& +\beta_{p} E_{t}\left[\frac{\Lambda_{p, t+1}}{\Lambda_{p, t}} \theta\left[\left(1+\mu_{t+1}\right) \nu_{L, t+1}+\mu_{t+1} \Lambda_{L}\right] L_{t+1}^{q}\right]
\end{aligned}
$$

Finally, verifying the initial guess for the value function yields

$$
\begin{aligned}
\nu_{k, t} & =\beta_{p} E_{t} \Omega_{t+1}\left(R_{t+1}^{k}-R_{t}^{d}\right) \\
\nu_{b, t} & =\beta_{p} E_{t} \Omega_{t+1}\left(R_{t+1}^{b}-R_{t}^{d}\right) \\
\nu_{p, t} & =\beta_{p} E_{t} \Omega_{t+1}\left(R_{t+1}^{p}-R_{t}^{d}\right) \\
\nu_{n, t} & =\beta_{p} E_{t} \Omega_{t+1} R_{t}^{d} \\
\nu_{L, t} & =\beta_{p} E_{t}\left[\Omega_{t+1}\left(R_{t}^{d}-R_{t}^{L}\right)+\theta \rho_{c b l} \frac{\Lambda_{p, t+1}}{\Lambda_{p, t}}\left[\left(1+\mu_{t+1}\right) \nu_{L, t+1}+\mu_{t+1} \lambda_{L}\right]\right]
\end{aligned}
$$

where the last equality follows from the fact that $L_{t}^{q}$ follows an $\operatorname{AR}(1)$ in $\operatorname{logs}$ with persistence parameter $\rho_{c b l}$.

sumption that it is binding throughout all experiments. 


\section{Appendix B.6 Policy and market clearing}

The policy makers in our model are the central bank as conductor of interest rate policy and QE, and the government sector.

\section{Monetary Policy}

We model conventional monetary policy as a standard reaction function with the central bank responding to deviations of inflation from it's target, the output gap and its growth rate

$$
\frac{R_{t}^{s}}{R^{n}}=\left(\frac{R_{t-1}^{s}}{R^{n}}\right)^{\rho_{R}}\left[\left(\frac{\Pi_{t}}{\Pi}\right)^{\phi_{\pi}}\left(\frac{Y_{t}}{Y_{t}^{*}}\right)^{\phi_{y}}\left(\Delta\left(\frac{Y_{t}}{Y_{t}^{*}}\right)\right)^{\phi_{d y}}\right]^{1-\rho_{R}} v_{r, t},
$$

with the ZLB constraint

$$
R_{t}^{n}=\max \left\{\bar{R}, R_{t}^{s}\right\}
$$

where we refer to the unconstrained nominal rate $R_{t}^{s}$ as the notational (or shadow) rate. $Y_{t}^{*}$ denotes the potential output and $\Delta\left(\frac{Y_{t}}{Y_{t}^{*}}\right)$ denotes the growth in the output gap. The parameter $\rho_{R}$ expresses an interest rate smoothing motive by the central bank over the notational rate and $\phi_{\pi}, \phi_{y}$ and $\phi_{d y}$ are feedback coefficients. The max-operator in (B.45) reflects the zero lower bound (ZLB) on the nominal interest rate $R_{t}^{n}$, which we take into account in our estimation procedure. For this purpose, $\bar{R}$ denotes the exact level at which the ZLB binds. ${ }^{37}$ When the economy is away from the ZLB, the stochastic process $v_{r, t}$ which follows an AR(1) in logs - represents a regular interest rate shock. However, when the nominal interest rate is zero, $v_{r, t}$ may not directly affect the level of the nominal interest rate. Instead, $v_{r, t}$ affects the expected path of the notational rate, first through it's own persistence and second through the persistence in the notional rate, and therefore alter the expected duration of the lower bound spell. At the ZLB, it can hence be viewed as a forward guidance shock.

We capture emergency liquidity injections with as an exogenous variable that eases banks' incentive compatibility constraint (B.30) and thereby stimulates lending. In our estimation, we feed these liquidity injections into the model and assume they follow $\operatorname{AR}(1)$ process in logs. That is, formally

$$
\tilde{L}_{t}=\rho_{c b l} \tilde{L}_{t-1}+\epsilon_{C B L, t},
$$

where $\tilde{L} \equiv \frac{L_{t}^{q}}{P_{t} Y_{t}}$ denotes central bank liquidity as percentage of GDP.

In our analysis, we divide large scale asset purchases into private (capital) security purchases and government bond purchases, both which we assume to follow an $\mathrm{AR}(2)$ process in logs.

$$
\begin{aligned}
\tilde{K}_{c b, t} & =\rho_{k, 1} \tilde{K}_{c b, t-1}+\rho_{k, 2} \tilde{K}_{c b, t-2}+\epsilon_{Q E K, t}, \\
\tilde{B}_{c b, t} & =\rho_{b, 1} \tilde{B}_{c b, t-1}+\rho_{b, 2} \tilde{B}_{c b, t-2}+\epsilon_{Q E B, t} .
\end{aligned}
$$

\footnotetext{
${ }^{37}$ Given that, empirically, the Federal Funds rate remained strictly above zero, we choose $\bar{R}$ to be slightly above one in our estimation. Moreover, due to the fact that the Fed never implemented negative rates, we use the term "zero lower bound" and "effective lower bound" interchangeably.
} 
Similar to the liquidity injections, $\tilde{K}$ and $\tilde{B}$ denote, respectively, the central banks capital claim and government bond purchases as a fraction of GDP.

\section{Fiscal policy and market clearing}

Government spending, $G_{t}$, is exogenous and follows an $\operatorname{AR}(1)$ process

$$
\begin{aligned}
G_{t} & =G e^{g_{t}}, \\
\text { and } \quad g_{t} & =\rho_{g} g_{t-1}+\epsilon_{t}^{g},
\end{aligned}
$$

where $G$ is the steady state government consumption, $\rho_{g}$ is the autocorrelation of government consumption, and $\epsilon_{t}^{g}$ is a shock to government spending. The government finances its expenditures, by issuing government bonds, which are bought by banks and the central bank, as well as by raising lump sum taxes, $T_{t}$. Taxes follow a simple feedback rule, such that they are sensitive to the level of public debt,

$$
T_{t}=T+\kappa_{b}\left(B_{t-1}-B\right),
$$

where $T$ and $B$ are the steady state levels of tax revenue and government debt, respectively. $\kappa_{b}$ is set to ensure that the real value of debt grows a rate smaller than the gross real rate on government debt. As shown by Bohn (1998), this rule is a sufficient condition to guarantee the solvency of the government. Bonds are modeled analogously to private securities by impatient households.

$$
R_{t}^{b}=\frac{\xi+\kappa_{b} Q_{t}^{b}}{Q_{t-1}^{b}} .
$$

The flow budget constraint of the government reads

$$
G_{t}+R_{t}^{b} Q_{t-1}^{b} B_{t-1}=Q_{t}^{b} B_{t}+T_{t}
$$

Finally, the aggregate resource constraint in real terms reads

$$
Y_{t}=C_{t}+I_{t}+G_{t}+a\left(U_{t}\right) K_{t-1},
$$

where the last term on the right hand side of the equation marks the resource costs of adjusting the utilization of installed capital.

\section{Appendix B.7 Linearized Equilibrium conditions}

This subsection briefly presents the linearized equilibrium conditions. Small letters denote the log-deviation of the corresponding variable from its steady state value.

\section{Non-financial part of the economy}

With the exception of equations (B.59), (B.60), the equation for the return on capital and the considerations of household heterogeneity, the equations in this subsections are identical to those of the model by Smets and Wouters (2007).

Equation (B.55 and B.56) are the Euler equation for consumption for patient and impatient households. The presence of habit formation justifies the presence of lagged 
consumption in the equation.

$$
\begin{array}{r}
c_{t}^{p}=\frac{h / \gamma}{(1+h / \gamma)} c_{t-1}^{p}+\frac{1}{1+h / \gamma} E_{t}\left[c_{t+1}^{p}\right]+ \\
-\frac{\left(\sigma_{c}-1\right)\left(W^{h} L / C\right)}{\sigma_{c}(1+h / \gamma)}\left(l_{t}^{p}-E_{t}\left[l_{t+1}^{p}\right]\right) \ldots \\
(1+h / \gamma) \sigma_{c} \\
\left.-r_{t}^{n}-E_{t}\left[\pi_{t+1}\right]+v_{u, t}\right), \\
c_{t}^{m}=\frac{h / \gamma}{(1+h / \gamma)} c_{t-1}^{m}+\frac{1}{1+h / \gamma} E_{t}\left[c_{t+1}^{m}\right]+\frac{\left(\sigma_{c}-1\right)\left(W^{h} L / C\right)}{\sigma_{c}(1+h / \gamma)}\left(l_{t}^{m}-E_{t}\left[l_{t+1}^{m}\right]\right) \ldots \\
-\frac{(1-h / \gamma)}{(1+h / \gamma) \sigma_{c}}\left(r_{t+1}^{p}\right) .
\end{array}
$$

The deposit rate is given by

$$
r_{t}^{d}=r r_{t}+v_{u, t},
$$

and the relationship between the real and the nominal interest rate is given by the Fisher equation

$$
r r_{t}=r_{t}^{n}-E_{t}\left[\pi_{t+1}\right] .
$$

The linearized conditions that relate to the patient households' choices of capital assets and government bonds are

$$
\begin{gathered}
\kappa_{K} K_{h} k_{h, t}=\left(R^{k}-R\right)\left(-r_{t}^{d}\right)+R^{k} r_{t+1}^{k}-R^{d} r_{t}^{d}, \\
\kappa_{B} B_{h} b_{h, t}=\left(R^{b}-R\right)\left(-r_{t}^{d}\right)+R^{b} r_{t+1}^{b}-R^{d} r_{t}^{d} .
\end{gathered}
$$

The linearized link between price and return on private bonds reads

$$
-R^{p}\left(r_{t}^{p}+q_{t-1}^{p}\right)=\kappa_{p} q_{t}^{p} .
$$

The efficient wage equals the marginal rate of substitution between consumption and leisure for both household types reads

$$
\begin{gathered}
w_{t}^{h}=\frac{1}{(1-h \gamma)}\left(c_{t}^{m}-h \gamma c_{t-1}^{m}\right)+\sigma_{l} l_{t}^{m}, \\
w_{t}^{h}=\frac{1}{(1-h \gamma)}\left(c_{t}^{p}-h \gamma c_{t-1}^{p}\right)+\sigma_{l} l_{t}^{p} .
\end{gathered}
$$

Economy-wide consumption and labor are the aggregates of the corresponding household specific variables

$$
\begin{gathered}
c_{t}=\chi c_{t}^{m}+(1-\chi) c_{t}^{p} \\
l_{t}=\chi l_{t}^{m}+(1-\chi) l_{t}^{p}
\end{gathered}
$$

Equation (B.66) is the linearized first order condition for investment

$$
i_{t}=\frac{1}{1+\bar{\beta}}\left[i_{t-1}\right]+\frac{\bar{\beta}}{1+\bar{\beta}} E_{t}\left[i_{t+1}\right]+\frac{1}{(1+\bar{\beta}) \gamma^{2} S^{\prime \prime}} q_{t}^{k}
$$


where $\bar{\beta}=\beta \gamma^{\left(1-\sigma_{c}\right)}$. The dynamics of investment are governed by Tobins q. $S^{\prime \prime}$ is the steady state value of the second derivative of the investment adjustment cost function. The accumulation equation of physical capital reads

$$
k_{t}=(1-\delta) / \gamma k_{t-1}+(1-(1-\delta) / \gamma) \hat{i}_{t}+(1-(1-\delta) / \gamma)(1+\bar{\beta}) \gamma^{2} S^{\prime \prime} v_{i, t} .
$$

The marginal cost of the firms and the marginal product of capital are given by (B.68) and (B.69), while (B.70) is the equation for the return on capital.

$$
\begin{gathered}
m c_{t}=w_{t}-z_{t}+\alpha\left(l_{t}-\bar{k}_{t}\right) \\
m p k_{t}=w_{t}-\bar{k}_{t}+l_{t} \\
R^{k} r_{t}^{k}=M C * M P K\left(m c_{t}+y_{t}-\bar{k}_{t}\right)+(1-\delta) q_{t}-R^{k} q_{t-1} .
\end{gathered}
$$

The relation between physical capital and effective capital is given by (B.71). Here, parameter $\psi$ is the elasticity of the capital utilization adjustment cost function and normalized to be between zero and one.

$$
\begin{aligned}
& \bar{k}_{t}=u_{t}+k_{t-1} . \\
& u_{t}=\frac{1-\psi}{\psi} m p k_{t} .
\end{aligned}
$$

(B.73) is the aggregate production function, and (B.74) is the aggregate resource constraint.

$$
\begin{gathered}
y_{t}=\Phi\left(\alpha \bar{k}_{t}+(1-\alpha) l_{t}+z_{t}\right) \\
y_{t}=\frac{G}{Y} g_{t}+\frac{C}{Y} c_{t}+\frac{I}{Y} i_{t}+\frac{R^{k} K}{Y} u_{t} \\
\pi_{t}=\frac{\bar{\beta}}{1+\mathrm{1}_{p} \bar{\beta}} E_{t} \pi_{t+1}+\frac{\mathrm{l}_{p}}{1+\mathrm{1}_{p} \bar{\beta}} \pi_{t-1}+\frac{\left(1-\zeta_{p} \bar{\beta}\right)\left(1-\zeta_{p}\right)}{\left(1+\bar{\beta}_{p}\right) \zeta_{p}\left((\Phi-1) \epsilon_{p}+1\right)}\left(w_{t}-z_{t}+\alpha l_{t}-\alpha k_{t}\right)
\end{gathered}
$$

Equation (B.75) is the New Keynesian Phillips curve. The last term in parenthesis corresponds to the marginal cost of production. As we employ the Kimball aggregator, the sensitivity of inflation to fluctuations in marginal cost is affected by the market power of firms, represented by the steady state price markup, $(\Phi-1){ }^{38}$ Furthermore, the curvature of the Kimball aggregator, $\epsilon_{p}$, affects the adjustment of prices to marginal cost, since a higher $\epsilon_{p}$ implies a higher degree of strategic complementarity in price setting

\footnotetext{
${ }^{38}$ Note, that in equilibrium, the fixed cost parameter is related to the steady state price markup by a zero profit condition.
} 
and dampens the price adjustment to shocks.

$$
\begin{aligned}
w_{t}=\frac{1}{1+\bar{\beta} \gamma}\left(w_{t-1}+1_{w} \pi_{t-1}\right) & +\frac{\bar{\beta} \gamma}{1+\bar{\beta} \gamma} E_{t}\left[w_{t+1}+\pi_{t+1}\right]-\frac{1+1_{w} \bar{\beta} \gamma}{1+\bar{\beta} \gamma} \pi_{t} \\
& +\frac{\left(1-\zeta_{w} \bar{\beta} \gamma\right)\left(1-\zeta_{w}\right)}{(1+\bar{\beta} \gamma) \zeta_{w}\left(\left(\lambda_{w}-1\right) \epsilon_{w}+1\right)}\left(w_{t}^{h}-w_{t}\right)
\end{aligned}
$$

Equation (B.76) is the Wage Phillips curve. $w_{t}^{h}$ is the wage that would prevail in the absence of market power by unions. Therefore, $\left(w_{t}-w_{t}^{h}\right)$ is the wage markup. Analogous to equation (B.75), the terms $\lambda_{w}$ and $\epsilon_{w}$ represent the steady state wage markup and the curvature of the Kimball aggregator for labor services.

\section{The financial sector}

The variable $\mu_{t}$ is the Lagrangian multiplier on the incentive constraint of financial intermediaries.

Linearizing the banks' first order conditions for capital assets, bonds and private loans yields

$$
\begin{aligned}
\frac{\lambda_{k}}{\lambda_{k}-\nu_{k}}\left(\hat{\nu}_{k, t}-\hat{\lambda}_{k, t}\right) & =\hat{\mu}_{t}, \\
\nu_{b, t} & =\nu_{k, t}-\lambda_{k, t}, \\
\nu_{b, t} & =\nu_{p, t} .
\end{aligned}
$$

The first order condition for the Lagrangian multiplier of the incentive constraint can be linearized as

$$
\begin{aligned}
&\left(\hat{\lambda}_{k, t}-\hat{\nu}_{k t}\right) K_{b}+\left(\lambda_{k}-\nu_{k}\right) K_{b}\left(q_{t}+k_{b, t}\right)-Q^{b} B_{b}\left(\nu_{b} \hat{\nu}_{b, t}\right. \\
&\left.=\left(\nu_{b}-\lambda_{b}\right)\left(q_{t}^{b}+b_{b, t}\right)\right)+Q^{p} B_{b}^{p}\left(\nu_{p} \hat{\nu}_{p, t}+\left(\nu_{p}-\lambda_{p}\right)\left(q_{t}^{p}+b_{b, t}^{p}\right)\right)+\left(\nu_{L}+\lambda_{L}\right) L_{t}^{q}+\nu_{n} N\left(\hat{\nu}_{n, t}+n_{t}\right)
\end{aligned}
$$

Note: as the steady state of central bank liquidity injections is zero, $L_{t}^{q}$ denotes absolute deviations in the calculations above instead of log-deviations.

The shadow value of capital assets, government bonds and private loans and net worth for financial intermediaries are

$$
\begin{array}{rc}
\nu_{k} \hat{\nu}_{k, t} & =\beta \Omega E_{t}\left(\hat{\Omega}_{t+1}\left(R^{k}-R^{d}\right)+R_{k} r_{t+1}^{k}-R^{d} r_{t}^{d}\right) \\
\nu_{b} \hat{\nu}_{b, t} & =\beta \Omega E_{t}\left(\hat{\Omega}_{t+1}\left(R^{b}-R^{d}\right)+R_{k} r_{t+1}^{b}-R^{d} r_{t}^{d}\right) \\
\nu_{p} \hat{\nu}_{p, t} & =\beta \Omega E_{t}\left(\hat{\Omega}_{t+1}\left(R^{p}-R^{d}\right)+R_{k} r_{t+1}^{p}-R^{d} r_{t}^{d}\right) \\
\hat{\nu}_{n, t} & =E_{t} \hat{\Omega}_{t+1}+r_{t}^{d}
\end{array}
$$

Note, that we can omit the shadow of central bank liquidity injections for financial intermediaries as it does not affect the rest of the equilibrium dynamics.

Acknowledging that $\frac{\Lambda_{p, t}}{\Lambda_{p, t-1}} R_{t}^{d}=1$, we can linearize the stochastic discount factor of 
financila intermediaries as

$$
\Omega \hat{\Omega}_{t}=\Omega r_{t-1}^{d}+\theta\left((1+\mu) \nu_{n} \hat{\nu}_{n, t}+\nu_{n} \mu \hat{\mu}_{t}\right)
$$

The remaining equations are the linearized law of motion of bankers, and the linearized equation, defining the starting capital that new bankers have, when they enter the sector

$$
\begin{aligned}
N n_{t}= & \frac{\theta}{\gamma}\left[\left(R^{k}-R\right) K_{b}\left(q_{t-1}+k_{b, t-1}\right)+R^{k} K_{b} r_{t}^{k}+\left(R^{b}-R\right) Q^{b} B_{b}\left(q_{t-1}^{b}+b_{b, t-1}\right)+Q^{b} B_{b} R^{b} r_{t}^{b}\right. \\
& \left.+B_{b}^{p}\left(q_{t-1}^{p}+b_{b, t-1}^{p}\right)+Q^{p} B_{b}^{p} R^{p} r_{t}^{p}+\left(R-R^{L}\right) L_{t-1}^{q}-R^{d} D r_{t-1}^{d}+R^{d} N n_{t-1}\right]+N n_{n}(\mathrm{~B} .86)
\end{aligned}
$$

and

$$
N_{n} n_{n, t}=\frac{\omega}{\gamma}\left(K_{b}\left(q_{t-1}+k_{b, t-1}\right)+Q^{b} B_{b}\left(q_{t-1}^{b}+b_{b, t-1}\right)+Q^{p} B_{b}^{p}\left(q_{t-1}^{p}+b_{b, t-1}^{p}\right)\right)
$$

Policy and exogenous processes

The fiscal sector can be summarized by the linearized budget constraint, which already entails the tax rule (B.88), and the linearized return on long-term bonds, (B.89).

$$
\begin{gathered}
\frac{R^{b} Q^{b} B}{\gamma}\left(r_{t}^{b}+q_{t-1}^{b}+b_{t-1}\right) * G g_{t}-\kappa_{b} b_{t-1} \frac{B}{\gamma}=Q^{b} B\left(q_{t}^{b}+b_{t}\right), \\
-R^{b}\left(r_{t}^{b}+q_{t-1}^{b}\right)=\kappa_{b} q_{t}^{b}
\end{gathered}
$$

Equation (B.90) is the linearized Taylor rule in terms of the shadow interest rate.

$$
\begin{gathered}
r_{t}^{n}=\max \left\{0, \rho r_{t-1}^{s}+(1-\rho)\left(\phi_{\pi} \pi_{t}+\phi_{y} y_{t}+\phi_{d y}\left(y_{t}-y_{t-1}\right)\right)+v_{r_{t}}\right\}, \\
\tilde{L}_{t}=\rho_{c b l} \tilde{L}_{t-1}+\epsilon_{C B L, t},
\end{gathered}
$$

where $\tilde{L} \equiv \frac{L_{t}^{q}}{P_{t} Y_{t}}$ denotes central bank liquidity as percentage of GDP.

In terms of the overall capital (bond) stock, central bank asset purchases can be written as

$$
\begin{aligned}
& x_{k, t}=k_{t}-\frac{K_{b}}{K} k_{b, t}-\frac{K_{h}}{K} k_{h, t}, \\
& x_{b, t}=b_{t}-\frac{B_{b}}{B} b_{b, t}-\frac{B_{h}}{B} b_{h, t} .
\end{aligned}
$$

In order to match them with the observables, which are defined relative to GDP, they can be rewritten as

$$
\begin{aligned}
\tilde{K}_{c b, t} & =x_{k, t} K /(4 Y), \\
\tilde{B}_{c b, t} & =x_{b, t} B /(4 Y) .
\end{aligned}
$$


Finally, the stochastic drivers of our model are the following eleven processes

$$
\begin{aligned}
v_{u, t} & =\rho_{u} v_{u, t-1}+\epsilon_{t}^{u}, \\
z_{t} & =\rho_{z} z_{t-1}+\epsilon_{t}^{z}, \\
g_{t} & =\rho_{g} g_{t-1}+\epsilon_{t}^{g}+\rho_{g z} z_{t}, \\
v_{r, t} & =\rho_{r} v_{r, t-1}+\epsilon_{t}^{r}, \\
v_{i, t} & =\rho_{i} v_{i, t-1}+\epsilon_{t}^{i}, \\
v_{p, t} & =\rho_{p} v_{p, t-1}+\epsilon_{t}^{p}-\mu_{p} \epsilon_{t-1}^{p}, \\
v_{w, t} & =\rho_{w} v_{w, t-1}+\epsilon_{t}^{w}-\mu_{w} \epsilon_{t-1}^{w}, \\
v_{l k, t} & =\rho_{l k} v_{l k, t-1}+\epsilon_{t}^{l k}, \\
\tilde{K}_{c b, t} & =\rho_{k, 1} \tilde{K}_{c b, t-1}+\rho_{k, 2} \tilde{K}_{c b, t-2}+\epsilon_{Q E K, t}, \\
\tilde{B}_{c b, t} & =\rho_{b, 1} \tilde{B}_{c b, t-1}+\rho_{b, 2} \tilde{B}_{c b, t-2}+\epsilon_{Q E B, t}, \\
\tilde{L}_{t} & =\rho_{c b l} \tilde{L}_{t-1}+\epsilon_{C B L, t} .
\end{aligned}
$$

where the last three processes are the unconventional policy tools employed by the central bank. It holds that $\epsilon_{t}^{k} \stackrel{i i d}{\sim} N\left(0, \sigma_{k}^{2}\right)$ for all $k=\{u, z, g, r, i, p, w, l k, Q E K, Q E B, C B L\}$.

\section{Additional equations}

Additional to the equations above, the model features equations for a flex-price-flexwage equilibrium, which is used to define output under these conditions and consequently the output gap. Also, the codes contain equations to track various excess premia, the leverage ratio, the sum of all unconventional monetary policy measures (e.g. the central banks balance sheet), the notational nominal interest rate, and the equations for the observables.

\section{Appendix C Additional impulse response functions of the benchmark model}

Figures C.14 and C.15 illustrate the impulse response functions with respect to a shock of central bank liquidity provisions and a shock of government bond purchases, respectively. The impulse responses of a conventional monetary policy shock a shown in Figure C.16. 
Output

0.2

0.1

0.0

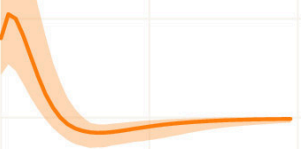

Inflation
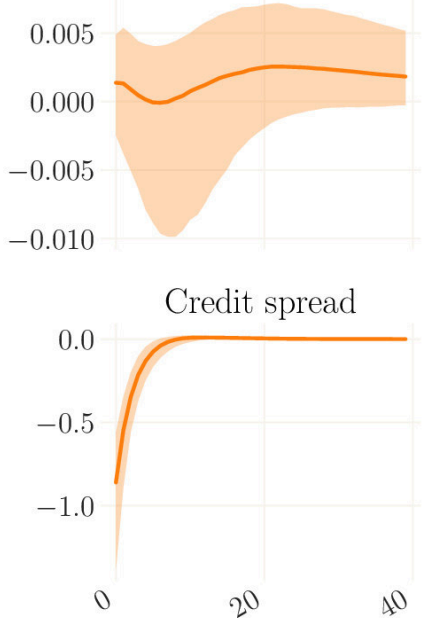

Cons. lending $\mathrm{HH}$

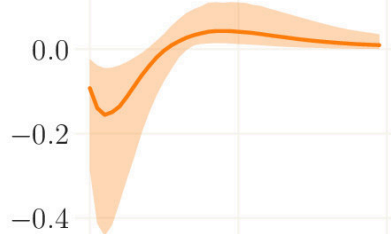

Investment

1.0

0.5

0.0

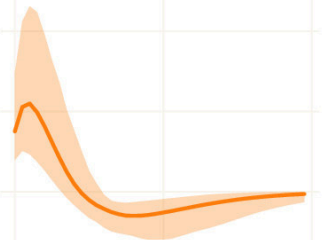

Net worth of banks

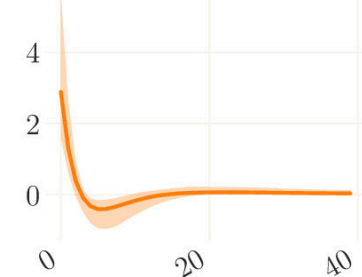

Cons. borrowing $\mathrm{HH}$

2

1

0

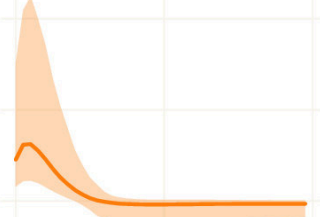

Labor hours

0.2

0.1

0.0

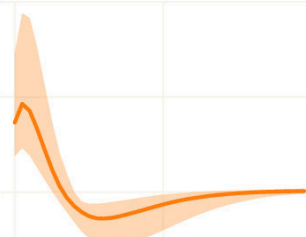

Capital held by banks

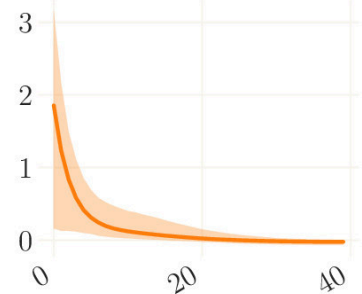

Figure C.14: Impulse response functions with respect to a shock of central bank liquidity provision (in orange). Sampled from the posterior distribution with $95 \%$ confidence intervals. The prior is not shown because it is far broader than the posterior. Displaying it would render the figure less informative.

Note: Posterior sample obtained from 1000 draws from the posterior distribution. Solid lines represent the mean. For each draw, the strength of the shock matches the peak of the empirical time series. Annualized measures where applicable. 
Output

2

0

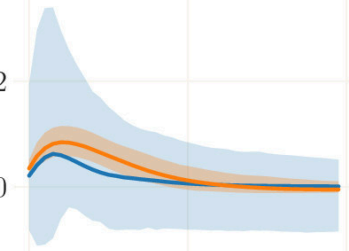

Inflation

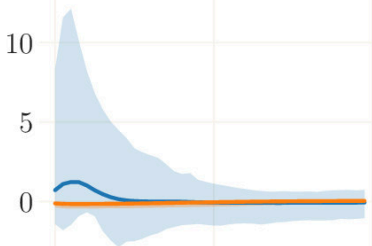

Credit spread

2.5

0.0

$-2.5$

$-5.0$

0
政

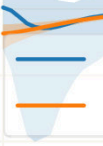

prior

posterior

20
Cons. lending $\mathrm{HH}$

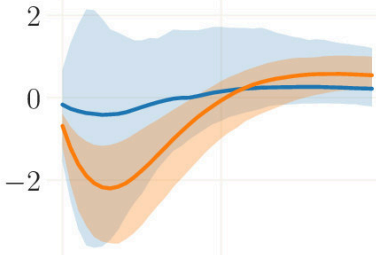

Investment

10

0

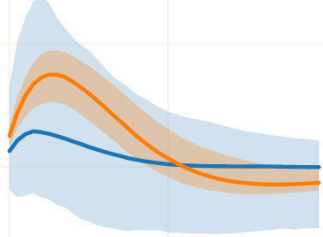

Net worth of banks

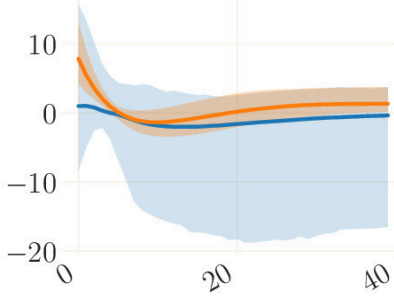

15

Cons. borrowing $\mathrm{HH}$

10

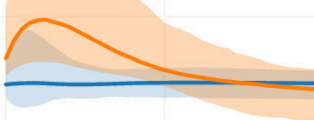

Labor hours

2

0

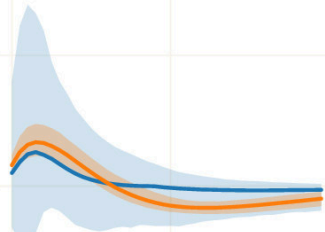

Capital held by banks

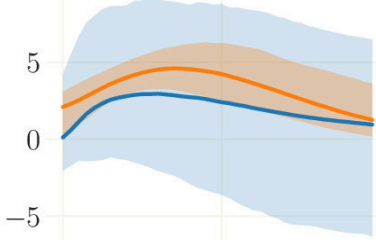

20

40

Figure C.15: Impulse response functions with respect to a shock of government bond purchases (in orange). Sampled from the posterior distribution with $95 \%$ confidence intervals. In blue: impulse responses sampled from the prior.

Note: Posterior sample obtained from 1000 draws from the posterior distribution. Solid lines represent the mean. For each draw, the strength of the shock is chosen such that the peak of the corresponding stochastic process matches the peak of the empirical time series. See Appendix F for details. The prior sample is obtained from 2000 draws, account for strong heterogeneity of effects. Prior draws adjusted for high autoregressive coefficients with mean/std of 0.9 and 0.05 because AR-coefficients are identified independently from the model. 
Output

4

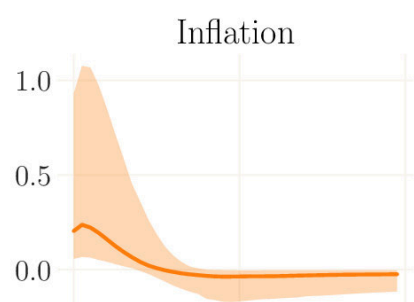

Credit spread

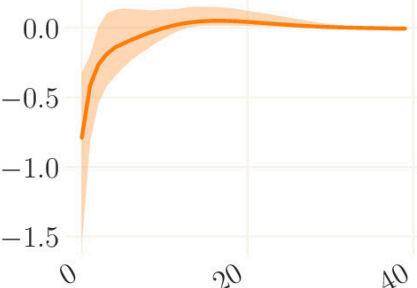

Cons. lending $\mathrm{HH}$

3

2

1

0

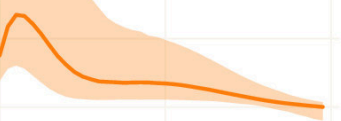

Investment

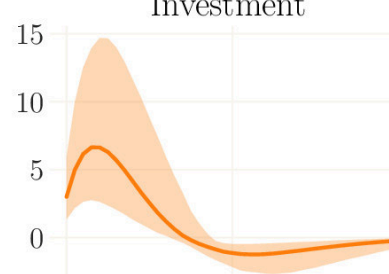

Net worth of banks

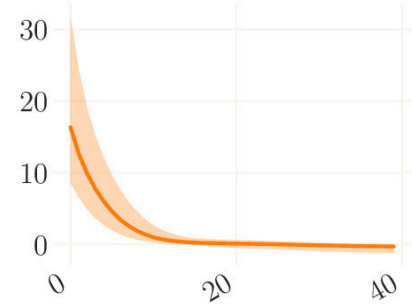

Cons. borrowing $\mathrm{HH}$

4

2

0

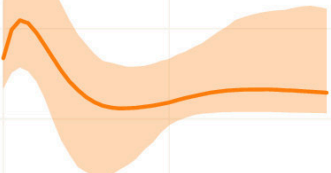

Labor hours

4

0

Capital held by banks

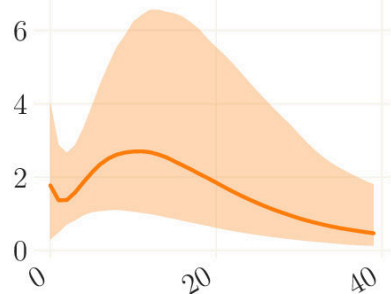

Figure C.16: Impulse response functions to an accommodative 100 basis point monetary policy shock. Sampled from the posterior distribution with $95 \%$ confidence intervals.

Note: Posterior sample obtained from 1000 draws from the posterior distribution. Solid lines represent the mean. 


\section{Appendix D Model-implied expected ZLB durations}

The long duration of the ZLB is largely interpreted by our estimation as an endogenous response of the central bank to the deterioration of fundamentals via the Taylor rule, rather than to an active lower-for-longer policy.

Figure D.17 shows the dynamics and the distribution of the expected duration of the ZLB spell over the sample. The mean expected durations vary between seven and eleven quarters throughout the ZLB years. Although we do not target, nor use any prior information on the actual expectations of market participants on the duration of the ZLB, for the most our results are in close range to expected durations in survey data. The lower panels of Figure D.17 show the distributions of expected ZLB durations at different points in time. In 2009:Q1, most of the probability mass lies on durations of, or higher than, 10 quarters. The same holds for the first quarters of 2012 and 2013, for which survey data shows high expected durations as well. In contrast, for 2011:Q1 when our mean expected duration of seven quarters slightly exceeds the mean implied by the Primary Dealer Survey, the distribution shows that considerable probability mass is allocated to lower expected durations and the survey mean is within the confidence interval of the RANK estimation.

Our results concerning the expected durations of the ZLB are quite similar to those in ?[BS]boehl2020, confirming that the inclusion of the financial sectorá la Gertler and Karadi (2013) does not fundamentally alter the interpretation of business cycle dynamics. BS also provides a comparison to the expected durations obtained by Gust et al. (2017) who obtain an average ZLB spell of merely 3.5 quarters, and those obtained by Kulish et al. (2017), who use survey data to construct priors on expected durations, which they estimate directly. As in BS, but in contrast to the other aforementioned papers, our sample also covers the takeoff from the ZLB. The mean of the smoothed nominal interest rate series leaves the ZLB a year after the actual ZLB period ended. The model therefore interprets the still very low federal fund rate in 2016 to have the same effects on equilibrium dynamics as a binding ZLB. This might capture uncertainty effects that could not explicitly included in our modeling approach. 
Expected durations

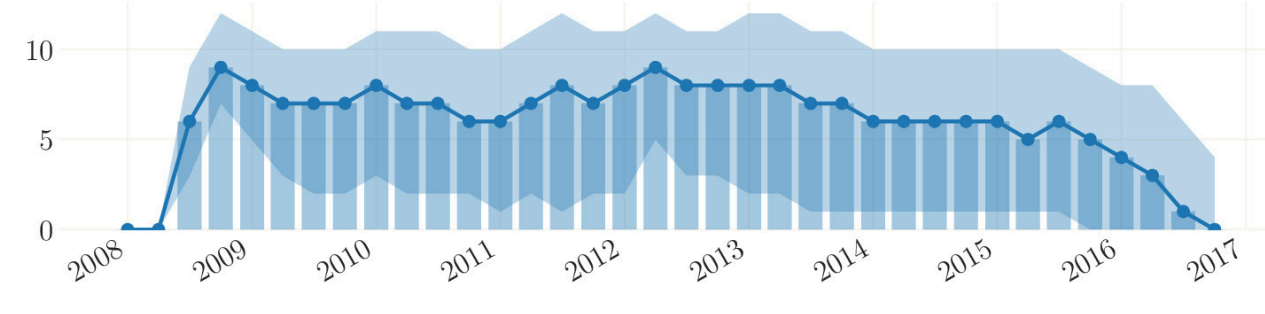

distribution in 2009:Q1

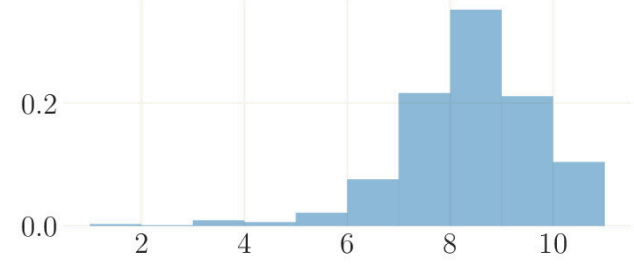

distribution in 2011:Q1

distribution in 2012:Q1

0.1
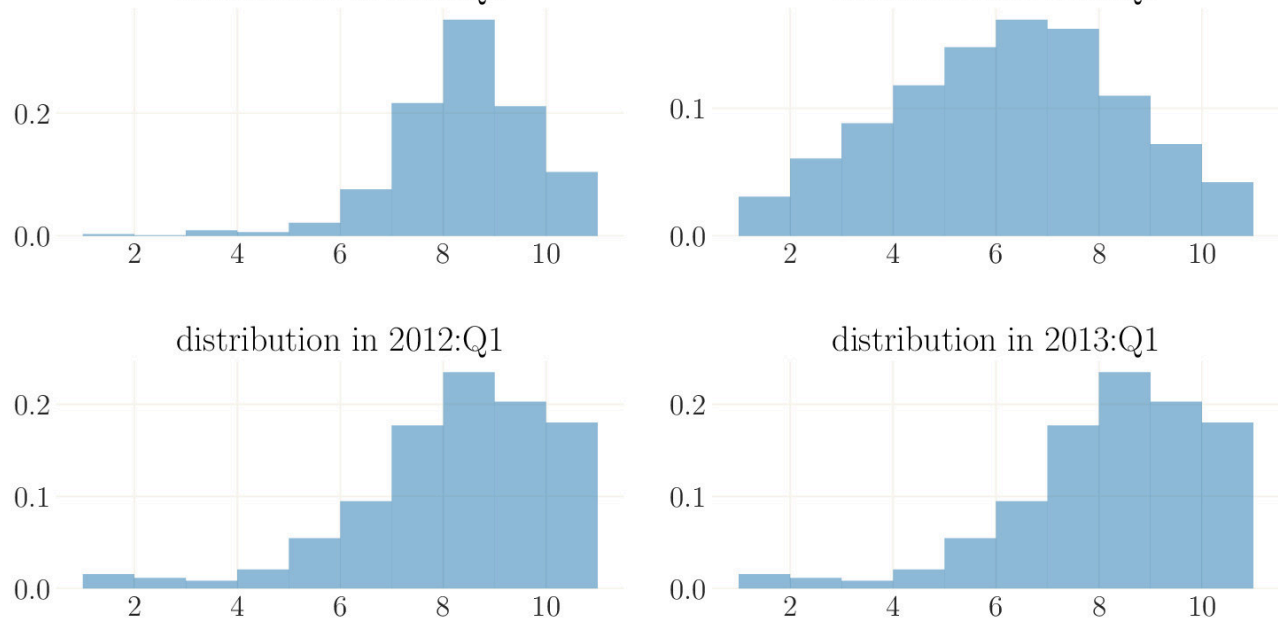

0.2

distribution in 2013:Q1

Figure D.17: ZLB durations

Note: Means over 1000 simulations drawn from the posterior. The contribution of each shock is normalized and calculated as in Boehl (2020b). 


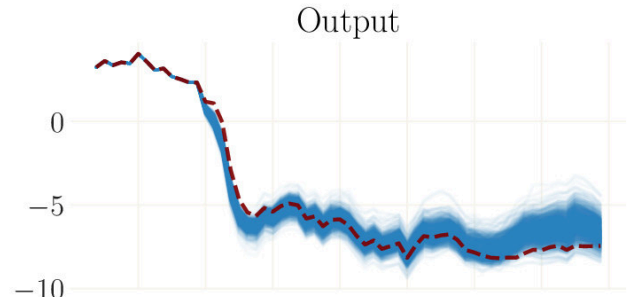

Inflation

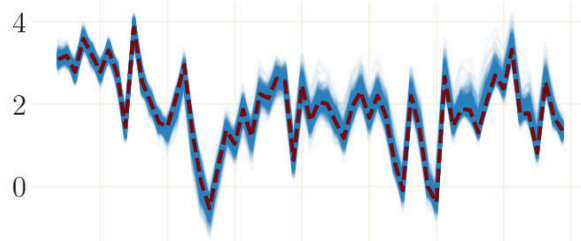

Interest rate

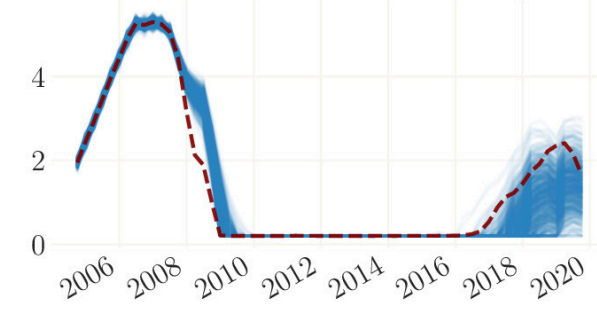

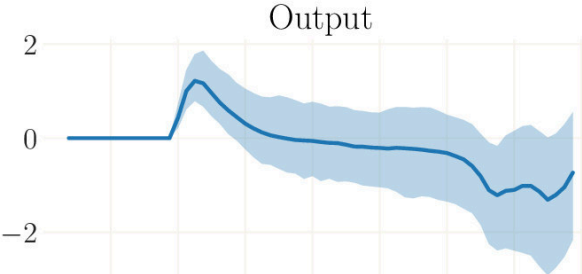

Inflation

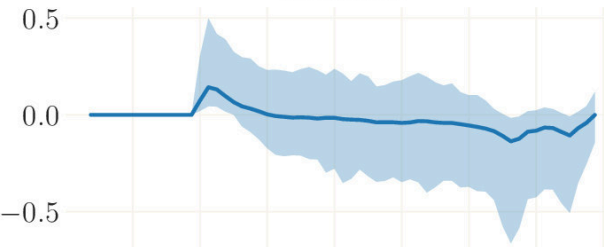

Interest rate

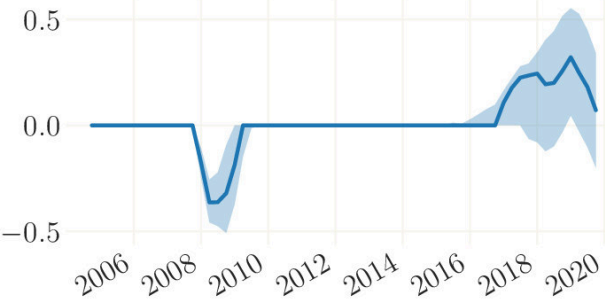

Figure D.18: Decomposition of the net-effect of forward guidance and interest rate measures since 2009. Note: Means over 1000 simulations drawn from the posterior. The contribution of each shock is normalized and calculated as in Boehl (2020b). Annualized measures where applicable. 


\section{Appendix E Estimation of plain vanilla Smets and Wouters (2007) model}

Table E.3 reproduces the estimates of the Smets and Wouters (2007) model taken from Boehl and Strobel (2020) who use the same sample as for our benchmark model. This is solely done for robustness considerations: we use these estimates as reference points to determine which parameters of our model are identified independently of the financial frictions building block of our model, and which are specific to it. 


\begin{tabular}{|c|c|c|c|c|c|c|c|c|}
\hline & dist. & $\begin{array}{l}\text { Prior } \\
\text { mean }\end{array}$ & std & mean & std & $\begin{array}{c}\text { Posterio } \\
\text { mode }\end{array}$ & $5 \%$ & $95 \%$ \\
\hline$\sigma_{c}$ & normal & 1.500 & 0.375 & 0.930 & 0.081 & 0.882 & 0.831 & 1.048 \\
\hline$\sigma_{l}$ & normal & 2.000 & 0.750 & 1.753 & 0.459 & 1.315 & 1.021 & 2.505 \\
\hline$\beta_{t p r}$ & gamma & 0.250 & 0.100 & 0.158 & 0.055 & 0.141 & 0.068 & 0.244 \\
\hline$h$ & beta & 0.700 & 0.100 & 0.833 & 0.027 & 0.839 & 0.793 & 0.878 \\
\hline$S^{\prime \prime}$ & normal & 4.000 & 1.500 & 5.287 & 0.914 & 4.926 & 3.731 & 6.662 \\
\hline$\iota_{p}$ & beta & 0.500 & 0.150 & 0.192 & 0.066 & 0.166 & 0.086 & 0.302 \\
\hline$\iota_{w}$ & beta & 0.500 & 0.150 & 0.371 & 0.112 & 0.426 & 0.186 & 0.547 \\
\hline$\alpha$ & normal & 0.300 & 0.050 & 0.168 & 0.013 & 0.175 & 0.146 & 0.188 \\
\hline$\zeta_{p}$ & beta & 0.500 & 0.100 & 0.852 & 0.033 & 0.840 & 0.801 & 0.906 \\
\hline$\zeta_{w}$ & beta & 0.500 & 0.100 & 0.710 & 0.044 & 0.678 & 0.642 & 0.786 \\
\hline$\Phi_{p}$ & normal & 1.250 & 0.125 & 1.254 & 0.076 & 1.249 & 1.128 & 1.382 \\
\hline$\psi$ & beta & 0.500 & 0.150 & 0.757 & 0.080 & 0.802 & 0.633 & 0.893 \\
\hline$\phi_{\pi}$ & normal & 1.500 & 0.250 & 1.353 & 0.218 & 1.512 & 0.995 & 1.685 \\
\hline$\phi_{y}$ & normal & 0.125 & 0.050 & 0.207 & 0.029 & 0.190 & 0.157 & 0.251 \\
\hline$\phi_{d y}$ & normal & 0.125 & 0.050 & 0.170 & 0.040 & 0.165 & 0.104 & 0.235 \\
\hline$\rho$ & beta & 0.750 & 0.100 & 0.816 & 0.042 & 0.833 & 0.751 & 0.886 \\
\hline$\rho_{r}$ & beta & 0.500 & 0.200 & 0.754 & 0.088 & 0.710 & 0.622 & 0.909 \\
\hline$\rho_{g}$ & beta & 0.500 & 0.200 & 0.918 & 0.019 & 0.915 & 0.886 & 0.948 \\
\hline$\rho_{z}$ & beta & 0.500 & 0.200 & 0.979 & 0.013 & 0.982 & 0.962 & 0.999 \\
\hline$\rho_{u}$ & beta & 0.500 & 0.200 & 0.866 & 0.022 & 0.871 & 0.833 & 0.902 \\
\hline$\rho_{p}$ & beta & 0.500 & 0.200 & 9 & 0.090 & 0.679 & 0.496 & 0.776 \\
\hline$\rho_{w}$ & beta & 0.500 & 0.200 & 0.455 & 0.097 & 0.369 & 0.303 & 0.607 \\
\hline$\rho_{i}$ & beta & 0.500 & 0.200 & 0.602 & 0.127 & 0.528 & 0.436 & 0.854 \\
\hline$\mu_{p}$ & beta & 0.500 & 0.200 & 0.315 & 0.121 & 0.300 & 0.109 & 0.502 \\
\hline$\mu_{w}$ & beta & 0.500 & 0.200 & 0.255 & 0.090 & 0.166 & 0.125 & 0.391 \\
\hline$\rho_{g z}$ & normal & 0.500 & 0.250 & 0.607 & 0.085 & 0.646 & 0.463 & 0.745 \\
\hline$\sigma_{g}$ & IG & 0.100 & 2.000 & 0.222 & 0.025 & 0.208 & 0.180 & 0.261 \\
\hline$\sigma_{u}$ & $\mathrm{IG}$ & 0.100 & 2.000 & 0.681 & 0.148 & 0.626 & 0.456 & 0.915 \\
\hline$\sigma_{z}$ & $\mathrm{IG}$ & 0.100 & 2.000 & 0.399 & 0.043 & 0.412 & 0.329 & 0.467 \\
\hline$\sigma_{r}$ & $\mathrm{IG}$ & 0.100 & 2.000 & 0.106 & 0.017 & 0.122 & 0.080 & 0.133 \\
\hline$\sigma_{p}$ & $\mathrm{IG}$ & 0.100 & 2.000 & 0.184 & 0.058 & 0.139 & 0.101 & 0.253 \\
\hline$\sigma_{w}$ & $\mathrm{IG}$ & 0.100 & 2.000 & 1.272 & 0.294 & 1.487 & 0.818 & 1.761 \\
\hline$\sigma_{i}$ & IG & 0.100 & 2.000 & 0.881 & 0.276 & 1.041 & 0.365 & 1.254 \\
\hline $\bar{\gamma}$ & normal & 0.440 & 0.050 & 0.382 & 0.036 & 0.386 & 0.322 & 0.439 \\
\hline $\bar{l}$ & normal & 0.000 & 2.000 & 0.997 & 0.634 & 1.099 & 0.038 & 2.103 \\
\hline $\bar{\pi}$ & gamma & 0.625 & 0.100 & 0.632 & 0.059 & 0.659 & 0.539 & 0.733 \\
\hline
\end{tabular}

Table E.3: Estimation results for the model of Smets and Wouters (2007) estimated from 1998:I 2019:IV. 


\section{Appendix $\mathrm{F}$ The $\mathrm{AR}(2)$ processes for exogenous QE}

A autoregressive process of second order $\operatorname{AR}(2)$ is given by

$$
x_{t}=\rho_{1} x_{t-1}+\rho_{2} x_{t-2}+\epsilon_{t} .
$$

The two autoregressive parameters $\rho_{1}$ and $\rho_{2}$ can be expressed in terms of the roots of the process

$$
\begin{aligned}
& \rho_{1}=\lambda_{1}+\lambda_{2}, \\
& \rho_{2}=-\lambda_{1} \lambda_{2} .
\end{aligned}
$$

The implicit two-dimensional system is given by

$$
\left|\begin{array}{l}
x_{t} \\
y_{t}
\end{array}\right|=\mathbf{A}\left|\begin{array}{c}
x_{t-1} \\
y_{t-1}
\end{array}\right|+\mathbf{b} \epsilon_{t},
$$

where $y_{t}=x_{t-1}$ is an auxiliary variable and

$$
\begin{aligned}
& \mathbf{A}=\left|\begin{array}{cc}
\lambda_{1}+\lambda_{2} & -\lambda_{1} \lambda_{2} \\
1 & 0
\end{array}\right|, \\
& \mathbf{b}=\left|\begin{array}{l}
1 \\
0
\end{array}\right| .
\end{aligned}
$$

We want to find the impulse response

$$
x_{t+s}=\Omega(s) \epsilon_{t} .
$$

Assuming $\epsilon_{\bar{t}}=0$ for all $\bar{t} \neq t$, we can iterate (F.4) forward to express

$$
\left|\begin{array}{c}
x_{t+s} \\
y_{t+s}
\end{array}\right|=\mathbf{A}^{s} \mathbf{b} \epsilon_{t} .
$$

Denote the spectral decomposition of $\mathbf{A}$ as $\mathbf{A}=\mathbf{Q} \mathbf{\Lambda} \mathbf{Q}^{-1}$ with $\mathbf{\Lambda}=\operatorname{diag}\left(\lambda_{1}, \lambda_{2}\right)$ (A is clearly non-singular for $\lambda_{1}, \lambda_{2} \neq 0$ ) and acknowledge that

$$
\mathbf{A}^{k}=\mathbf{Q} \mathbf{\Lambda}^{k} \mathbf{Q}^{-1} .
$$

A pair of eigenvectors $\left\{q_{1}, q_{2}\right\}$ of $\mathbf{A}$ is given by

$$
\begin{aligned}
& q_{1}=\left(\lambda_{1}, 1\right), \\
& q_{2}=\left(\lambda_{2}, 1\right) .
\end{aligned}
$$

Let $\mathbf{Q}=\left|\begin{array}{ll}q_{1} & q_{2}\end{array}\right|$. Since $\boldsymbol{\Lambda}$ is diagonal it holds that $\boldsymbol{\Lambda}^{k}=\operatorname{diag}\left(\lambda_{1}^{k}, \lambda_{2}^{k}\right)$ and we can rewrite (F.8) as

$$
\left|\begin{array}{c}
x_{t+s} \\
y_{t+s}
\end{array}\right|=\mathbf{Q}\left|\begin{array}{cc}
\lambda_{1}^{s} & 0 \\
0 & \lambda_{2}^{s}
\end{array}\right| \mathbf{Q}^{-1} \mathbf{b} \epsilon_{t} .
$$


Inserting $\mathbf{Q}$ and reduction finally yields for the impulse response in (F.7) that

$$
\Omega(s)=\frac{\lambda_{1}^{1+s}-\lambda_{2}^{1+s}}{\lambda_{1}-\lambda_{2}} .
$$

We are looking for the peak response of (F.1). This can be found by setting the first derivative of $\Omega(s)$ to zero. Hence

$$
\frac{\partial \Omega(s)}{\partial s}=\frac{\lambda_{1}^{1+s} \ln \lambda_{1}-\lambda_{2}^{1+s} \ln \lambda_{2}}{\lambda_{1}-\lambda_{2}} \doteq 0
$$

The solution is

$$
1+s=\frac{\ln \left\{\frac{\ln \lambda_{1}}{\ln \lambda_{2}}\right\}}{\ln \lambda_{1}-\ln \lambda_{2}},
$$

which can directly be inserted into (F.13) to give the peak effect of the $\operatorname{AR}(2)$ process. Assume that $\lambda_{1}, \lambda_{2} \in[0,1]$ to ensure stationarity and to exclude oscillating dynamics. Then both $\ln \lambda_{1}$ and $\ln \lambda_{2}$ are defined and smaller than zero. It follows that $\frac{\ln \lambda_{1}}{\ln \lambda_{2}}>0$, ensuring that $\ln \left\{\frac{\ln \lambda_{1}}{\ln \lambda_{2}}\right\}$ is defined as well.

\section{Appendix G Comparing the effects of QE and interest rate policy}

There has been an active debate on whether unconventional monetary policy measures can act as a substitute for conventional interest rate policy once the nominal interest rate is constrained by the ZLB. ${ }^{39}$ In this section, we briefly compare the effectiveness of the LSAPs with a standard accommodative monetary policy shock using our estimated model.

An accommodative monetary policy shock, which lowers the federal funds rate by 25 basis points (annualized), creates a peak output response of around $0.19 \%$. We ask the question of how large, as a percentage of GDP, asset purchases have to be, in order to achieve a similar effect on output. Figures G.19 and G.20 summarize the result for capital asset and government bond purchases. For each draw from the posterior, the size of the QE shock is chosen such that its peak response on output equals the peak response of a quarterly 25 basis points monetary policy shock.

Before turning to the results, let us stress one important caveat of this comparison. We do not restrict the short term rate to remain unchanged, which - in our model implies that the central bank raises rates to counter the expansionary effects of QE. The reason for doing so lies in the different model-implied expected durations of the ZLB for each posterior draw which render a comparison difficult.

With this caveat in mind, we find - in line with our previous results - that an expansion of the Fed's balance sheet of $0.63 \%$ of GDP through capital asset purchases is needed in order to stimulate output by the same amount as a 25 basis points monetary policy shock. In the case of treasury purchases, this number increases to $1.8 \%$ of GDP. To put this numbers into context, in 2019 this translated into roughly 135 and 385.7 Billion Dollar, respectively.

\footnotetext{
${ }^{39}$ To name a few, see e.g.Eberly et al. (2019); Doniger et al. (2019); Sims and Wu (2020).
} 
The results for government bond purchases is comparable in size to Doniger et al. (2019), who find that treasuries worth $2 \%$ GDP have to be purchased in order to achieve a similar effect on output as a $25 \mathrm{bps}$ rate cut using the FRB/US model. Nonetheless, there is a word of caution and the above numbers are to be interpreted carefully. First, across the posterior, there is a large heterogeneity of how large the volume of the purchases must be to get comparable output effects. The corresponding posterior standard deviations of the above numbers are $0.2674 \%$ and $0.8284 \%$ of GDP for capital asset and treasury purchases, respectively. Second, there are crucial differences in the dynamics of several variables when comparing a standard monetary policy shock with a LSAPs. Specifically, as outlined above, we find LSAPs to exercise downward pressure on prices, consistent with a dominant cost channel, and to induce a non-negligible decline in consumption. Finally, as the standard deviation of the peak-output response of the QE shocks is rather small compared to the standard deviations of the output response to a monetary policy shock (compare Figs. 6, C.15 and C.16), we suspect that this heterogeneity is due to the large uncertainty surrounding the effects of a conventional monetary policy shock in our model. This uncertainty is likely due to the fact that monetary policy shocks do not play a vivid role in our sample, and the characteristics of the respective $\operatorname{AR}(1)$ process for monetary policy shocks are hence probably poorly identified. 


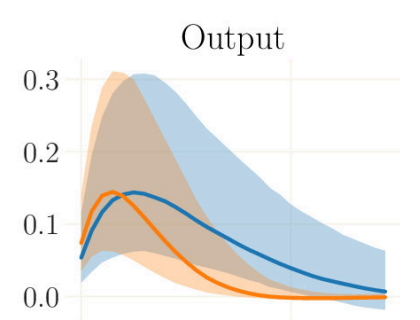

Inflation

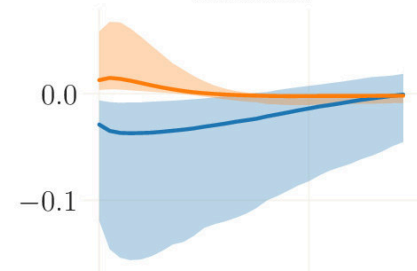

Credit spread

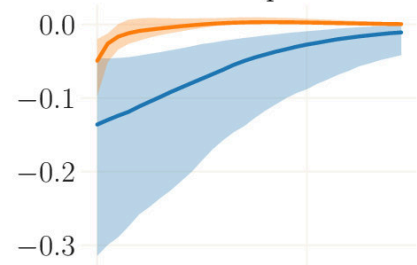

o

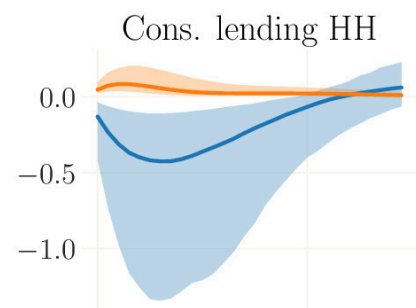

Investment

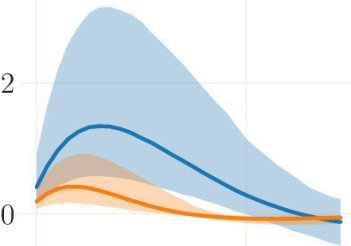

Net worth of banks

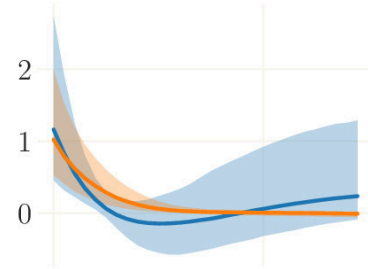

20
Cons. borrowing $\mathrm{HH}$

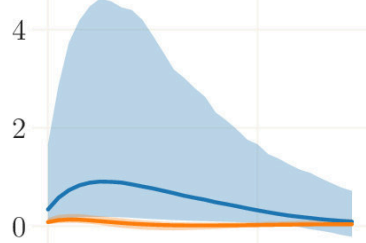

Labor hours

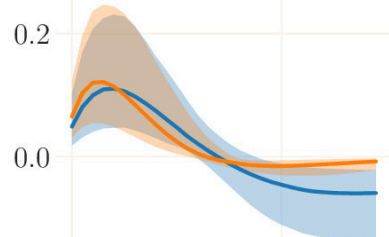

Interest rate

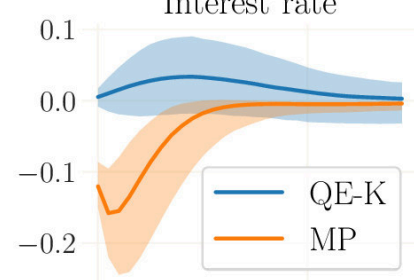

0

Figure G.19: Impulse response functions to an accommodative annualized 25 basis points monetary policy shock, compared to capital purchases shocks where for each draw from the posterior, the size of each shock is chosen such that the peak effect of QE on output equals the peak effect to the monetary policy shock. Sampled from the posterior distribution with $95 \%$ confidence intervals.

Note: Posterior sample obtained from 1000 draws from the posterior distribution. Solid lines represent the mean. 

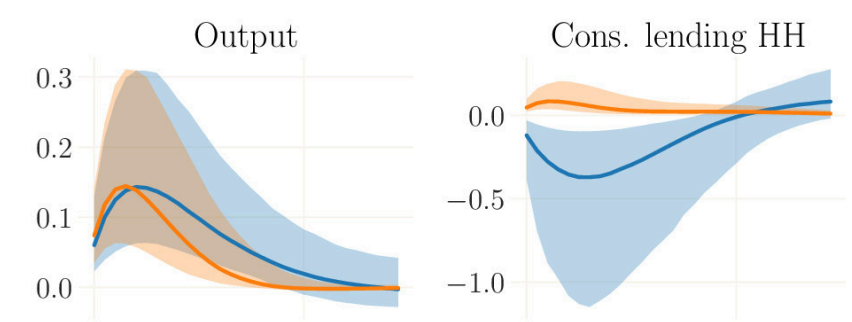

4 Cons. borrowing $\mathrm{HH}$
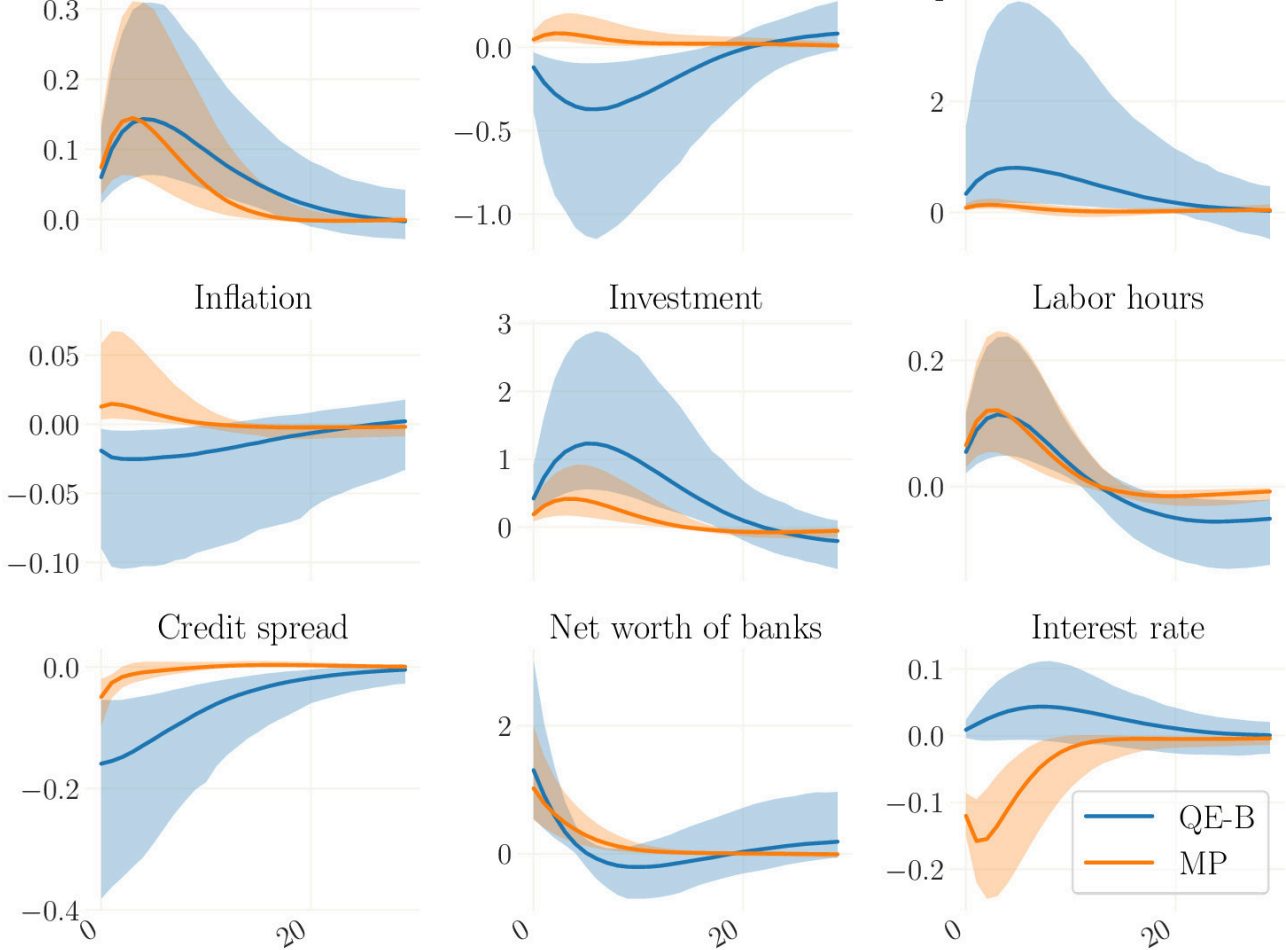

Figure G.20: Impulse response functions to an accommodative annualized 25 basis points monetary policy shock, compared to bond purchases shocks where for each draw from the posterior, the size of each shock is chosen such that the peak effect of QE on output equals the peak effect to the monetary policy shock. Sampled from the posterior distribution with $95 \%$ confidence intervals.

Note: Posterior sample obtained from 1000 draws from the posterior distribution. Solid lines represent the mean. 


\section{Appendix H Comparing posterior estimates of the RANK and H2M vin- tages}

Tables H.4 and H.5 below compare the parameter estimates of our benchmark model with impatient households with alternative model specifications. The RANK version basically remains closer to Gertler and Karadi (2013) and restricts the household sector to a representative household - the "saver" or patient household in our benchmark model - by setting the fraction of impatient households to be zero, i.e. $\chi=0$. Instead, the "hand-to-mouth" (H2M) version keeps the heterogeneous agent structure in the household sector, yet restricts the second type to be a "hand-to-mouth" household following, among others, Kaplan et al. (2018). A H2M household consumes all his labor income immediately and does not save. 


\begin{tabular}{|c|c|c|c|c|c|c|c|c|c|c|c|c|}
\hline & \multirow{2}{*}{\multicolumn{3}{|c|}{ Prior }} & \multicolumn{9}{|c|}{ Posterior } \\
\hline & & & & \multicolumn{3}{|c|}{ Benchmark } & \multicolumn{3}{|c|}{ H2M } & \multicolumn{3}{|c|}{ RANK } \\
\hline & dist. & mean & std & mean & std & mode & mean & std & mode & mean & std & mode \\
\hline$\sigma_{c}$ & normal & 1.500 & 0.375 & 0.908 & 0.033 & 0.876 & 0.861 & 0.025 & 0.865 & 0.848 & 0.036 & 0.848 \\
\hline$\sigma_{l}$ & normal & 2.000 & 0.750 & 1.160 & 0.351 & 1.046 & 0.461 & 0.166 & 0.396 & 0.485 & 0.222 & 0.590 \\
\hline$\beta_{t p r}$ & gamma & 0.250 & 0.100 & 0.201 & 0.058 & 0.186 & 0.155 & 0.046 & 0.223 & 0.158 & 0.054 & 0.159 \\
\hline$h$ & beta & 0.700 & 0.100 & 0.799 & 0.033 & 0.804 & 0.854 & 0.018 & 0.866 & 0.848 & 0.019 & 0.876 \\
\hline$S^{\prime \prime}$ & normal & 4.000 & 1.500 & 5.119 & 0.754 & 4.181 & 7.524 & 0.897 & 7.427 & 7.055 & 0.798 & 8.058 \\
\hline$\iota_{p}$ & beta & 0.500 & 0.150 & 0.232 & 0.067 & 0.155 & 0.205 & 0.067 & 0.180 & 0.225 & 0.077 & 0.227 \\
\hline$\iota_{w}$ & beta & 0.500 & 0.150 & 0.426 & 0.118 & 0.648 & 0.435 & 0.120 & 0.456 & 0.406 & 0.117 & 0.305 \\
\hline$\alpha$ & normal & 0.300 & 0.050 & 0.210 & 0.012 & 0.200 & 0.185 & 0.011 & 0.195 & 0.183 & 0.012 & 0.173 \\
\hline$\zeta_{p}$ & beta & 0.500 & 0.100 & 0.870 & 0.025 & 0.861 & 0.892 & 0.020 & 0.890 & 0.894 & 0.020 & 0.908 \\
\hline$\zeta_{w}$ & beta & 0.500 & 0.100 & 0.747 & 0.046 & 0.728 & 0.696 & 0.048 & 0.671 & 0.708 & 0.043 & 0.740 \\
\hline$\Phi_{p}$ & normal & 1.250 & 0.125 & 1.331 & 0.071 & 1.364 & 1.305 & 0.069 & 1.293 & 1.305 & 0.060 & 1.259 \\
\hline$\psi$ & beta & 0.500 & 0.150 & 0.810 & 0.067 & 0.841 & 0.773 & 0.075 & 0.850 & 0.789 & 0.071 & 0.783 \\
\hline$\phi_{\pi}$ & normal & 1.500 & 0.250 & 1.323 & 0.207 & 1.542 & 1.158 & 0.142 & 0.987 & 1.160 & 0.152 & 1.017 \\
\hline$\phi_{y}$ & normal & 0.125 & 0.050 & 0.171 & 0.022 & 0.168 & 0.202 & 0.025 & 0.219 & 0.193 & 0.025 & 0.188 \\
\hline$\phi_{d y}$ & normal & 0.125 & 0.050 & 0.181 & 0.041 & 0.239 & 0.166 & 0.039 & 0.162 & 0.178 & 0.039 & 0.199 \\
\hline$\rho$ & beta & 0.750 & 0.100 & 0.829 & 0.031 & 0.850 & 0.782 & 0.034 & 0.757 & 0.787 & 0.032 & 0.794 \\
\hline$\kappa_{\tau}$ & gamma & 0.300 & 0.100 & 0.287 & 0.081 & 0.188 & 0.291 & 0.079 & 0.242 & 0.291 & 0.079 & 0.331 \\
\hline$P A C$ & gamma & 2.000 & 4.000 & 0.495 & 1.189 & 0.132 & 0.169 & 0.493 & 0.062 & 0.139 & 0.453 & 0.059 \\
\hline$L E V$ & normal & 3.000 & 1.000 & 4.312 & 0.405 & 4.433 & 3.177 & 0.469 & 3.487 & 3.336 & 0.468 & 3.433 \\
\hline$\theta$ & beta & 0.950 & 0.050 & 0.815 & 0.034 & 0.747 & 0.820 & 0.038 & 0.795 & 0.806 & 0.044 & 0.772 \\
\hline$\lambda_{c b l}$ & gamma & 3.000 & 3.000 & 0.229 & 0.207 & 0.086 & 0.113 & 0.107 & 0.029 & 0.100 & 0.088 & 0.057 \\
\hline$\chi$ & beta & 0.300 & 0.100 & 0.190 & 0.059 & 0.133 & 0.316 & 0.085 & 0.317 & & & \\
\hline$\overline{\text { termspread }}$ & gamma & 0.500 & 0.100 & 0.594 & 0.106 & 0.427 & 0.527 & 0.099 & 0.466 & 0.496 & 0.092 & 0.493 \\
\hline$\overline{\text { ppremium }}$ & gamma & 0.100 & 0.030 & 0.083 & 0.020 & 0.110 & & & & & & \\
\hline spread & normal & 0.500 & 0.100 & 0.428 & 0.051 & 0.563 & 0.482 & 0.064 & 0.489 & 0.502 & 0.061 & 0.509 \\
\hline $\bar{\gamma}$ & normal & 0.440 & 0.050 & 0.399 & 0.029 & 0.414 & 0.394 & 0.022 & 0.406 & 0.392 & 0.019 & 0.382 \\
\hline $\bar{\pi}$ & gamma & 0.625 & 0.100 & 0.624 & 0.058 & 0.688 & 0.624 & 0.052 & 0.636 & 0.618 & 0.052 & 0.564 \\
\hline $\bar{l}$ & normal & 0.000 & 2.000 & 1.246 & 0.488 & 0.701 & 0.826 & 0.523 & 0.948 & 0.710 & 0.554 & 0.596 \\
\hline MDD & & & & - & & & -57 & , & & -56 & ) - & .337 \\
\hline
\end{tabular}

Table H.4: Comparison of estimation results for different model vintages. Marginal data density (MDD) given as Modified Harmonic Mean and Laplace Approximations. 


\begin{tabular}{|c|c|c|c|c|c|c|c|c|c|c|c|c|}
\hline & \multirow{2}{*}{\multicolumn{3}{|c|}{ Prior }} & \multicolumn{9}{|c|}{ Posterior } \\
\hline & & & & & enchma & & & $\mathrm{H} 2 \mathrm{M}$ & & & RANK & \\
\hline & dist. & mean & std & mean & std & mode & mean & std & mode & mean & std & mode \\
\hline$\rho_{r}$ & beta & 0.500 & 0.200 & 0.566 & 0.086 & 0.525 & 0.556 & 0.071 & 0.587 & 0.543 & 0.073 & 0.576 \\
\hline$\rho_{g}$ & beta & 0.500 & 0.200 & 0.887 & 0.081 & 0.944 & 935 & 0.029 & 0.924 & 0.941 & 0.021 & .955 \\
\hline$\rho_{i}$ & beta & 0.500 & 0.200 & 0.734 & 0.048 & 0.651 & 0.551 & 0.087 & 0.524 & 0.601 & 0.075 & .603 \\
\hline$\rho_{z}$ & beta & 0.500 & 0.200 & 0.951 & 0.025 & 0.954 & 0.955 & 0.024 & 0.968 & 0.942 & 0.024 & .964 \\
\hline$\rho_{p}$ & beta & 0.500 & 0.200 & 0.617 & 0.098 & 0.624 & 0.598 & 0.070 & 0.537 & 0.584 & 0.086 & 0.587 \\
\hline$\rho_{w}$ & beta & 0.500 & 0.200 & 0.735 & 0.070 & 0.707 & 0.578 & 0.108 & 0.552 & 0.682 & 0.097 & 0.700 \\
\hline$\rho_{u}$ & beta & 0.500 & 0.200 & 0.896 & 0.013 & 0.906 & 895 & 0.015 & 0.885 & .894 & 0.015 & .883 \\
\hline$\rho_{l k}$ & beta & 0.500 & 0.200 & 0.934 & 0.027 & 0.936 & 0.926 & 0.018 & 0.944 & 0.916 & 0.023 & 0.923 \\
\hline$\rho_{c b l}$ & beta & 0.500 & 0.200 & 0.762 & 0.036 & 0.762 & 0.742 & 0.038 & 0.735 & 0.745 & 0.039 & 0.756 \\
\hline $\operatorname{root}_{b, 1}$ & beta & 0.500 & 0.200 & 0.903 & 0.049 & 0.786 & 0.899 & 0.044 & 0.832 & 0.900 & 0.049 & .921 \\
\hline $\operatorname{root}_{b, 2}$ & beta & 500 & 0.200 & 880 & 0.054 & 0.973 & 0.890 & 0.048 & 0.946 & .887 & 0.050 & 0.863 \\
\hline $\operatorname{root}_{k, 1}$ & beta & .500 & 0.200 & 901 & 0.041 & 0.917 & 0.914 & 0.035 & 0.884 & .913 & 0.030 & 0.923 \\
\hline $\operatorname{root}_{k, 2}$ & beta & 0.500 & 0.200 & 0.926 & 0.037 & 0.902 & 0.913 & 0.033 & 0.933 & 0.919 & 0.028 & 0.930 \\
\hline$\mu_{p}$ & beta & 0.500 & 0.200 & 0.450 & 0.139 & 0.293 & 0.239 & 0.102 & 0.128 & 0.258 & 0.134 & 0.285 \\
\hline$\mu_{w}$ & beta & 0.500 & 0.200 & 0.517 & 0.102 & 0.485 & 0.354 & 0.113 & 0.314 & 0.460 & 0.124 & 0.502 \\
\hline$\rho_{g z}$ & normal & 0.500 & 0.250 & 0.570 & 0.188 & 0.463 & 0.492 & 0.117 & 0.546 & 0.486 & 0.110 & 0.483 \\
\hline$\sigma_{g}$ & inv. gamma & 0.100 & 0.250 & 0.260 & 0.029 & 0.235 & 0.263 & 0.024 & 0.251 & 0.261 & 0.024 & 0.239 \\
\hline$\sigma_{z}$ & inv. gamma & 0.100 & 0.250 & 0.345 & 0.035 & 0.313 & 0.349 & 0.037 & 0.300 & 0.353 & 0.038 & 0.317 \\
\hline$\sigma_{r}$ & inv. gamma & 0.100 & 0.250 & 0.147 & 0.031 & 0.164 & 0.146 & 0.025 & 0.137 & 0.151 & 0.027 & 0.132 \\
\hline$\sigma_{i}$ & inv. gamma & 0.100 & 0.250 & 0.610 & 0.086 & 0.766 & 0.910 & 0.215 & 0.879 & 0.795 & 0.165 & 0.714 \\
\hline$\sigma_{p}$ & inv. gamma & 0.100 & 0.250 & 0.235 & 0.070 & 0.190 & 0.179 & 0.034 & 0.183 & 0.200 & 0.046 & 0.197 \\
\hline$\sigma_{w}$ & inv. gamma & 0.100 & 0.250 & 0.691 & 0.074 & 0.687 & 1.056 & 0.218 & 1.196 & 0.845 & 0.141 & 0.789 \\
\hline$\sigma_{u}$ & inv. gamma & 0.100 & 0.250 & 0.482 & 0.086 & 0.454 & 0.592 & 0.097 & 0.694 & 0.571 & 0.093 & 0.714 \\
\hline$\sigma_{l k}$ & inv. gamma & 0.100 & 0.250 & 0.272 & 0.040 & 0.244 & 0.496 & 0.088 & 0.487 & 0.543 & 0.104 & 0.542 \\
\hline$\sigma_{c b l}$ & inv. gamma & 0.100 & 0.250 & 0.956 & 0.084 & 0.966 & 0.965 & 0.089 & 0.972 & 0.966 & 0.090 & 0.962 \\
\hline$\sigma_{q e b}$ & inv. gamma & 0.100 & 0.250 & 0.197 & 0.014 & 0.186 & 0.192 & 0.014 & 0.193 & 0.193 & 0.014 & 0.189 \\
\hline$\sigma_{q e k}$ & inv. gamma & 0.100 & 0.250 & 0.176 & 0.015 & 0.183 & 0.174 & 0.013 & 0.175 & 0.173 & 0.013 & 0.163 \\
\hline
\end{tabular}

Table H.5: Comparison of estimation results for different model vintages: exogenous processes. 
Output

0

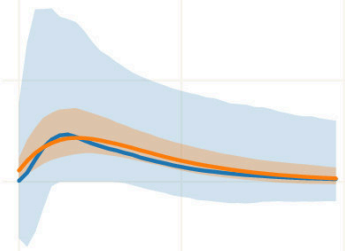

Investment

40

20

0

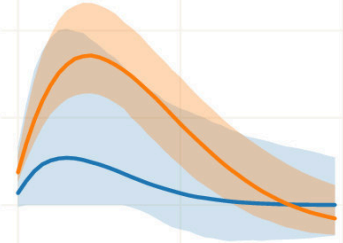

Credit spread

2

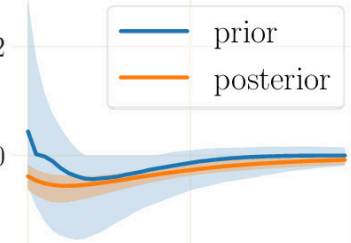

20

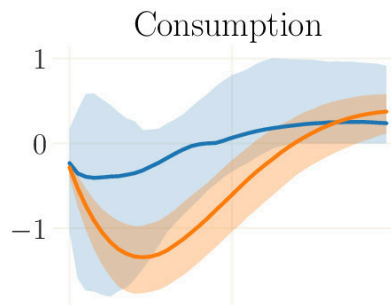

Inflation

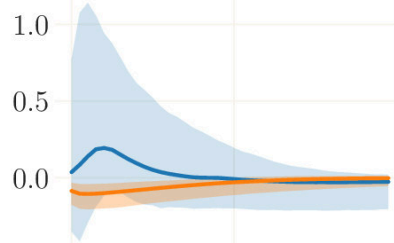

Net worth of banks

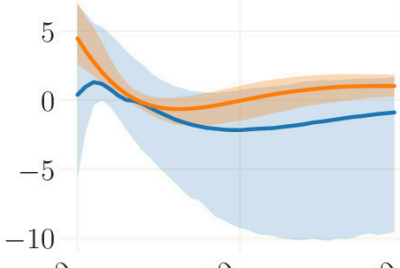

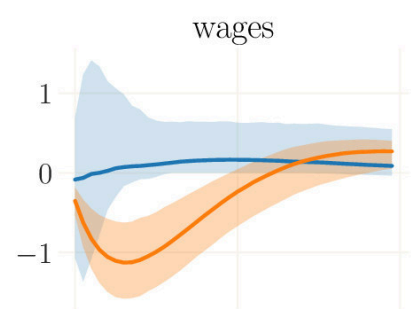

Labor hours

1

0

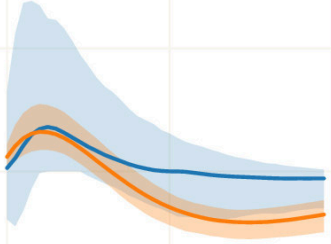

Capital held by banks

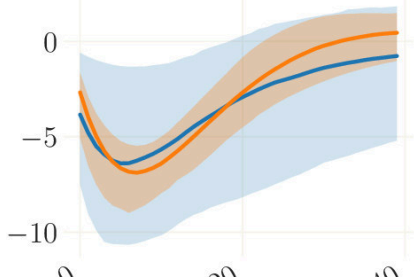

Figure I.21: H2M specification of the benchmark model. Impulse response functions with respect to a shock of MBS purchases (orange). Sampled from the posterior distribution with $95 \%$ confidence intervals. In blue: impulse responses sampled from the prior.

Note: Posterior sample obtained from 1000 draws from the posterior distribution. Solid lines represent the mean. For each draw, the strength of the shock is chosen such that the peak of the corresponding stochastic process matches the peak of the empirical time series. See Appendix F for details. The prior sample is obtained from 2000 draws, account for strong heterogeneity of effects. Prior draws adjusted for high autoregressive coefficients with mean/std of 0.9 and 0.05 because AR-coefficients are identified independently from the model. Annual measures where applicable.

\section{Appendix I Prior and posterior IRFs for RANK and H2M}

As with our benchmark model, both the pronounced fall in consumption as well as the disinflationary effect of QE stand in stark contrast to the results implied a priori. To illustrate this, Figures I.22 and I.21 compares the a priori impulse response functions to a capital asset purchase shock with those a posteriori for the RANK and H2M model vintages, respectively. 
Output

0

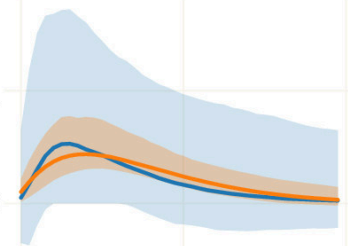

Investment

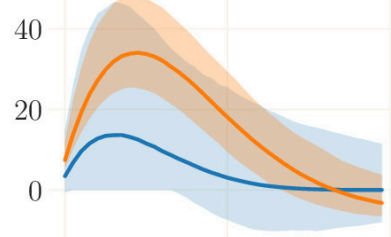

Credit spread

2

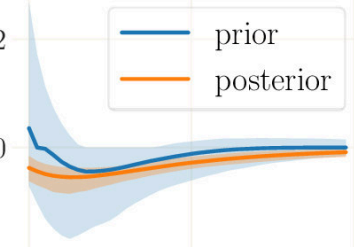

20

A)

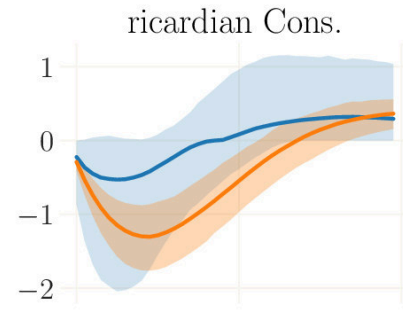

Inflation

0.5

0.0

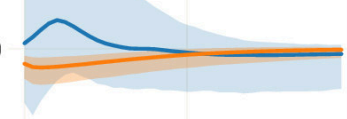

Net worth of banks

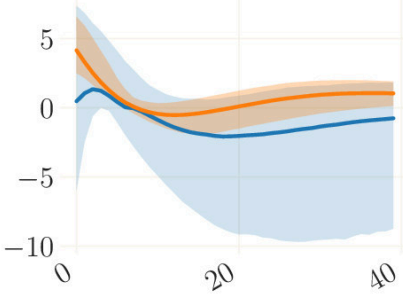

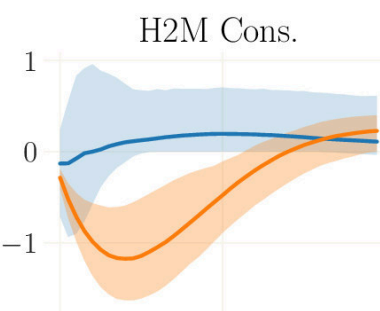

Labor hours

1

0

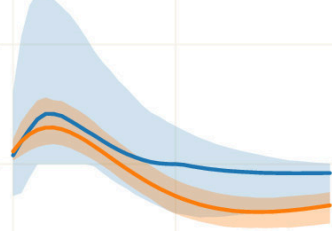

Capital held by banks

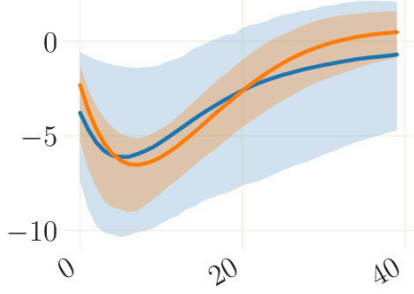

Figure I.22: RANK specification of the benchmark model. Impulse response functions with respect to a shock of MBS purchases (orange). Sampled from the posterior distribution with $95 \%$ confidence intervals. In blue: impulse responses sampled from the prior.

Note: Posterior sample obtained from 1000 draws from the posterior distribution. Solid lines represent the mean. For each draw, the strength of the shock is chosen such that the peak of the corresponding stochastic process matches the peak of the empirical time series. See Appendix F for details. The prior sample is obtained from 2000 draws, account for strong heterogeneity of effects. Prior draws adjusted for high autoregressive coefficients with mean/std of 0.9 and 0.05 because AR-coefficients are identified independently from the model. Annual measures where applicable.

\section{Appendix J Historic shock decompositions for RANK and H2M}

Finally, there is large degree of consistency in how the different model vintages rationalize the historic dynamics in our sample. For completeness, Figures J.23 until J.26 show the historical decompositions of selected variables for both vintages (RANK and $\mathrm{H} 2 \mathrm{M})$. 


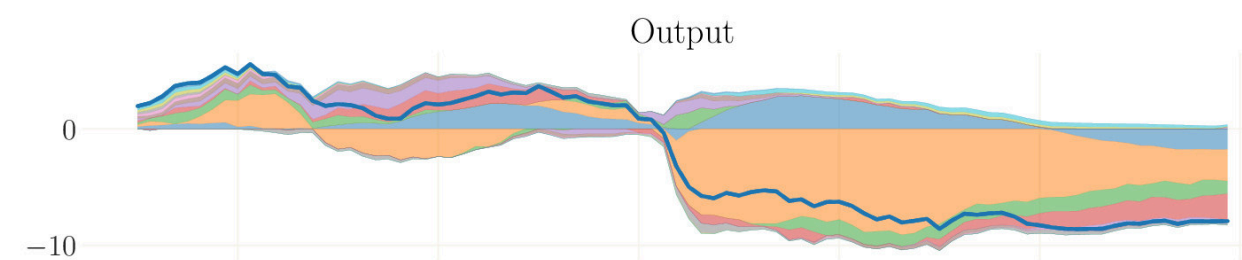

\section{Consumption}

0

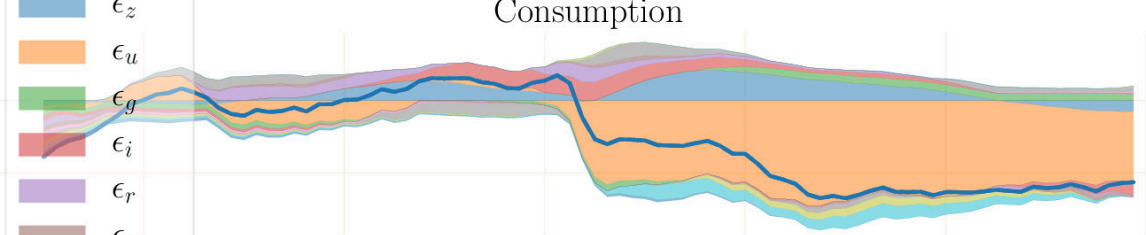

$-5$

$\epsilon_{p}$

$\epsilon_{u}$

$\epsilon_{l k}$

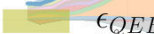

$\epsilon_{Q E K}$

$\epsilon_{C B L}$

Inflation

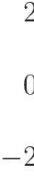

0

$-2$

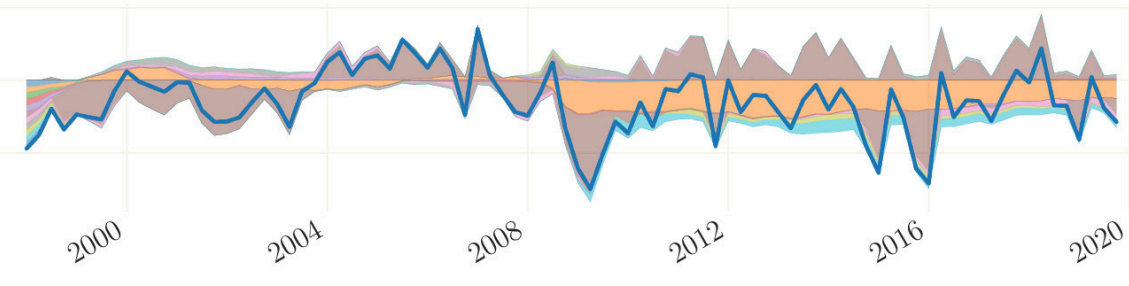

Figure J.23: Estimated RANK version of model. Decomposition of the smoothed states into the contribution of the different shocks.

Note: Means over 1000 simulations drawn from the posterior. The contribution of each shock is normalized and calculated as in Boehl (2020b). Annual measures where applicable. 


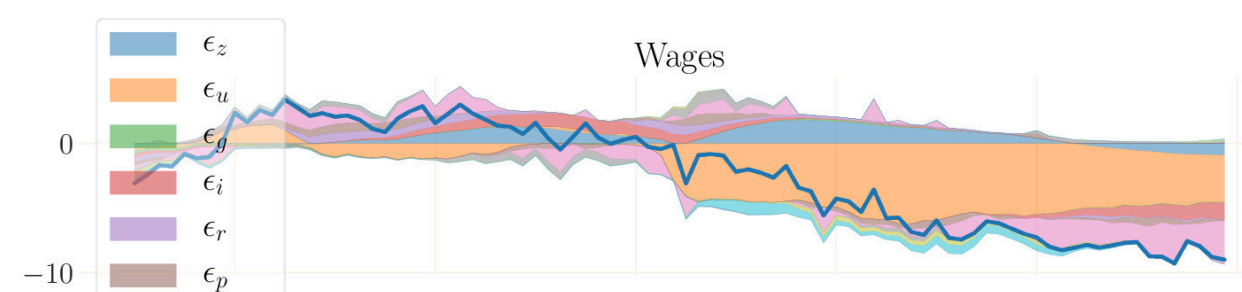

(Shadow) Interest rate

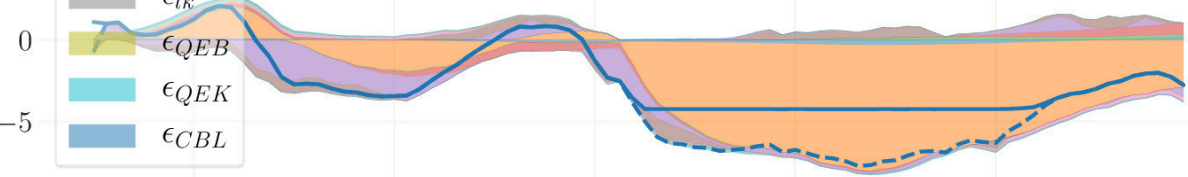

Credit spread

5

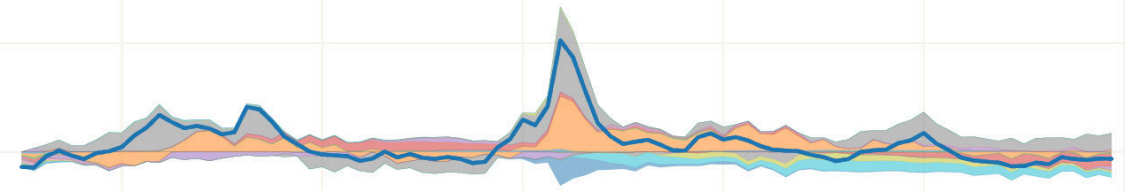

Capital utilization

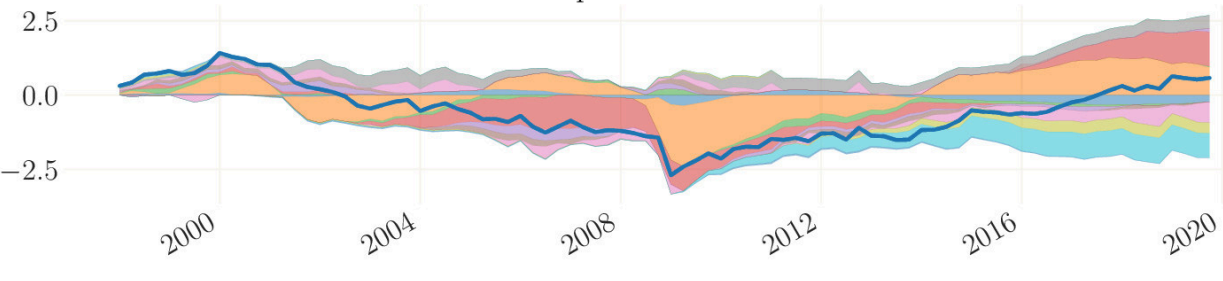

Figure J.24: Estimated RANK version of model. Decomposition of the smoothed states into the contribution of the different shocks.

Note: Means over 1000 simulations drawn from the posterior. The contribution of each shock is normalized and calculated as in Boehl (2020b). Annual measures where applicable. 

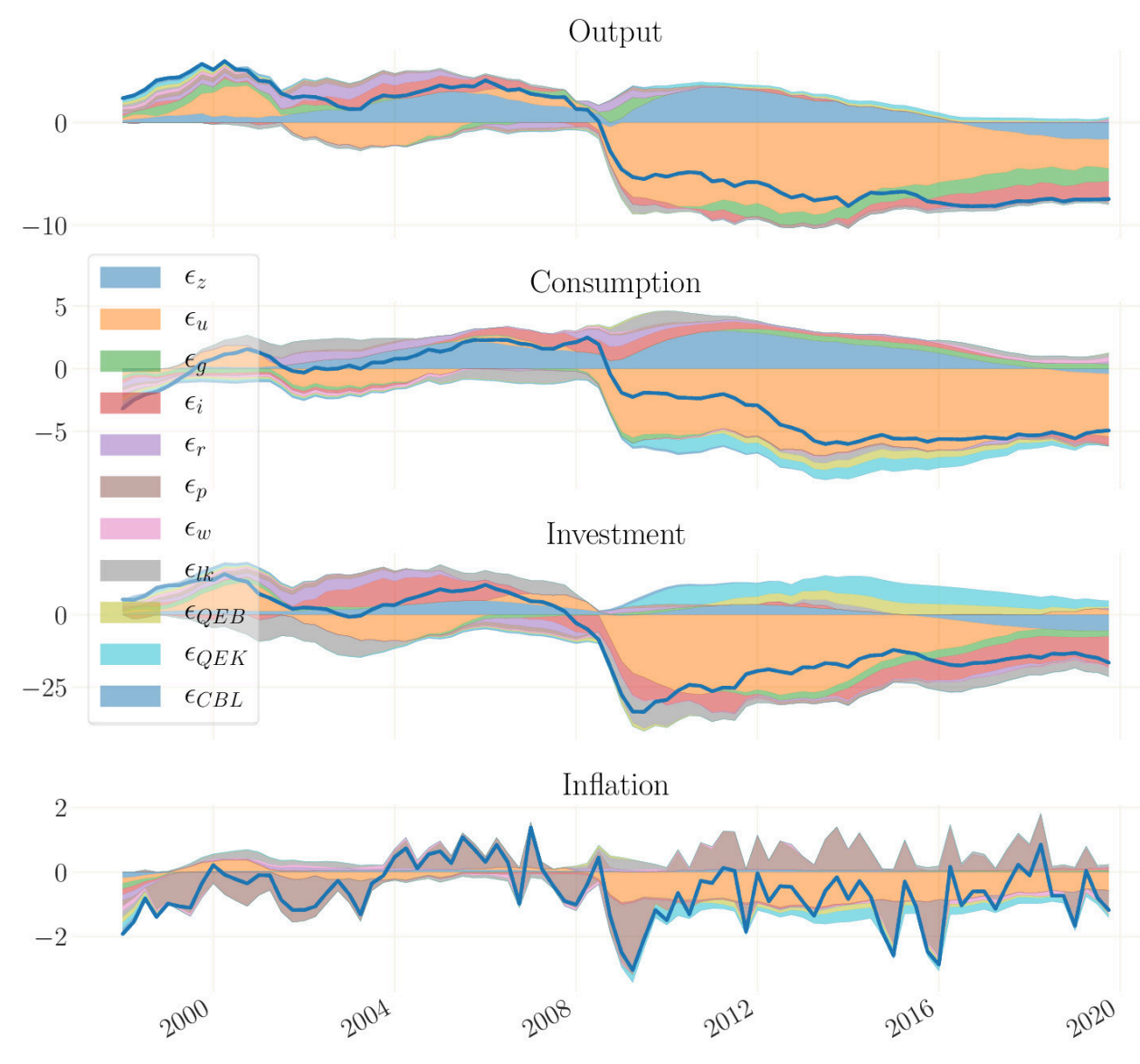

Figure J.25: Estimated model with H2M. Decomposition of the smoothed states into the contribution of the different shocks.

Note: Means over 1000 simulations drawn from the posterior. The contribution of each shock is normalized and calculated as in Boehl (2020b). Annual measures where applicable. 


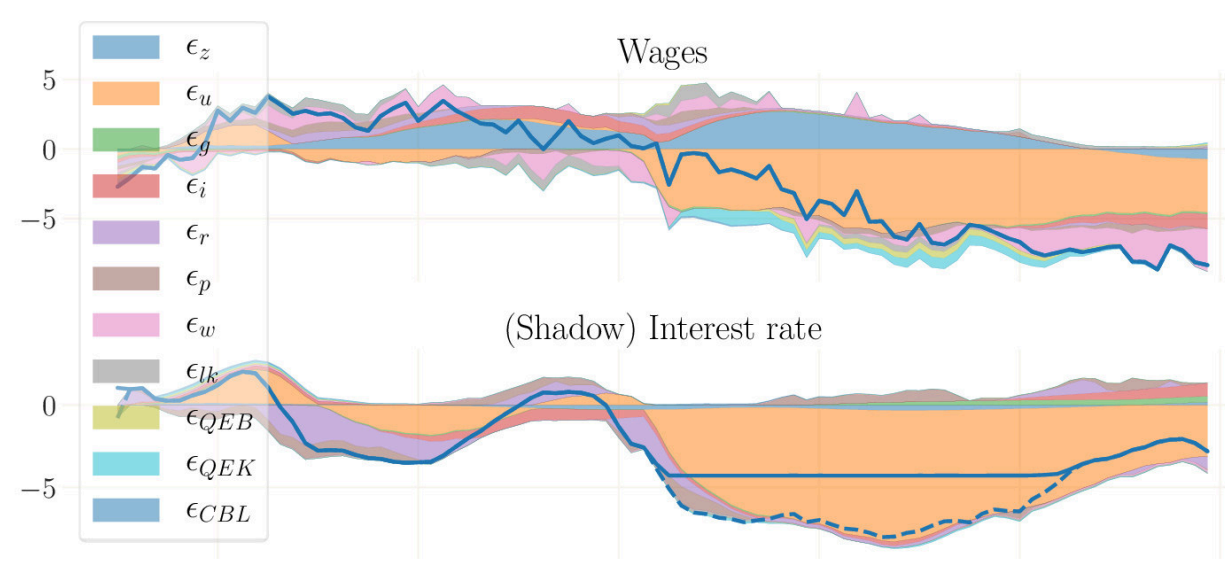

Credit spread

5

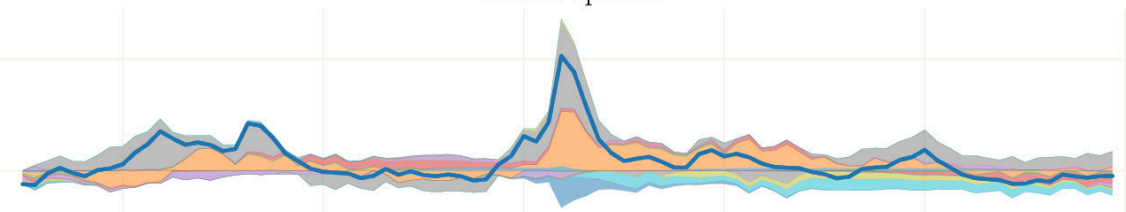

Capital utilization

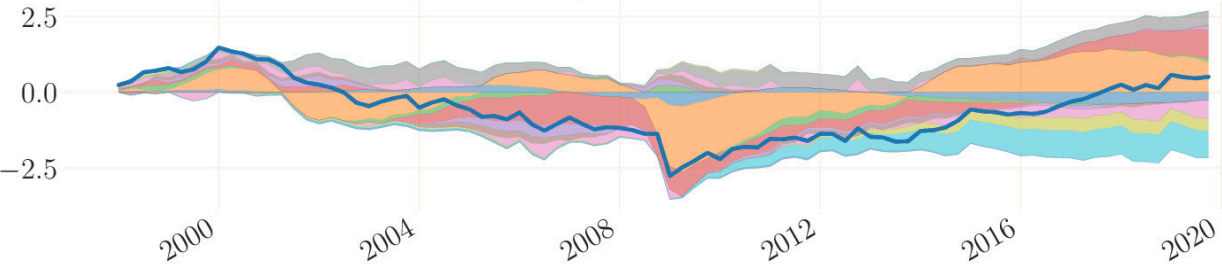

Figure J.26: Estimated model with H2M. Decomposition of the smoothed states into the contribution of the different shocks.

Note: Means over 1000 simulations drawn from the posterior. The contribution of each shock is normalized and calculated as in Boehl (2020b). Annual measures where applicable. 

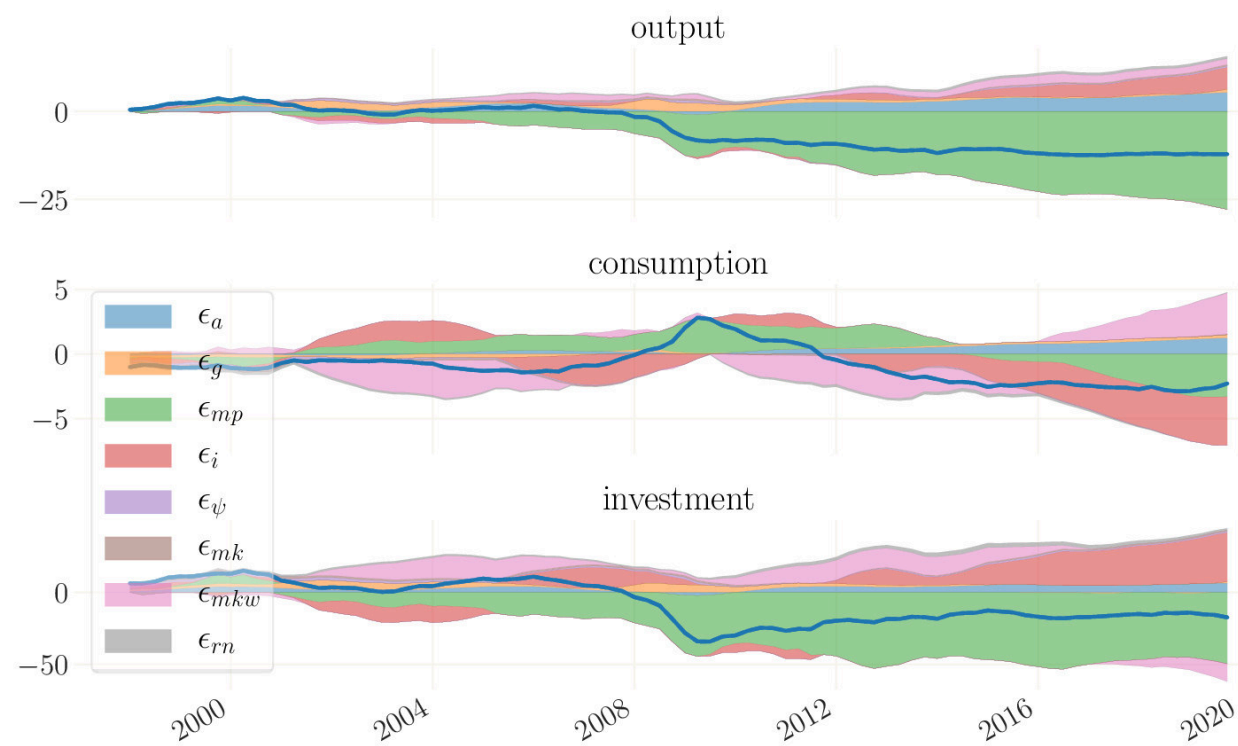

Figure K.27: Estimated CFP model. Decomposition of the smoothed states into the contribution of the different shocks.

Note: Means over 1000 simulations drawn from the posterior. The contribution of each shock is normalized and calculated as in Boehl (2020b). Annual measures where applicable.

\section{Appendix K Replicating Carlstrom et al. (2017)}

In order to gauge whether our results are robust to the model choice, we also replicate Carlstrom et al. (2017) by estimating their model using our nonlinear Bayesian likelihood approach and the same sample period including the ZLB. Although we use the same sample period as for the estimation or our benchmark model, some observables differ between both models. Specifically, the model includes quarterly changes in PCE inflation, real GDP growth and investment, hours worked and real wages as explained in section Appendix A. Moreover, we lumped all asset purchases of the Fed under the variable "QE tot" by simply adding "CB GBonds" and "CB CBonds". Although we agree that this is a very stylized approach, we do so because the price (and hence the yield) of long-term corporate and government bonds is the same in CFP. Finally, we include the quarterly Federal Funds rate and 10-year treasury term premium from Adrian et al. (2013), the latter which is downloaded from the New York Fed's homepage. ${ }^{40}$

Table K.6 presents our parameter estimates of the CFP model using our sample from 1998:I until 2019:IV and compares these those published by Carlstrom et al. (2017).

For a selection of variables, Figures K.27 and K.28 show the historical decompositions. Finally, Figure K.29 shows the impulse responses to a QE shock.

\footnotetext{
${ }^{40}$ https://www.newyorkfed.org/research/data_indicators/term_premia.html
} 


\begin{tabular}{|c|c|c|c|c|c|c|c|c|c|c|c|}
\hline & Prior & & & & & Posterio & & & Carlst & om et al & (2017) \\
\hline & dist. & mean & $\mathrm{std} / \mathrm{df}$ & mean & std & mode & $5 \%$ & $95 \%$ & mean & $5 \%$ & $95 \%$ \\
\hline$\eta$ & gamma & 2.0 & 0.75 & 2.608 & 0.376 & 2.509 & 2.009 & 3.214 & 2.0259 & 1.2673 & 2.7526 \\
\hline $\mathrm{h}$ & beta & 0.6 & 0.10 & 0.888 & 0.019 & 0.884 & 0.864 & 0.915 & 0.6225 & 0.5760 & 0.6687 \\
\hline$\psi_{n}$ & uniform & 5.0 & 2.89 & 0.140 & 0.584 & 0.045 & 0.005 & 0.113 & 0.7850 & 0.3389 & 1.2394 \\
\hline$\phi$ & gamma & 3.0 & 1.00 & 5.433 & 0.995 & 5.752 & 3.794 & 6.917 & 3.2821 & 2.1857 & 4.3639 \\
\hline$\tau_{\pi}$ & normal & 1.5 & 0.10 & 1.575 & 0.086 & 1.602 & 1.441 & 1.718 & 1.4202 & 1.2828 & 1.5493 \\
\hline$\tau_{y}$ & normal & 0.5 & 0.10 & 0.666 & 0.070 & 0.726 & 0.545 & 0.779 & 0.4906 & 0.3566 & 0.6292 \\
\hline$\rho_{i}$ & beta & 0.8 & 0.10 & 0.895 & 0.011 & 0.898 & 0.875 & 0.913 & 0.7712 & 0.7309 & 0.8109 \\
\hline$\iota_{p}$ & beta & 0.6 & 0.10 & 0.311 & 0.060 & 0.359 & 0.212 & 0.409 & 0.4175 & 0.2752 & 0.5610 \\
\hline$\iota_{w}$ & beta & 0.6 & 0.10 & 0.611 & 0.089 & 0.627 & 0.470 & 0.760 & 0.5110 & 0.4085 & 0.6205 \\
\hline$\kappa_{p c}$ & beta & 0.2 & 0.10 & 0.045 & 0.011 & 0.043 & 0.026 & 0.063 & 0.0860 & 0.0104 & 0.1544 \\
\hline$\kappa_{w}$ & beta & 0.2 & 0.10 & 0.060 & 0.022 & 0.062 & 0.026 & 0.096 & 0.0002 & 0.0001 & 0.0004 \\
\hline$\rho_{a}$ & beta & 0.6 & 0.20 & 0.947 & 0.031 & 0.963 & 0.905 & 0.997 & 0.9921 & 0.9841 & 0.9997 \\
\hline$\rho_{m u}$ & beta & 0.6 & 0.20 & 0.938 & 0.014 & 0.936 & 0.918 & 0.961 & 0.8695 & 0.8281 & 0.9122 \\
\hline$\rho_{\phi}$ & beta & 0.6 & 0.20 & 0.985 & 0.013 & 0.984 & 0.967 & 1.000 & 0.9821 & 0.9682 & 0.9963 \\
\hline$\rho_{m k}$ & beta & 0.6 & 0.20 & 0.235 & 0.071 & 0.225 & 0.125 & 0.349 & 0.6650 & 0.4945 & 0.8405 \\
\hline$\rho_{m k w}$ & beta & 0.6 & 0.20 & 0.198 & 0.059 & 0.165 & 0.098 & 0.289 & 0.2059 & 0.1036 & 0.3027 \\
\hline$\rho_{m}$ & beta & 0.6 & 0.20 & 0.690 & 0.053 & 0.644 & 0.618 & 0.776 & 0.1564 & 0.0646 & 0.2515 \\
\hline$\rho_{r n}$ & beta & 0.6 & 0.20 & 0.852 & 0.036 & 0.856 & 0.795 & 0.914 & 0.9483 & 0.9212 & 0.9751 \\
\hline root $_{1}$ & beta & 0.5 & 0.20 & 0.916 & 0.047 & 0.891 & 0.845 & 0.984 & & & \\
\hline $\operatorname{root}_{2}$ & beta & 0.5 & 0.20 & 0.922 & 0.046 & 0.962 & 0.853 & 0.991 & & & \\
\hline$\sigma_{a}$ & inv. gamma (df) & 0.5 & 1.00 & 0.433 & 0.048 & 0.457 & 0.360 & 0.515 & 0.6481 & 0.5936 & 0.7030 \\
\hline$\sigma_{i}$ & inv. gamma (df) & 0.5 & 1.00 & 5.441 & 0.693 & 5.884 & 4.384 & 6.574 & 7.3454 & 5.5735 & 9.2124 \\
\hline$\sigma_{m p}$ & inv. gamma (df) & 0.1 & 1.00 & 0.131 & 0.017 & 0.141 & 0.104 & 0.155 & 0.2151 & 0.1935 & 0.2368 \\
\hline$\sigma_{m k}$ & inv. gamma (df) & 0.1 & 1.00 & 1.307 & 0.510 & 1.228 & 0.567 & 2.029 & 0.2442 & 0.1830 & 0.3049 \\
\hline$\sigma_{m k w}$ & inv. gamma (df) & 0.1 & 1.00 & 5.894 & 2.039 & 6.487 & 2.713 & 8.753 & 0.4840 & 0.4103 & 0.5569 \\
\hline$\sigma_{r n}$ & inv. gamma (df) & 0.1 & 1.00 & 0.495 & 0.144 & 0.433 & 0.258 & 0.717 & 0.1588 & 0.1179 & 0.2000 \\
\hline$\sigma_{p s i}$ & inv. gamma (df) & 0.5 & 1.00 & 11.060 & 4.174 & 11.733 & 4.695 & 17.854 & 2.7196 & 1.9449 & 3.4826 \\
\hline$\sigma_{q e}$ & inv. gamma (df) & 0.1 & 2.00 & 0.277 & 0.026 & 0.268 & 0.234 & 0.319 & & & \\
\hline
\end{tabular}

Table K.6: Parameter estimates for Carlstrom et al. (2017) model. For the inverse gamma distribution the same specification (via mean and degrees of freedem) as in dynare is chosen to ensure comparability of results. 


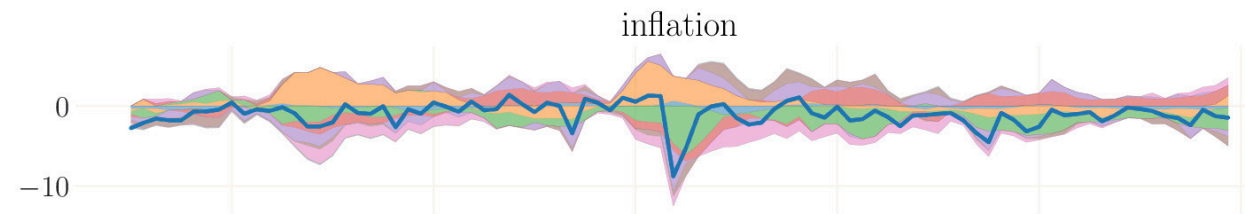

(shadow) interest rate

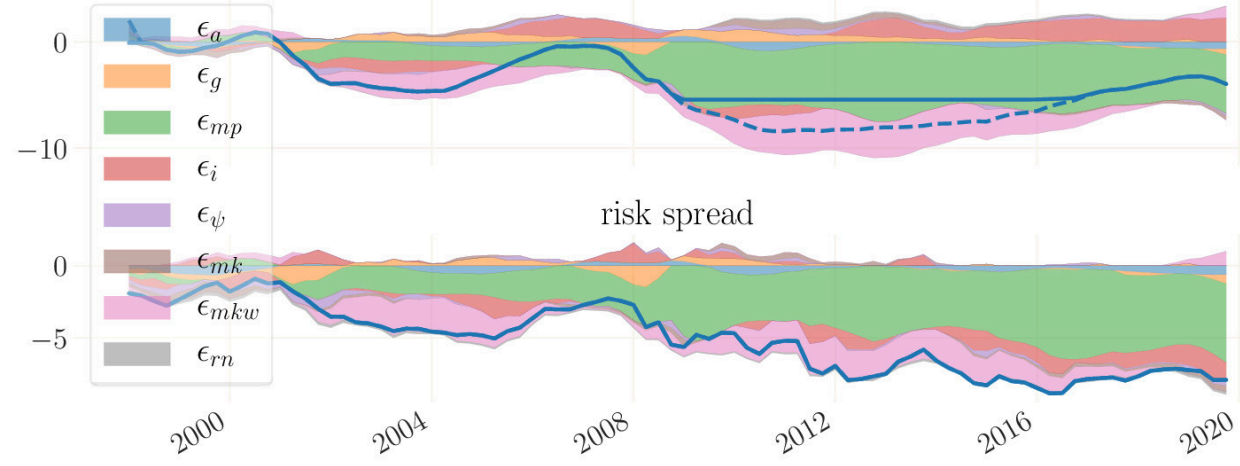

Figure K.28: Estimated CFP model. Decomposition of the smoothed states into the contribution of the different shocks.

Note: Means over 1000 simulations drawn from the posterior. The contribution of each shock is normalized and calculated as in Boehl (2020b). Annual measures where applicable. 


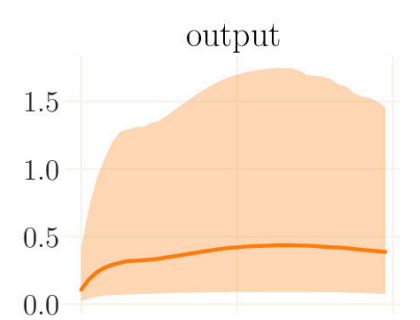

investment

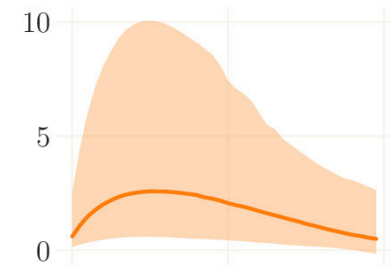

risk premium

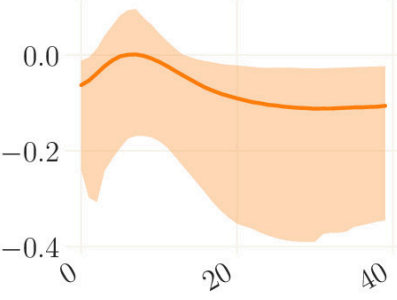

consumption

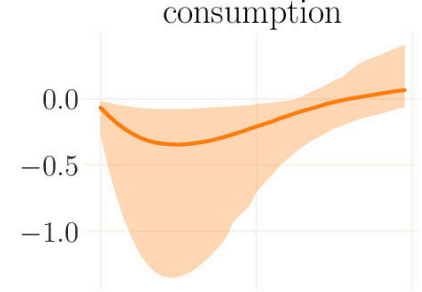

inflation
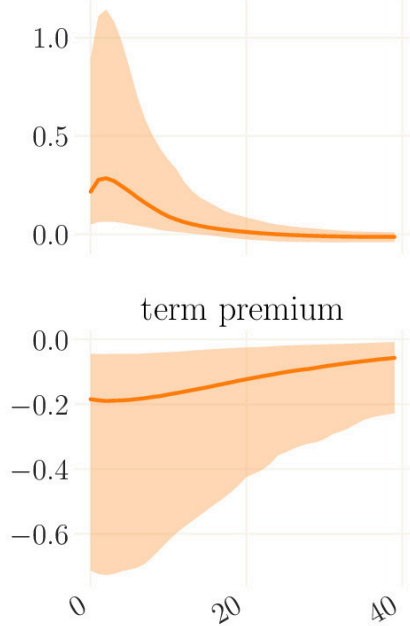

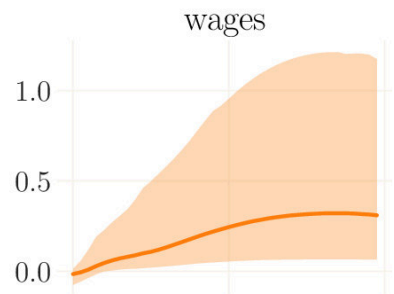

interest rate

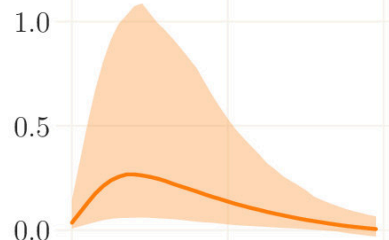

0.0

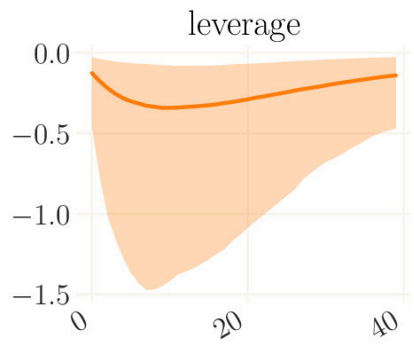

Figure K.29: CFP model. Impulse response functions with respect to a generic QE-shock. Sampled from the posterior distribution with $95 \%$ credible set.

Note: Posterior sample obtained from 1000 draws from the posterior distribution. Solid lines represent the mean. For each draw, the strength of the shock is chosen such that the peak of the corresponding stochastic process matches the peak of the empirical time series. See Appendix F for details. Annual measures where applicable. 


\section{Appendix L Model vintage with capital quality shocks}

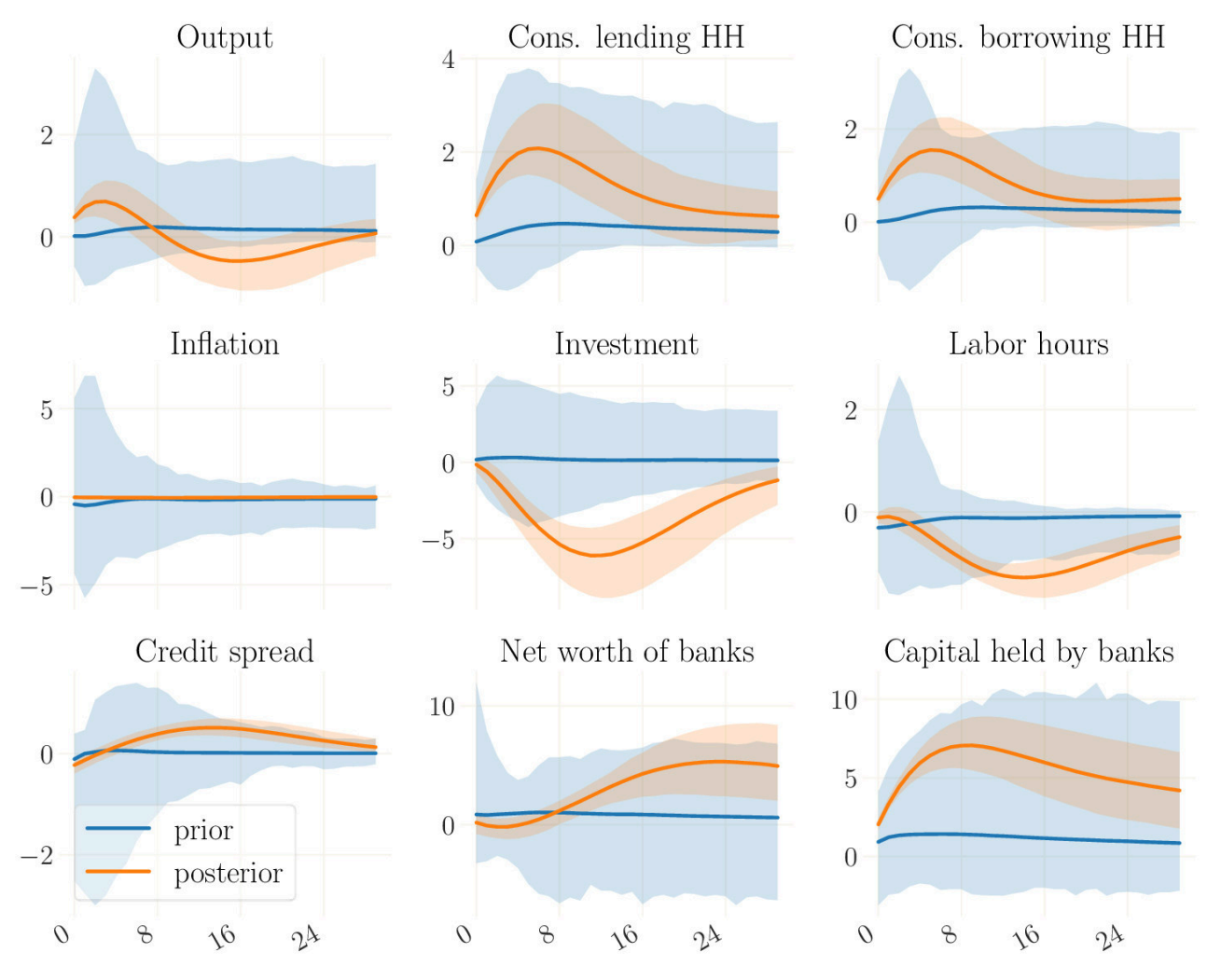

Figure L.30: Estimated benchmark model with the risk premium shock replaced by the capital quality shock. Prior and posterior impulse response functions with respect to a negative capital quality shock with $95 \%$ credible set.

Note: Means over 2000 simulations drawn from the posterior. The contribution of each shock is normalized and calculated as in Boehl (2020b). Annual measures where applicable.

As an additional exercise, we estimate a version of our benchmark model in which we replace the risk premium shock by the capital quality shock proposed in Gertler and Kiyotaki (2010) and Gertler and Karadi (2011). The latter shock reduces the physical capital stock, thereby affecting both the productivity and value of capital. In Gertler and Karadi (2011), capital quality shocks triggers fire sales in the banking sector that raises the credit spread and, ultimately, leads to a simultaneous decline in aggregate consumption and investment. In sum, this shock was calibrated to explain the key events of the GFC. Note, however, that the co-movement in investment and aggregate consumption that is needed to explain the GFC hinges critically on the calibration of $\theta$. Specifically, if one changes $\theta$ from 0.972 in Gertler and Karadi (2013) to any value smaller or equal to 0.95 , this co-movement disappears.

Through the lens of our estimated model, the this co-movement disappears for the capital quality shock. Yet, as the prior impulse responses in Figure L.30 illustrate, this 

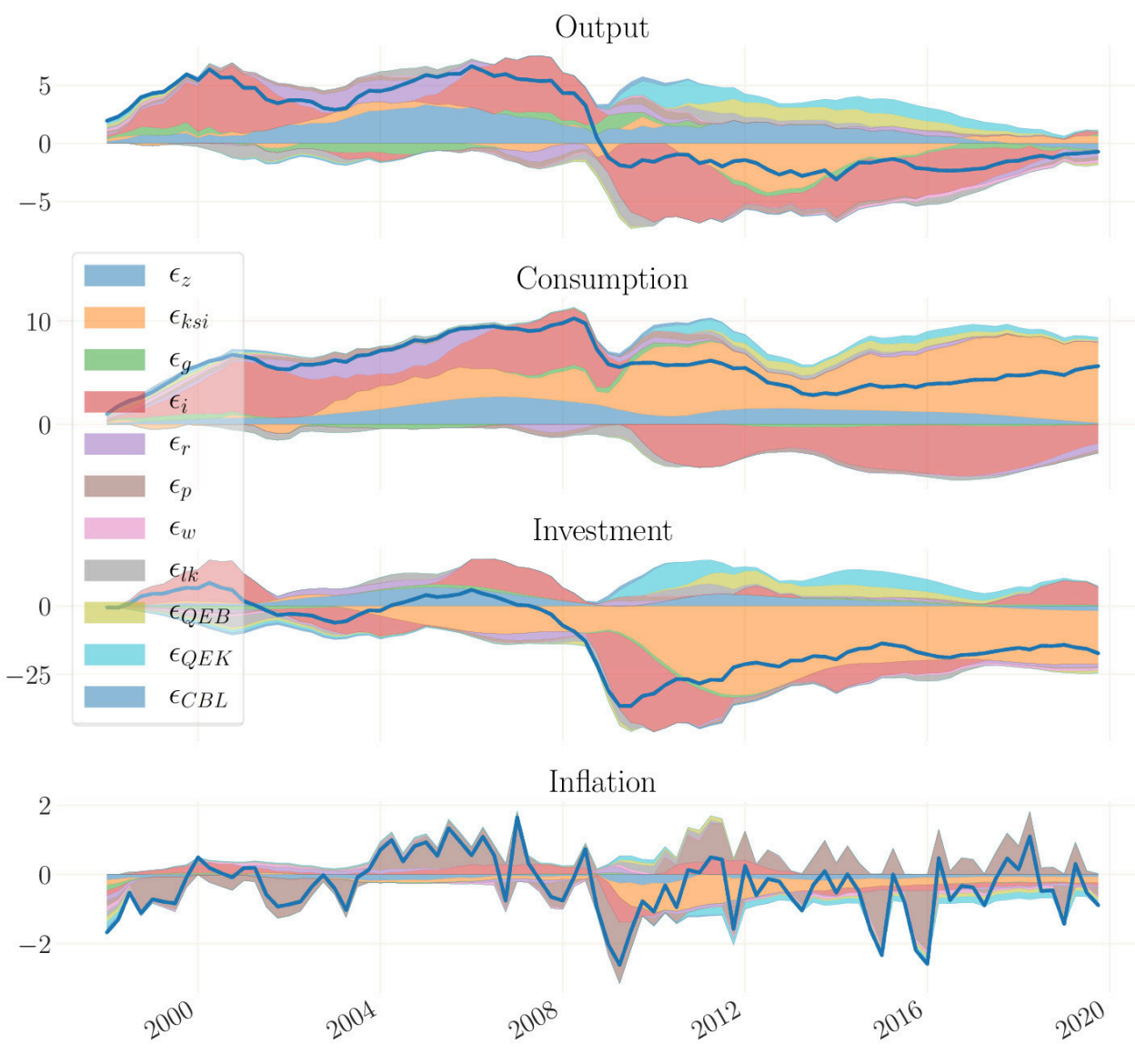

Figure L.31: Estimated benchmark model with the risk premium shock replaced by the capital quality shock. Decomposition of the smoothed states into the contribution of the different shocks.

Note: Means over 2000 simulations drawn from the posterior. The contribution of each shock is normalized and calculated as in Boehl (2020b). Annual measures where applicable.

result is not hardwired a priori. Figures L.31 and L.31 show that while capital quality shock reduces investment, it actually stimulates aggregate consumption and plays only a limited role for the spike of the credit spread observed in the GFC. Overall, in the context of our benchmark model estimated on crisis data, the capital quality shock has far less explanatory power for the events triggered by the GFC, than the risk premium shock it replaces. As the risk premium shock, which plays a dominant role for macroeconomic dynamics in the benchmark model, is replaced in this variant, other shocks, such as the investment-specific shock, inevitably gain a more prominent role in the decomposition of macroeconomic dynamics. The historical shock decomposition shows that at the mean the effect of the Fed's asset purchases on investment and consumption are positive during the Great Recession. After 2011, the effect of capital purchases on price dynamics turns and becomes deflationary. 

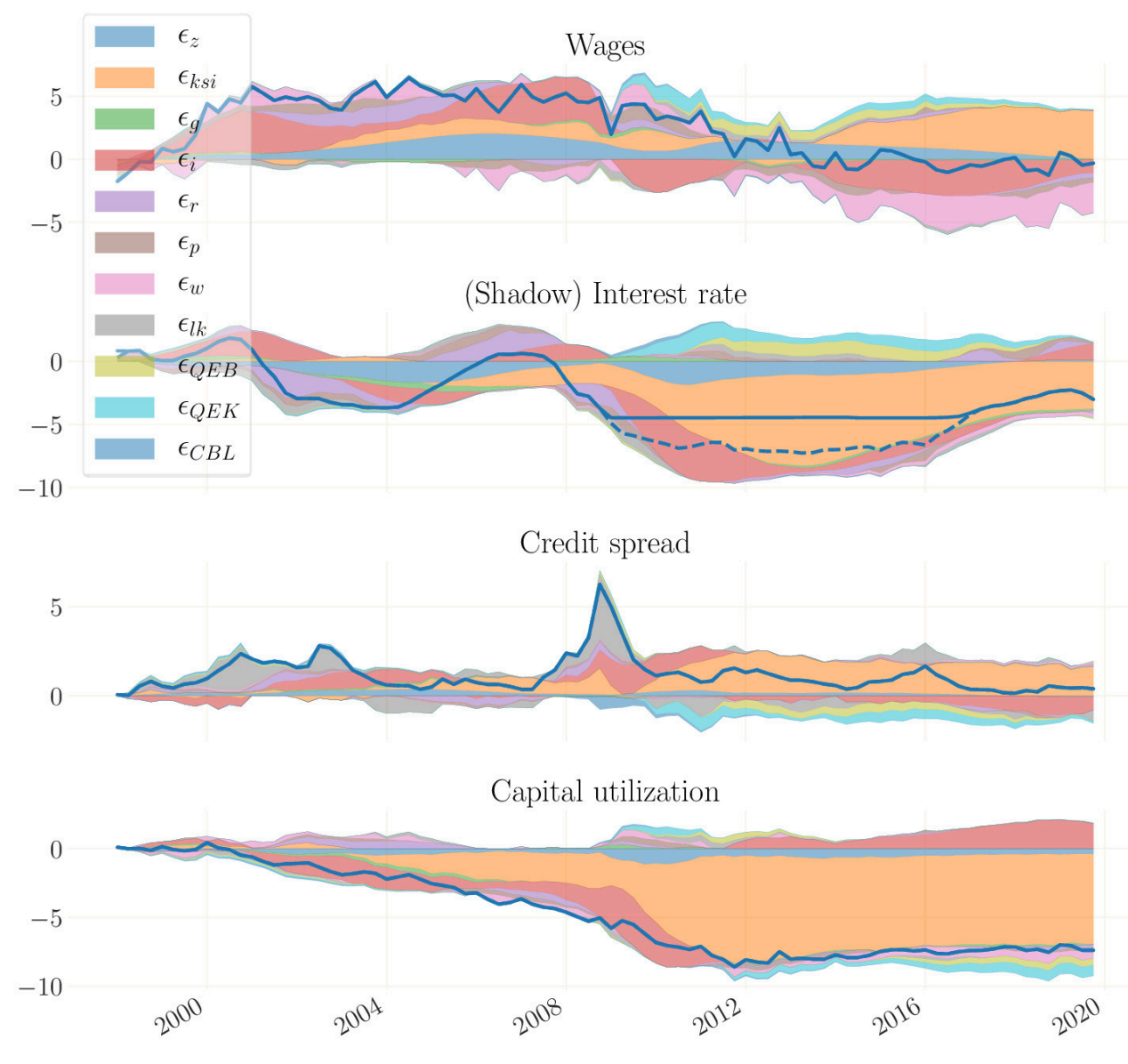

Figure L.32: Estimated benchmark model with the risk premium shock replaced by the capital quality shock. Decomposition of the smoothed states into the contribution of the different shocks.

Note: Means over 2000 simulations drawn from the posterior. The contribution of each shock is normalized and calculated as in Boehl (2020b). Annual measures where applicable.

These findings should be taken with caution. As it is hard to identify a main common driver for the economic dynamics of the model, the respective smoothed series of economic shocks are less probable compared to our baseline estimation. For this reason, the smoothing procedure via NPAS becomes unstable for some posterior draws. While this could be fixed by increasing the shock search-space of the smoother, it reflects the poor performance of the augmented model to explain the post-2007 dynamics. We hence find that this variant is not well suited for a structural investigation of quantitative easing. 


\section{IMFS WORKING PAPER SERIES}

\section{Recent Issues}

141 / $2020 \quad$ Karl-Heinz Tödter

$\begin{array}{ll}140 / 2020 & \begin{array}{l}\text { Helmut Siekmann } \\ \text { Volker Wieland }\end{array}\end{array}$

139 / $2020 \quad$ Volker Wieland

$138 / 2020$

$137 / 2019$

$136 / 2019$

134 / 2019 Helmut Siekmann

133 / 2019 Josefine Quast

Maik H. Wolters

132 / $2019 \quad$ Galina Potjagailo

Maik Wolters

131 / 2019 Philipp Lieberknecht

Volker Wieland

$130 / 2019 \quad$ Eduard Hofert

129 / $2018 \quad$ Olga Goldfayn-Frank Johannes Wohlfart

$128 / 2018$
Christopher Roth Johannes Wohlfart
Ein SIRD-Modell zur Infektionsdynamik mit endogener Behandlungskapazität und Lehren für Corona-Statistiken

The Ruling of the Federal Constitutional Court concerning the Public Sector Purchase Program: A Practical Way Forward

Verfahren zum Anleihekaufprogramm der EZB

Household Finance

(Un)expected Monetary Policy Shocks and Term Premia

Informative Social Interactions

Perceived wealth, cognitive sophistication and behavioral inattention

The Asset Purchase Programmes of the ESCB - an interdisciplinary evaluation

Reliable Real-time Output Gap Estimates Based on a Modified Hamilton Filter

Global Financial Cycles since 1880

On the Macroeconomic and Fiscal Effects of the Tax Cuts and Jobs Act

Regulating Virtual Currencies

How Do Consumers Adapt to a New

Environment in their Economic

Forecasting? Evidence from the German

Reunification

How Do Expectations About the Macroeconomy Affect Personal Expectations and Behavior? 


\section{7 / $2018 \quad$ Michael Haliassos \\ Thomas Jansson \\ Yigitcan Karabulut}

$126 / 2018 \quad$ Felix Strobel

125 / $2018 \quad$ Alexander Meyer-Gohde

Daniel Neuhoff

124 / 2018

Athanasios Orphanides

$123 / 2018$

Karl-Heinz Tödter

Gerhard Ziebarth

122 / $2018 \quad$ Helmut Siekmann

121 / $2018 \quad$ Maik H. Wolters

$120 / 2017$

Helmut Siekmann

119 / $2017 \quad$ Gregor Boehl

$118 / 2017$

117 / 2017

$116 / 2017$

Gregor Boehl

Thomas Fischer

Tobias H. Tröger

Tobias H. Tröger

115 / 2017 Guenter W. Beck

Volker Wieland

114 / 2017

Michael Binder

Jorge Quintana

Philipp Lieberknecht

Volker Wieland

$113 / 2017$

Mewael F. Tesfaselassie

Maik Wolters

112 / 2017
Financial Literacy Externalities

The Government Spending Multiplier, Fiscal Stress and the Zero Lower Bound

Generalized Exogenous Processes in DSGE: A Bayesian Approach

The Boundaries of Central Bank Independence: Lessons from Unconventional Times

Zinsen, Effektivpreise und Lebenskosten

- Ein Beitrag zur Konstruktion eines intertemporalen Preisindex

Legal Tender in the Euro Area

How the Baby Boomers' Retirement Wave

Distorts Model-Based Output Gap

Estimates

Die Einstandspflicht der Bundesrepublik

Deutschland für die Deutsche

Bundesbank und die Europäische

Zentralbank

Monetary Policy and Speculative Stock Markets

Can Taxation Predict US Top-Wealth

Share Dynamics?

Why MREL Won't Help Much

Too Complex to Work - A Critical

Assessment of the Bail-in Tool under the

European Bank Recovery and Resolution

Regime

How to Normalize Monetary Policy in the Euro Area

Model Uncertainty in Macroeconomics:

On the Implications of Financial Frictions

The Impact of Growth on Unemployment in a Low vs. a High Inflation Environment

Doing away with cash? The welfare costs of abolishing cash
Franz Seitz

Karl-Heinz Tödter 